\title{
Execução Programada de Statecharts
}

\author{
João Wagner Lima Cangussu
}

Orientador: Dr. Paulo Cesar Masiero

Dissertação apresentada ao Instituto de Ciências Matemáticas de São Carlos - USP, como parte dos requisitos para obtenção do título de mestre em "Ciências de Computação $e$ Matemática Computacional".

São Carlos

1993 
Aos meus pais, Nemésio e Irene, e aos meus irmãos, Judina, Junior e Miriam, pelo constante apoio, carinho e compreensão. 


\section{Agradecimentos}

Ao Professor Dr. Paulo Cesar Masiero pela excelente orientação e apoio no decorrer do desenvolvimento deste trabalho.

Ao Professor Dr. José Carlos Maldonado pela colaboração dada.

À FAPESP e ao CNPq pelo auxílio financeiro concedido.

Aos meus amigos Audax, Adriano, Taner, Marcelo, Guilherme, Omar, Luis Paulo, Dâmaris e Rosangela pelo companheirismo, apoio e incentivo.

Aos professores, alunos e funcionários do Instituto de Ciências Matemáticas de São Carlos que, de uma forma ou de outra, colaboraram para o desenvolvimento deste trabalho. 


\section{Resumo}

Sistemas Reativos podem ser definidos como sistemas que interagem direta ou indiretamente com o ambiente, recebendo e emitindo estímulos do mesmo, e que devem produzir os resultados corretos dentro de intervalos de tempo previamente especificados. Várias técnicas gráficas existem para modelar sistemas reativos, podendo-se citar Máquinas de Estados Finitos, Redes de Petri e Statecharts. Esta última tem se mostrado eficaz na especificação de sistemas reativos, pois além de possuir uma notação visual concisa e intuitiva, ainda possui sintaxe e semântica definidas formalmente.

Este trabalho trata de uma técnica de validação de modelos, denominada "Execução Programada" e de sua integração ao ambiente Statechart Simulator (StatSim), que é um ambiente composto de ferramentas para edição e simulação de statecharts. Na Execução Programada, o modelo comportamental do sistema sob desenvolvimento é simulado a partir de eventos gerados através de distribuições probabilísticas e é controlado por um programa que indica o que deve ser feito em cada passo. Como resultado final, além da simulação dinâmica visual, dois relatórios são fornecidos ao usuário: um contendo análises estatísticas da execução e outro contendo o registro de todas as configurações atingidas, passo a passo.

Uma revisão de ambientes e ferramentas para especificação de sistemas reativos é apresentada, enfatizando-se a sua capacidade para simulação dos modelos criados. Como aspecto central do trabalho, uma linguagem para controle da execuçāo programada , denominada Linguagem de Controle de Execução (LCE), é proposta. A LCE é, inicialmente, discutida informalmente, para depois ser discutida formalmente. Em seguida, mostra-se a implementação da LCE e sua integração ao ambiente StatSim, dentro do Módulo de Execução Programada (MEP). Para ilustrar o funcionamento da LCE alguns exemplos são apresentados e discutidos. 


\begin{abstract}
Reactive Systems can be defined as systems that interact directly or undirectly with the environment, receiving and emiting stimuli from/to it, and must to produce correct results within specified time intervals. Many graphical techniques exit to model reactive systems, such as Finite States Machines, Petri Nets and Statecharts. Statecharts proved a very efficient tool for reactive systems specification, having a concise and intuitive visual notation and a formaly defined sintax and semantics.

The two main concerns of this work are: a technique for model validation called "Programmed Execution" and its integration to the Statechart Simulator (StatSim) environment, which is an integrated set of tools for edition and simulation of statecharts. In the "Programmed Execution", a system control model of a system under developement is simulated from events generated according to probabilistic distributions and is controlled by a program that states what is to be done at each step. As results, besides the dynamic visual simulation, two reports are available: a statistical analysis about the simulation and a log file of all configurations reached during the simulation, step by step. A survey of environments and tools for reactive systems specification able to simulate the models created is presented. A language to control the execution of a model, called Execution Control Language (ECL), is also presented. The ECL syntax and semantics are discussed and formaly defined. Its implementation and integration into the StatSim environment, within the Programmed Execution Module (PEM), is shown. Some examples are presented and discussed to illustrate the use of ECL.
\end{abstract}




\section{Conteúdo}

\section{Capítulo 1 - Introdução}

1.1 - Situação do Problema . . . . . . . . . . . . . . . . . 001

1.2 - Motivação ... . . . . . . . . . . . . . 002

1.3 - Objetivos do Trabalho . . . . . . . . . . . . . 003

1.4 - Organização do Trabalho . . . . . . . . . . . . 004

\section{Capítulo 2 - Revisão Bibliográfica}

2.1 - Considerações Iniciais . . . . . . . . . . . . . . 005

2.2 - Introdução a Statecharts . . . . . . . . . . . . . 006

2.3 - Ambientes baseados em Statecharts . . . . . . . . . . . 009

2.4 - Linguagens baseadas em Especificação de Estados . . . . . 023

2.5 - Linguagens de Simulação . . . . . . . . . . . . . . . . 038

2.6 - Outras Técnicas de Execução de Modelos . . . . . . . . 042

2.7 - Avaliação das Referências Revisadas . . . . . . . . . 044

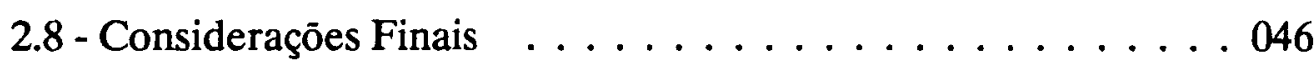

Capítulo 3 - Uma Linguagem de Controle de Execução para Statecharts

3.1 - Consideraçōes Iniciais . . . . . . . . . . . . . . . . . . . 047

3.2 - Requisitos da Linguagem de Controle de Execução (LCE) . . . 048 
3.3 - Sintaxe da LCE . . . . . . . . . . . . . . . 053

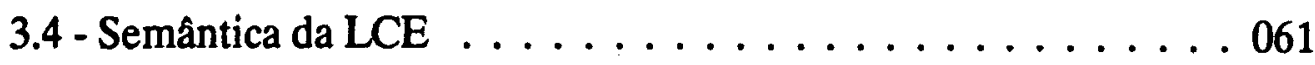

3.5 - Consideraçōes Finais $\ldots \ldots$. . . . . . . . . . 079

Capítulo 4 - $O$ Módulo de Execução Programada (MEP)

4.1 - Considerações Iniciais . . . . . . . . . . . . . . . 081

4.2 - Evolução do Ambiente StatSim . . . . . . . . . . 082

4.3 - Arquitetura do Módulo de Execução Programada (MEP) . . 085

4.4 - Implementação do Módulo de Execução Programada (MEP) 086

4.5 - Estudo de Caso . . . . . . . . . . . . . . . . . . . . 097

4.6 - Considerações Finais $\ldots \ldots \ldots \ldots \ldots \ldots . \ldots \ldots 112$

Capítulo 5 - Conclusão

5.1 - Consideraçōes Iniciais . . . . . . . . . . . . . . . 114

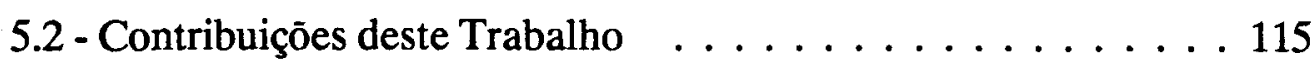

5.3 - Sugestões de Futuros Trabalhos $\ldots \ldots \ldots \ldots \ldots \ldots$

Referências Bibliográficas . . . . . . . . . . . . . 117

Apêndice A - BNF da Linguagem de Controle de Execução . . 122

Apêndice B - Exemplo 1: Manipulador de Mouse . . . . . . . . 127

Apêndice C - Exemplo 2: Jantar dos Filósofos $\ldots \ldots \ldots$. . . . 136 


\section{Lista de Figuras}

Figura 2.1 - Hierarquia em Statecharts [HARE88a] . . . . . . . 06

Figura 2.2 - Ortogonalidade em Statecharts [HARE88a] . . . . . 07

Figura 2.3 - Comunicação em Statecharts [HARE88a] . . . . . . . 08

Figura 2.4 - Arquitetura do Ambiente StatSim [MASI91] . . . . . . 11

Figura 2.5 - Tela de Edição do Ambiente StatSim . . . . . . . 12

Figura 2.6 - Tela de Simulação do Ambiente StatSim . . . . . . . 13

Figura 2.7 - Diagrama de Estruturas do

Ambiente Statemate [HARE88b] . . . . . . . 15

Figura 2.8 - Diagrama de Atividades do

Ambiente Statemate [HARE88b] . . . . . . . . 16

Figura 2.9 - Paralelismo em Argos [MARA89] . . . . . . . . . 18

Figura 2.10 - Comunicação em Argos [MARA89] . . . . . . . . . 19

Figura 2.11 - Decomposição Hierárquica

em Argos (Exemplo 1) [MARA89] . . . . . . . . 20

Figura 2.12 - Decomposição Hierárquica em Argos (Exemplo 2) [MARA89] . . . . . . . . . 21

Figura 2.13 - Operador "Internal" de Argos [MARA89] . . . . . . 21

Figura 2.14 - Estrutura Geral de Argonaute [MARA89] . . . . . . 22

Figura 2.15 - Tasks e Pontos de Interação em Estelle [BUDK87] . . . . . . . . . . . . . 31

Figura 2.16 - Hierarquia das Tasks em Estelle [BUDK87] . . . . . 32

Figura 2.17 - Representação Gráfica do

Exemplo de Estelle [BUDK87] . . . . . . . . . . 36 
Figura 2.18 - Diagrama de Estados do Módulos B e C do Exemplo de Estelle [BUDK87] . . . . . . . . . . 37

Figura 2.19 - Diagrama de Blocos do GPSS/H [SCHR91] . . . . . . 41

Figura 3.1 - Uma Arquitetura para Sistemas Reativos . . . . . . . 52

Figura 4.1 - Arquitetura do Módulo de Execução Programada . . . 85 Figura 4.2 - Estrutura do Interpretador da LCE . . . . . . . . . 87 Figura 4.3 - Tela Inicial do MEP . . . . . . . . . . . . . 90 Figura 4.4 - Editor de Programas Fonte em LCE . . . . . . . . 91 Figura 4.5 - Tela de Visualização do Relatório de Passos . . . . . 92 Figura 4.6 - Tela de Visualização do Relatório Estatístico . . . . . 93 Figura 4.7 - Tela com as Opções Show Var e

Show Events Disponíveis . . . . . . . . . . . . . 94

Figura 4.8 - Tela de Retorno à Simulação Interativa . . . . . . . . 95 Figura 4.9(a) - Primeiro Passo da Simulação do Manipulador de Mouse . . . . . . . . . . 96

Figura 4.9(b) - Segundo Passo da Simulação do Manipulador de Mouse . . . . . . . . . . . 97

Figura 4.10 - Sistema de Fila Única com Dois Servidores . . . . . . 98 


\section{Lista de Tabelas}

Tabela 2.1 - Comparação entre os Ambientes Statemate,

StatSim e Argonaute . . . . . . . . . . . . . 044

Tabela 3.1 - Comandos, Parâmetros e Funções da LCE . . . . . . 060

Tabela 3.2 - Conteúdo das Memórias do MEP (Módulo

de Execução Programada) . . . . . . . . . 065

Tabela 4.1 - Eventos Gerados pela LCE _. . . . . . . . 105 


\section{Capítulo 1 Introdução}

\section{1 - Situação do Problema}

Sistemas Reativos podem ser definidos como sistemas que interagem direta ou indiretamente com o ambiente, recebendo e emitindo estímulos do mesmo, e que devem produzir os resultados corretos dentro de intervalos de tempo previamente especificados. Se o sistema atrasa em responder a um estímulo externo ou interno, o sistema falha. Caso as conseqüências da falha sejam catastróficas, o sistema é classificado como um "hard system", senão ele é classificado como um "soft system" [BURN91]. São essas características de interação constante com o ambiente e as restrições de tempo impostas que tornam a especificação de sistemas reativos uma tarefa bastante complexa. Enquanto em um sistema transformacional o interesse é voltado para o estado inicial e o estado final do sistema, em um sistema reativo todos os estados internos são importantes, devido à contínua interação com o ambiente [HUIZ91].

Várias técnicas gráficas existem para modelar sistemas reativos, podendo-se citar Máquinas de Estados Finitos, Redes de Petri e Statecharts. Esta última tem se mostrado eficaz na especificação de sistemas reativos, pois além de possuir uma notação visual concisa e intuitiva, ainda possui sintaxe e semântica definidas formalmente.

Ambientes para desenvolvimento de sistemas reativos baseados em Statecharts têm surgido, tais como: Statemate, Argonaute e StatSim ([HARE88b], [MARA89], [MAS191]). Statemate pode ser considerado como o ambiente mais completo, possuindo ferramentas para especificação, simulação, geração de relatórios, geração de código, teste e validação. 
A maioria dos ambientes para especificação de sistemas reativos possui ferramentas para a execução interativa de modelos, seja de uma forma gráfica ou textual. Apesar de ser de grande valia para a verificação e validação de um modelo, a execução interativa (usuário interage diretamente com o sistema, acionando eventos e modificando variáveis e condições) explora o sistema de uma forma livre, ou seja, o usuário possui total controle sobre os acontecimentos no sistema. Muitas vezes é necessário, entretanto, que se possa observar o comportamento de um sistema reagindo sob condiçōes aleatórias. Uma das maneiras de se obter essa visão é através da geração aleatória de eventos, condições e variáveis, controladas por uma linguagem de execução.

\section{2 - Motivação}

A especificação de um sistema é uma tarefa de grande importância, pois a partir desta o sistema será desenvolvido. Portanto, a necessidade de se obter uma especificação correta (sem erros e interpretaçōes ambíguas) é o objetivo de qualquer desenvolvedor. A execução de modelos é uma técnica que auxilia nessa tarefa, pois através dela os modelos podem ser executados e erros podem ser encontrados antes que o sistema seja implementado. Existem várias maneiras de se executar um modelo, sendo uma delas a "Execução Programada" [HARE92]; em [ELIA92] uma outra forma de execução de modelos em statecharts pode ser vista. Assim, o auxílio que a "Execução Programada" traz às tarefas de verificação $\mathrm{e}$ validação de um modelo motivou o seu desenvolvimento.

Entende-se aqui por "Execução Programada" uma simulação do modelo (no caso Statecharts) conduzida através de um programa escrito em uma linguagem de controle, com capacidade para gerar eventos de uma forma aleatória e alterar valores de variáveis e condições, fazendo com que a configuração do Statechart possa ser alterada, ou nāo, durante a simulação.

Um dos motivos para o desenvolvimento de uma linguagem de controle, designada aqui como Linguagem de Controle de Execução (LCE), é que esta faz com que o modelo especificado fique sujeito a condições não previstas, devido à geração aleatória de eventos, o que ajuda nas tarefas de verificação e validação do modelo. 
O ambiente StatSim possui diversas ferramentas de apoio ao desenvolvimento, tais como: um editor gráfico de Statecharts com verificação sintática, um simulador interativo baseado na semântica formal de Statecharts e um conjunto de ferramentas para análise de propriedades dos Statecharts.

Apesar do ambiente StatSim já possuir ferramentas que auxiliam a verificação e a validação de modelos, tais como os algoritmos para deteç̧ão de deadlock, não-determinismo, e outros, estes são baseados em uma árvore de alcançabilidade, e de acordo com o tamanho do modelo, essa árvore pode ultrapassar a capacidade de memória disponível, nâo sendo possível, nesses casos, utilizar os algoritmos citados. Este foi um dos pontos que motivou o desenvolvimento da LCE, a qual não causa problemas de capacidade de memória e pode substituir esses algoritmos na busca das características de um modelo.

Outro ponto que motivou o desenvolvimento da Linguagem de Controle de Execução (LCE) foi o fato de poucos ambientes possuírem tal linguagem, e os que a possuem, mantêm sigilo das técnicas empregadas no desenvolvimento, através dos direitos autorais reservados. Esse ponto traz à tona a atualidade do tema, além do fato de que muito tem por se explorar do mesmo do ponto de vista conceitual.

\section{3 - Objetivos do Trabalho}

Este trabalho tem por objetivo definir uma linguagem para a execução de modelos especificados através de statecharts, complementando as técnicas de execuçāo (simulação) interativa, não-interativa e exaustiva do ambiente StatSim.

Tem-se também por objetivo, depois de definida a linguagem, implementá-la e integrá-la no rol de ferramentas que o ambiente StatSim possui. Depois de implementada, a LCE será validada através da execução de uma série de modelos, usando-se de vários programas escritos na Linguagem de Controle de Execução (LCE).

Outro objetivo do trabalho é apresentar exemplos ilustrativos da utilização da LCE em que possam ser fornecidas evidências da sua importância e aplicabilidade. 


\section{4 - Organização do Trabalho}

O presente trabalho está organizado em cinco capítulos, cujo objetivo é dar evidências de, primeiro, que Statecharts são uma técnica de grande poder para a especificação de sistemas reativos e, segundo, que a execução desses modelos (statecharts), tanto interativamente, não interativamente, quanto programada é de grande importância para a validação e verificação dos modelos, e que, portanto, o desenvolvimento de ferramentas para simulação é importante.

Neste capítulo foi apresentada a importåncia, a motivação e os objetivos que fizeram com que a Linguagem de Controle de Execução (LCE) fosse desenvolvida.

O segundo capítulo contém a revisão bibliográfica, onde é feita uma introdução a Statecharts, bem como a descrição de ambientes baseados nessa técnica. São descritas também no Capítulo 2, linguagens baseadas em especificação de estados, linguagens de simulação e técnicas de execução de modelos. Essa revisão fundamenta a proposta da LCE (Linguagem de Controle de Execução). Por fim apresenta-se uma avaliação das referências revisadas.

No terceiro capítulo são estabelecidos os requisitos da LCE, tanto os requisitos computacionais quanto os estatísticos. Uma arquitetura para sistemas reativos é apresentada e, por fim, o capítulo trata da definição da sintaxe e da semântica da Linguagem de Controle de Execução (LCE).

O Capítulo 4 trata da implementação do MEP (Módulo de Execução Programada). Primeiro faz-se uma descrição do ambiente StatSim antes da inclusão do MEP, em seguida é apresentada uma arquitetura para o ambiente StatSim com o MEP incluído. A seguir é feita uma análise dos fatos relevantes à implementação do MEP, tais como: dificuldades encontradas, esforço despendido, restrições do MEP, características da ferramenta, etc. Finalmente, um exemplo de utilização do MEP é apresentado e as consideraçōes finais são feitas.

O Capítulo 5 conclui o trabalho apresentando-se as suas contribuições, seguidas de sugestões para futuras pesquisas. 


\section{Capítulo 2}

\section{Revisão Bibliográfica}

\section{1 - Considerações Iniciais}

A execução de modelos tem se mostrado uma técnica de grande valia no processo de verificação e validação da especificação de um sistema. $O$ uso de simulação não-interativa e programada só vem a aumentar o poder desta técnica [HARE92].

Neste capítulo são vistos alguns tópicos e conceitos que são necessários para a compreensão e para o desenvolvimento da Linguagem de Controle de Execução (LCE) para modelos especificados por Statecharts. Os tópicos discutidos são:

- uma breve introdução a Statecharts;

- o estudo de três ambientes de desenvolvimento de software baseados em Statecharts;

- o estudo de linguagens baseadas na especificação de estados;

- o estudo de linguagens de simulação; $\mathrm{e}$

- uma breve descrição de técnicas de execução de modelos.

Os dois primeiros tópicos servem para a compreensão da sintaxe e semântica de Statecharts e para o estudo de ambientes baseados nessa técnica. Os três tópicos seguintes mostram conceitos e características de outras linguagens e técnicas necessários para o desenvolvimento da Linguagem de Controle de Execução (LCE) que será definida no próximo capítulo. Por fim, encerra-se o capítulo com uma avaliação das referências revisadas, apresentando-se uma tabela comparativa dos três ambientes vistos. 


\section{2 - Introdução a Statecharts}

Os Statecharts surgiram como uma alternativa para especificar sistemas reativos de uma forma clara, formal e rigorosa [HARE87]. Statecharts fundamentam-se no formalismo clássico das máquinas de estados finitos, solucionando alguns de seus problemas inerentes, tais como:

- diagramas de estados são planos, não suportando hierarquia ou modularidade;

- diagramas de estados crescem demasiadamente em relação ao número de estados e transições; e

- diagramas de estados não suportam concorrência, sendo seqüenciais por natureza.

Statecharts são definidos em [HARE88a] como:

Statecharts $=$ diagrama de estados + hierarquia + ortogonalidade + comunicação

Será apresentada a seguir uma breve descrição das principais características dessa técnica, as quais podem ser encontradas com detalhes em [HARE87] e [HARE88a].

\subsection{1 - Hierarquia}

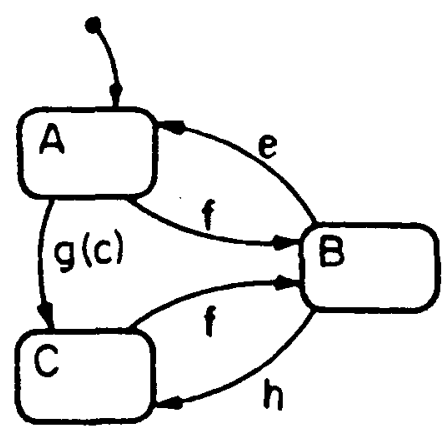

(o)

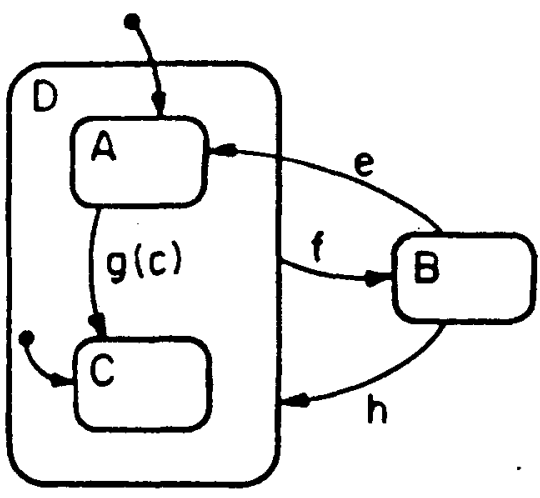

(b)

Figura 2.1 - Hierarquia em Statecharts [HARE88a] 
Hierarquia é definida como a decomposição de um estado em um ou mais subestados; e pode ser melhor compreendida através do exemplo na Figura 2.1(a e b). A Figura 2.1a mostra uma versão plana, que pode ser substituída pela Figura 2.1b. Os símbolos e, f, g são eventos, que ativam transições, A, B, C e D são estados e "c" é uma condição. A transição de rótulo "g[c]" de A para C só é executada se o evento g ocorrer e a condição "c" for verdadeira. O estado $D$ é uma decomposição XOR, ou seja, estar em D, significa estar em A ou C, nunca em ambos. Quando h ocorre e D se torna ativo, então a transição "default" (seta sem origem e não rotulada) determina que $C$ deve ser ativado. Quando focorre, o estado interno a D, seja qual for, é desativado junto com D, e B se torna ativo.

\subsection{2 - Ortogonalidade}

Ao contrário da decomposição XOR, ortogonalidade é obtida em statecharts através da decomposiçāo AND. Na Figura $2.2 \mathrm{~b}$ tem-se um estado $\mathrm{Y}$ com duas componentes ortogonais A e D. Então, estar em Y significa estar em A e D simultaneamente (note-se que A e D são decomposições XOR). A simplicidade da especificação é melhor percebida se a versāo plana (Figura 2.2a) for comparada com o statechart (Figura 2.2b), no qual o número de transições foi reduzido e a compreensão da especificação aprimorada.

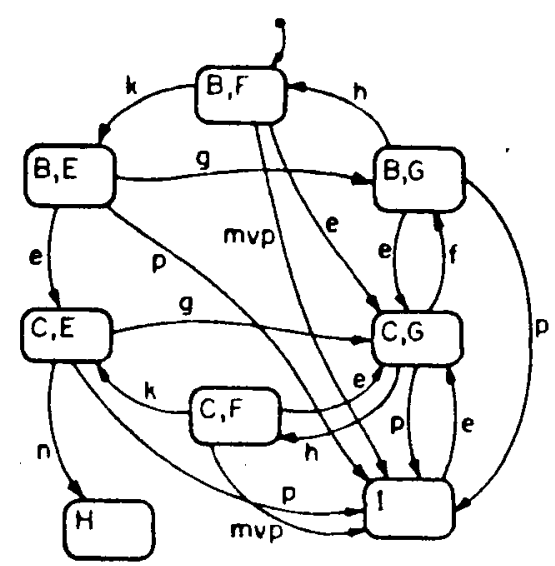

(a)

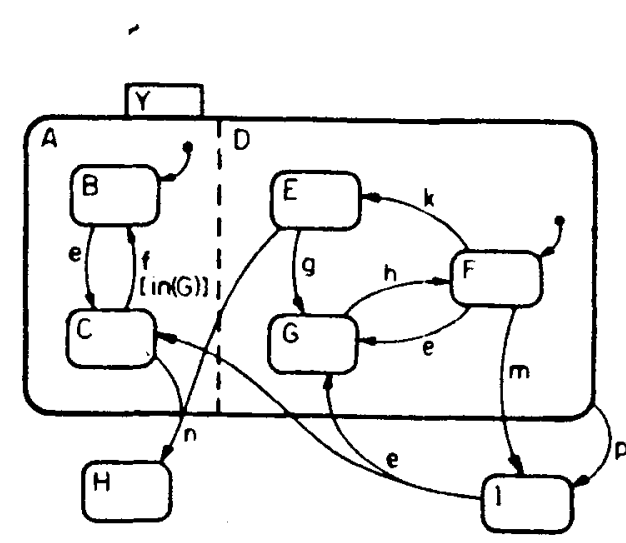

(b)

Figura 2.2 - Ortogonalidade em Statecharts [HARE88a] 


\subsection{3 - Comunicação}

O rótulo de uma transição pode ser definida por "e[c]/a", onde "e" é um evento, "c" é uma condição e "a" é uma ação, que pode ser um outro evento ou uma atribuição de variável. Se a ação for um evento, então este será ativado e poderá ser sentido nas componentes ortogonais, no mesmo passo (ou instante) em que foi gerado. Na Figura 2.3, suponha que o statechart possua uma configuração $\{I, C, G\}$ e suponha que ocorra o evento "n", então na componente "H" transiciona-se de "I" para "J" e o evento "f" é gerado, sendo sentido na componente "A", que transiciona de "C" para "B" e gera " $g$ ". Desta forma, ocorre a transição de "G" para "E" na componente " $\mathrm{D}$ ". Portanto, percebe-se que através da geração de eventos (ações), os componentes ortogonais de um statechart podem se comunicar sincronamente.

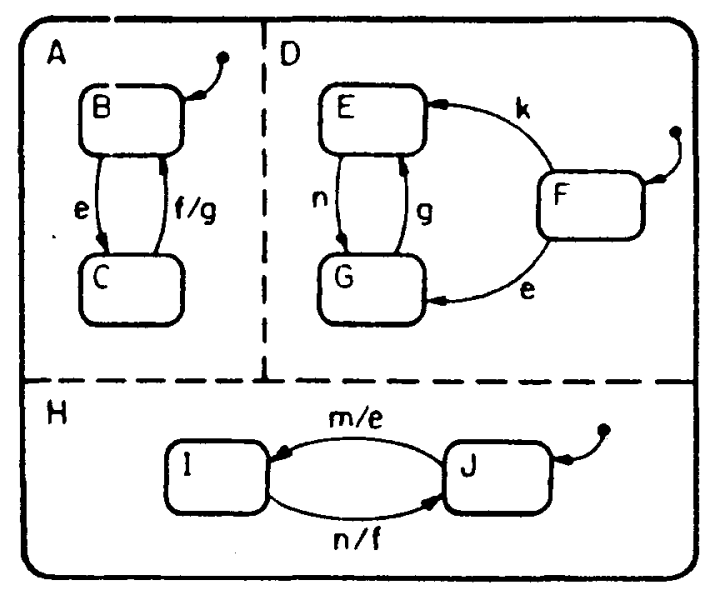

Figura 2.3 - Comunicação em Statecharts [HARE88a]

\subsection{4 - Outras Características de Statecharts}

Statecharts possuem sintaxe e semântica formalmente definidas em [HARE87], na qual estão sintetizadas características e operadores de statecharts não exemplificados aqui. Entre estas características pode-se citar não determinismo e a capacidade de armazenar a última configuração de um estado ("history"). 
Existem vários operadores, tais como: cr (current), ny (not yet), ch (changed) que, juntamente com os eventos internos ex (exit), en (entered), tr (true) e fs (false) enriquecem os statecharts, possibilitando a representação de sistemas reativos dos mais variados tipos.

Diagramas de estados podem ser classificados como Máquinas Moore (nas quais as ações ou atividades estão associadas ao estado em que a máquina se encontra) ou Máquinas Mealy (ações ou atividades estão associadas às transições). Statecharts, entretanto, não podem ser enquadrados exclusivamente como uma Máquina Mealy ou como uma Máquina Moore, mas como uma junção dessas, pois se as ações podem ser geradas quando transições são executadas, ao se ativar um estado uma atividade poderá ser executada enquanto esse estado estiver ativo. Portanto, Statecharts unem os conceitos de Máquinas Moore e Mealy. Entretanto, devido às características síncronas dos Statecharts, a execução das ações é considerada instantânea, enquanto as atividades não o são, isto é, as atividades têm um tempo associado a suas execuções.

Statecharts são portanto uma técnica visual que possibilita especificar o aspecto comportamental de sistemas de tempo real de alta complexidade de uma forma precisa, clara e sucinta. Possui sintaxe e semântica formalmente definidas, o que facilita a verificação e validação de modelos.

\section{3 - Ambientes baseados em Statecharts}

A complexidade encontrada para a especificação de sistemas de tempo real tem provocado o surgimento de várias técnicas e linguagens com o objetivo de diminuir essa complexidade.

Por ter se mostrado uma técnica bastante conveniente para modelagem de sistemas reativos, sugiram e continuam surgindo vários sistemas que utilizam statecharts como alicerce da especificação. Serão vistos agora alguns aspectos dos seguintes ambientes de desenvolvimento de software baseados em statecharts: StatSim, Statemate e Argonaute. 


\subsection{1 - StatSim}

StatSim é um ambiente para especificação de sistemas de tempo real em desenvolvimento no Instituto de Ciências Matemáticas de São Carlos, pelo grupo de Engenharia de Software. O ambiente é baseado em statecharts [HARE88a]. A sintaxe e semântica utilizadas no ambiente são provenientes da sintaxe e semântica formal de statecharts, vistos em [HARE87].

StatSim é constituído basicamente de dois grupos de ferramentas: o primeiro consiste de ferramentas para ediçāo gráfica e o segundo de ferramentas para simulação dos statecharts editados. E possível também que o usuário especifique o statechart de uma forma textual, para a qual existe uma Linguagem de Especificação de Statecharts (LES) e um analisador para a mesma. Deve-se notar que tanto a especificação gráfica quanto a textual geram bases de dados similares, que são usadas pelo simulador. Uma arquitetura do ambiente é ilustrada na Figura 2.4 e pode ser encontrada em [MASI91].

Foram desenvolvidos também algoritmos para detecção de deadlock, não determinismo, vivacidade e alcançabilidade dos statecharts editados [BOAV92].

\subsubsection{1 - Editor Gráfico}

O editor gráfico de statecharts foi desenvolvido em um ambiente UNIX, em estaçōes de trabalho SUN, utilizando-se X-Window para interfaces gráficas e manipulação de janelas. $O$ editor possui características como manipulação direta de objetos na tela, ou seja, a edição de bolhas ou arcos, bem como a seleção de operaçōes dos "menus" são realizadas com a utilização de mouse. Os rótulos das bolhas, das transições e todas as demais descrições textuais são fornecidas via teclado.

A sintaxe do statechart em edição é verificada a cada novo elemento inserido no mesmo, e caso seja identificada alguma incompatibilidade, são emitidas mensagens de erro e a inserção desse novo elemento é recusada pelo editor.

Além dos módulos para edição de bolhas e arcos, existem módulos para declaração e consulta de variáveis, bem como módulos para a manipulação de statecharts na memória, ou seja, módulos para salvar ou carregar um statechart na memória e imprimi-lo na tela, entre outros [BATI91]. 


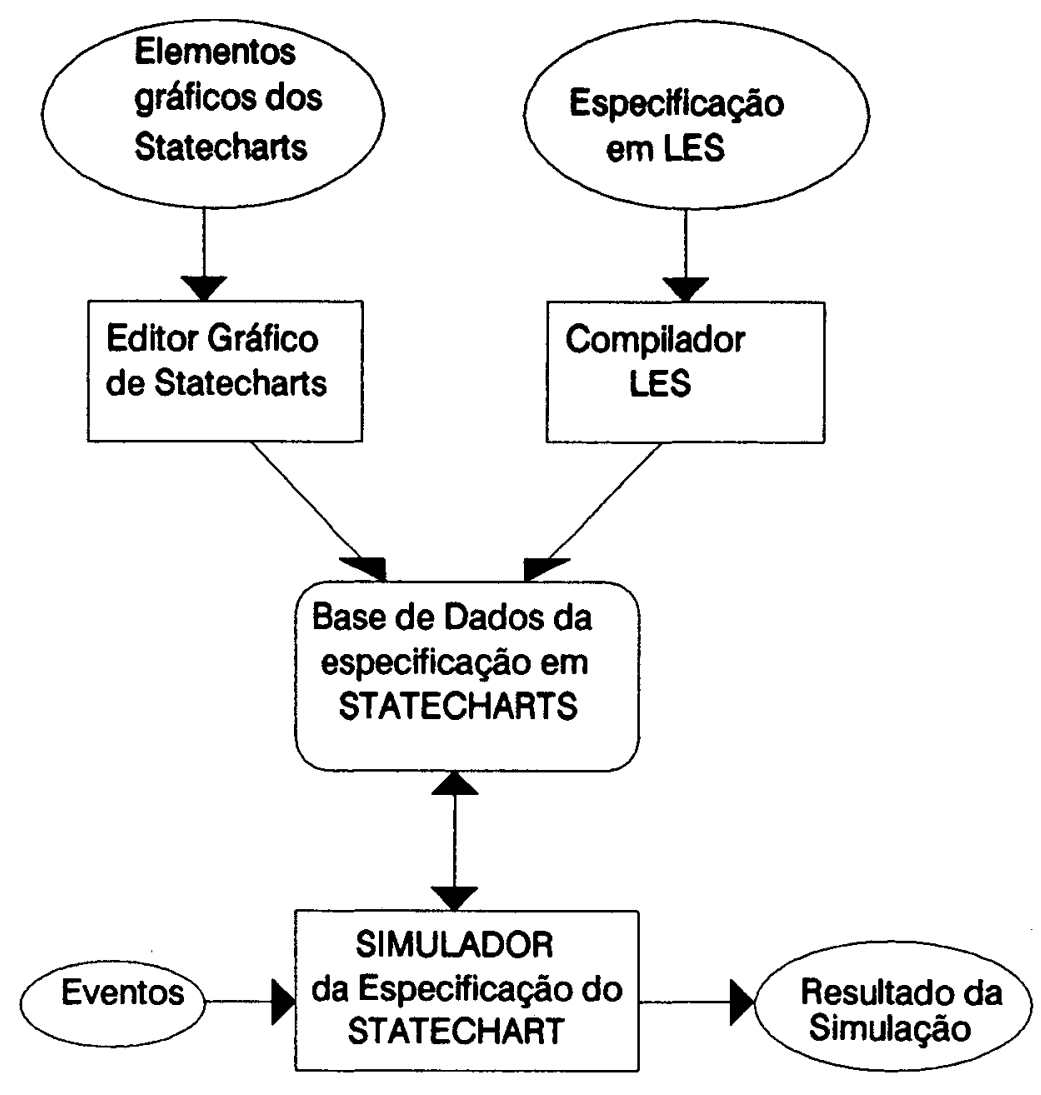

Figura 2.4 - Arquitetura do Ambiente Statsim [MASI91]

A base de dados criada pelo editor gráfico, excluindo as informações gráficas, é a mesma criada pelo compilador da Linguagem de Especificação de Statecharts (LES).

A Figura 2.5 mostra a tela de edição de statecharts do ambiente StatSim, na qual tem-se o exemplo de especificação de uma célula de manufatura. Uma descrição detalhada desse exemplo é encontrada em [COUT91].

\subsubsection{2 - Simulador}

O simulador do ambiente StatSim foi projetado inicialmente para uma versão em forma de texto, na qual a cada passo a configuração dos estados ativos e os estados que haviam sido ligados e desligados eram exibidos textualmente [FORT91]. A versão atual é gráfica, apresentando o statechart na tela. A configuração de estados ativos é notada pelos estados resaltados, isto é, se o estado ativo é atômico (não possui subestados) ele 
apresentará seu interior colorido, caso contrário apresentará seu contorno tracejado, indicando que o mesmo está ativo.

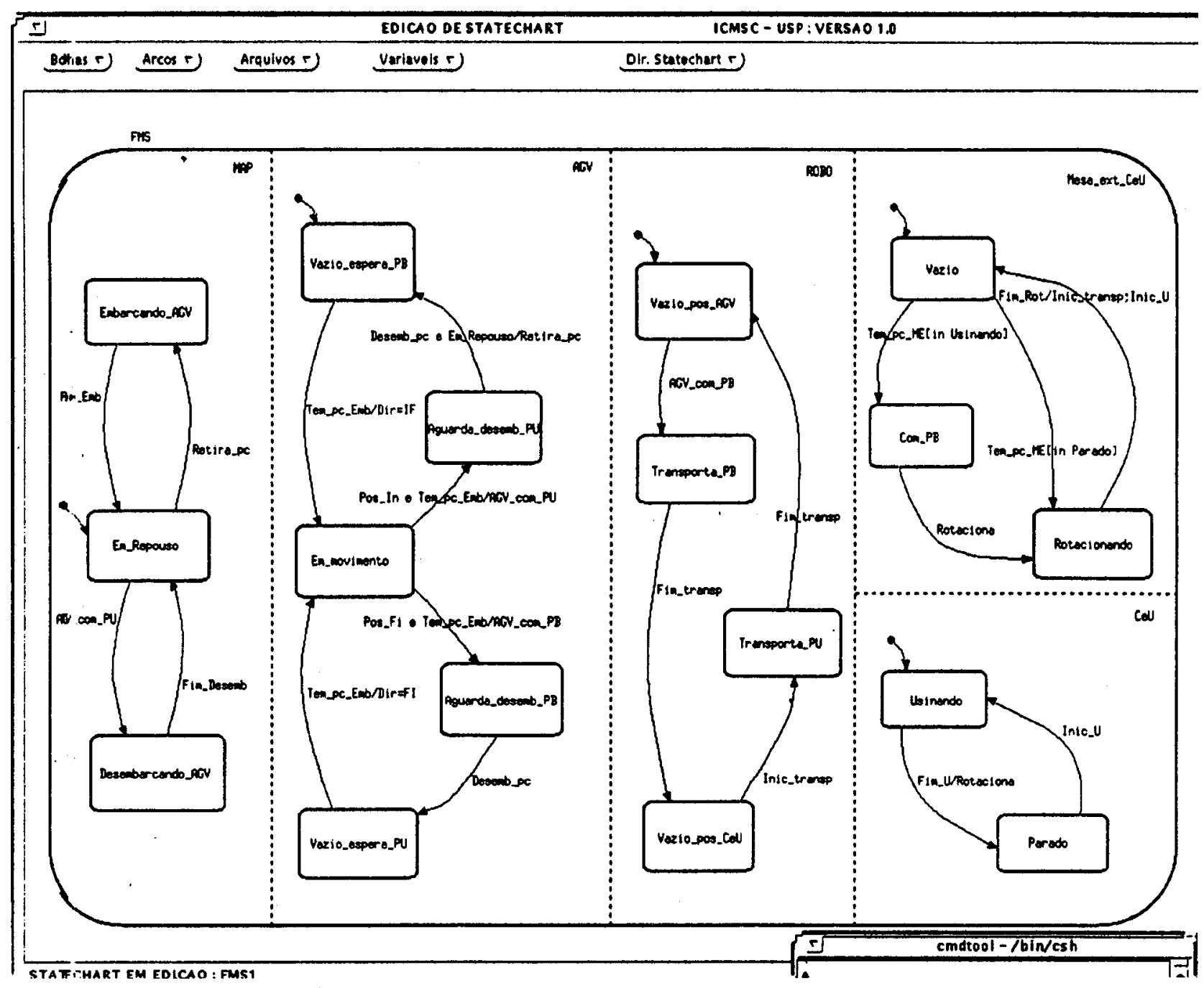

Figura 2.5 - Tela de Edição do Ambiente StatSim

O simulador funciona aceitando eventos externos acionados pelo usuário, eventos esses selecionados via mouse, e reagindo de acordo com a semântica de statecharts. Dessa forma, de acordo com os eventos acionados, o statechart alcançará uma nova configuração.

Além da manipulação de eventos, o usuário possui ainda opções para inicializar o statechart por default, limpar a memória do statechart, obter informações sobre arcos e bolhas e carregar um statechart da memória para que o mesmo seja simulado. Assim como na versão baseada em texto, ainda é possível que o usuário veja em cada passo os eventos 
ativados e os estados ligados e desligados, através de uma janela que pode ser ativada ou desativada pelo mesmo.

A tela de simulação do ambiente StatSim pode ser vista na Figura 2.6, na qual vê-se o mesmo exemplo da célula de manufatura citado anteriormente, onde se encontram ativos os estados defaults dos componentes paralelos (componentes ortogonais).

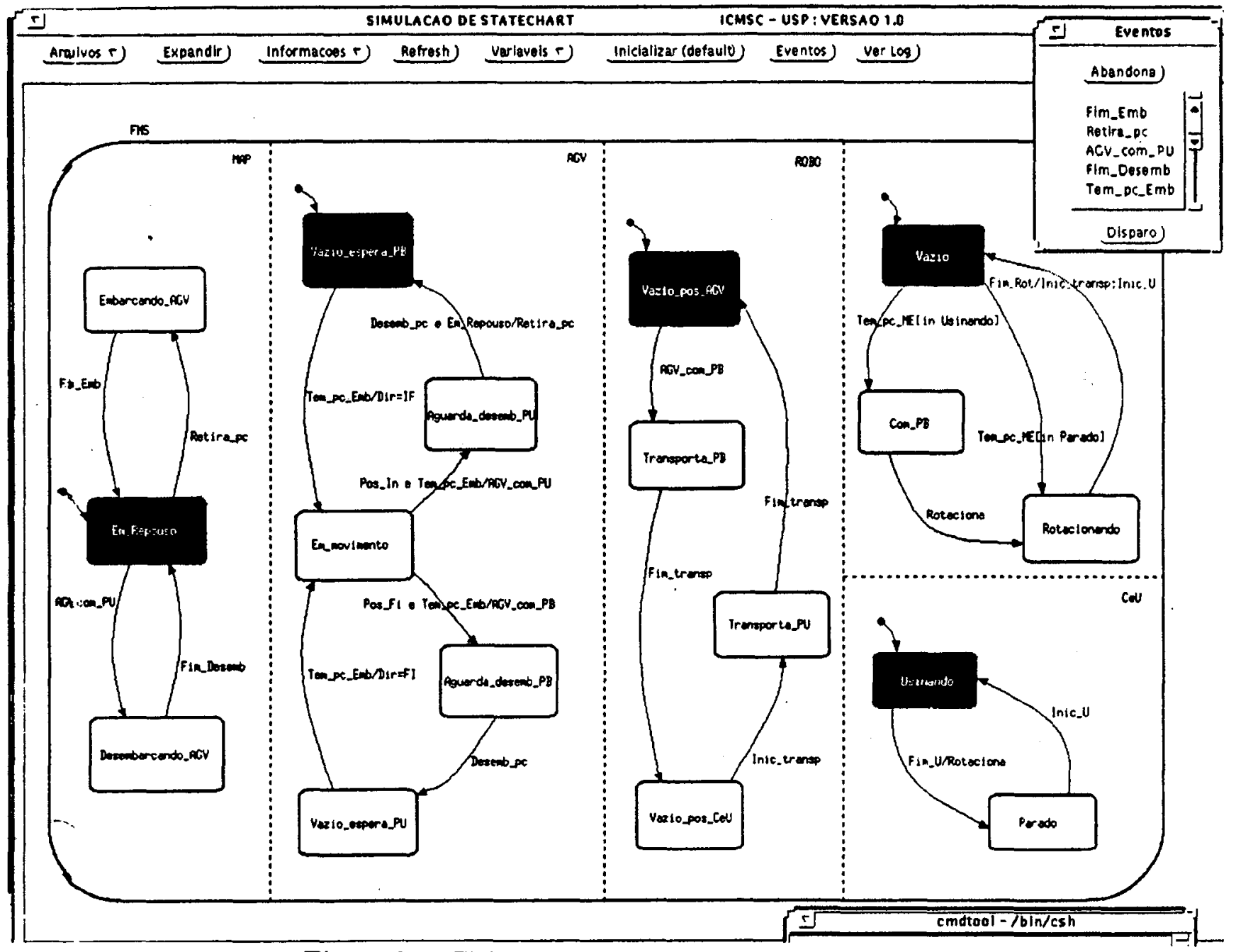

Figura 2.6 - Tela de Simulação do Ambiente StatSim

\subsubsection{3 - Outras Características e Futuras Extensões para o Ambiente StatSim}

Algoritmos para deteç̧ão de deadlock, não determinismo, vivacidade e alcançabilidade para um statechart já foram desenvolvidos. Estes algoritmos são baseados 
em uma árvore de alcançabilidade do statechart, a qual é similar à árvore de alcançabilidade para Redes de Petri. Detalhes sobre o projeto e implementação desses algoritmos e da própria árvore de alcançabilidade são encontrados em [BOAV92].

Encontra-se desenvolvido um editor gráfico de Diagramas de Atividades, o qual especifica a visão funcional de um sistema. Os diagramas são compostos por atividades, entidades, atividades de controle e depósitos de dados, além dos fluxos de dados e controle entre os mesmos. Um dicionário de dados também se encontra disponível na ferramenta. Detalhes sobre a implementação do Editor Gráfico de Diagrama de Atividades são encontrados em [TUTU92].

O ambiente StatSim já constitui atualmente uma ferramenta poderosa para especificação e validação de sistemas de tempo real, porém evoluções no ambiente estão sendo planejadas para que dessa forma se possa extrair resultados mais abrangentes da especificação. Dentre as evoluções pretendidas estão a geração de protótipos e a geração de código, ambas através da análise conjunta dos statecharts e do Diagrama de Atividades.

\subsection{2 - Statemate}

Statemate é um ambiente para desenvolvimento de software construido pela i-Logix Inc. e pela AdCad Ltda. Baseado fortemente no formalismo visual, Statemate é voltado principalmente para o desenvolvimento de sistemas reativos de alta complexidade.

Statemate fornece meios para se fazer não somente a especificação funcional ou somente a comportamental, mas possibilita a especificação inter-relacionada da visāo estrutural, funcional e comportamental. Cada visão possui um editor gráfico os quais são baseados em linguagens com sintaxes e semânticas bem definidas. A visão estrutural é especificada através dos diagramas de módulos, a visão funcional é especificada através dos diagramas de atividade e a visão comportamental pelos statecharts [HARE88b].

O ambiente não se restringe somente a editores gráficos, mas aproveita de forma excelente as especificações feitas usando os três editores gráficos e dá ao usuário resultados para avaliação da especificação através de testes, geração de código, geração de documentos e outras características que serão vistas a seguir. 


\subsubsection{1 - Visão Estrutural}

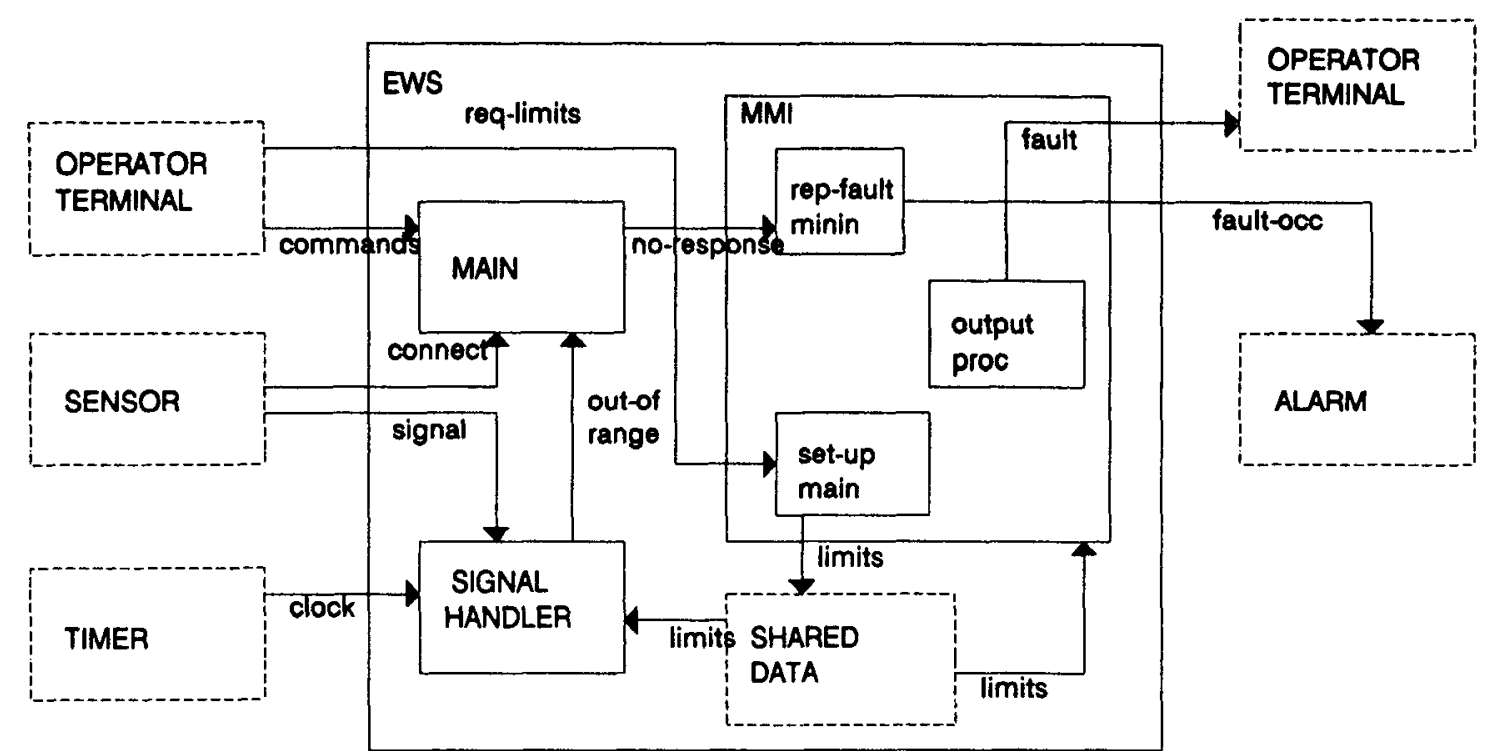

Figura 2.7 - Diagrama de Estruturas do Ambiente Statemate [HARE88b]

A decomposição hierárquica do sistema em componentes físicos é fornecida pela visão estrutural. Os componentes físicos correspondem aos módulos, entre os quais fluem informaçōes, desde que haja uma ligação física entre eles. Os diagramas de módulos são utilizados para especificar a visão estrutural, descrevendo os módulos do sistema, do ambiente e os dados e ou sinais de controle que fluem entre os mesmos. Na Figura 2.7 pode-se observar que módulos do ambiente são representados por retângulos tracejados externos ao sistema, módulos do sistema correspondem a formas retangulares e as bases de dados a retângulos tracejados internos ao sistema. O fluxo de informações é representado por vetores ou hipervetores, ou seja, vetores com mais de um ponto de origem ou destino.

\subsubsection{2 - Visão Funcional}

A especificação funcional permite a decomposição do sistema em uma hierarquia de atividades, juntamente com os itens de dados e sinais de controle que fluem entre estes. A decomposiçāo funcional especifica "o que" pode ocorrer e não "como" e "quando" as atividades e fluxos de dados ocorrem no sistema. 


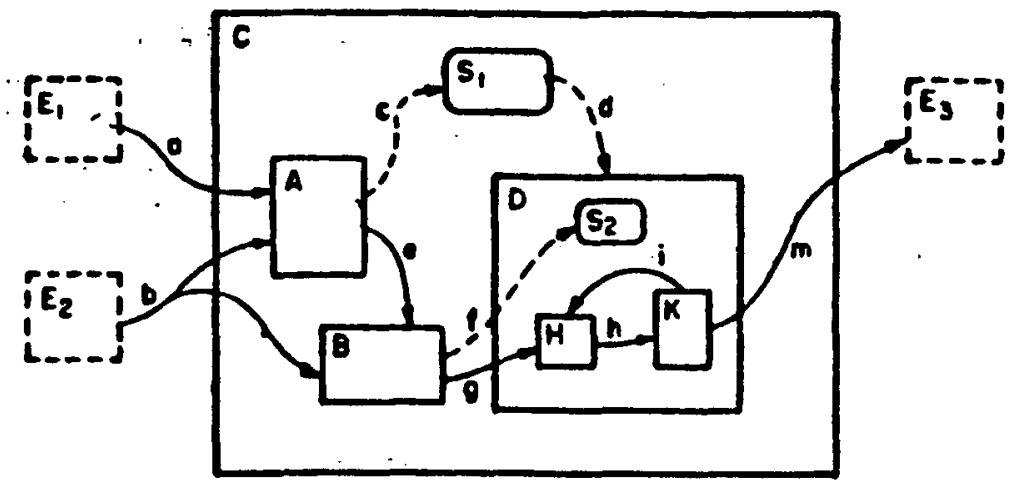

Figura 2.8 - Diagrama de Atividades do Ambiente Statemate [HARE88b]

Os diagramas de atividades são utilizados para modelar funcionalmente o sistema e graficamente são bastante similares aos diagramas de módulo. As atividades aceitam entradas e depois de um intervalo de tempo, produzem as saídas. A Figura 2.8 mostra as atividades (retângulos), os depósitos de dados (retângulos tracejados), as atividades de controle (retângulos com cantos arredondados), os fluxos de dados (vetores sólidos) e os fluxos de controle (vetores tracejados). As atividades de controle correspondem à visão comportamental do sistema, desta forma, no diagrama de atividades, elas sāo apenas caixas vazias, sendo que o seu conteúdo será determinado durante a especificação comportamental, a seguir.

\subsubsection{3 - Visão Comportamental}

A visão comportamental informa quando, como e porque as coisas acontecem no sistema. A linguagem gráfica utilizada para especificação comportamental são os statecharts, que já foram anteriormente descritos. Um exemplo de statecharts foi ilustrado na Figura 2.6. 


\subsubsection{4 - Outras características de Statemate}

Uma das grandes vantagens de Statemate é a capacidade de se executar a especificação. Dessa forma, o usuário pode interagir diretamente com o sistema, ativando eventos, alterando condiçōes e variáveis, e observando o comportamento do modelo. Outra forma de execução do modelo é através de uma Linguagem de Controle de Simulação, na qual o usuário escreve um programa especificando os eventos, valores de variáveis, etc. e executa o modelo, de forma não interativa, através do programa. Existe a possibilidade de se parar a execução do modelo, gerar eventos e posteriormente voltar à execução não interativa, além da geração aleatória de eventos e condiçōes.

Além da checagem da sintaxe dos modelos construídos, Statemate permite a realização de testes para detectar não-determinismo, testes de alcançabilidade e detecção de deadlock. Modelos podem ser testados exaustivamente através da geração de todos os possíveis eventos externos e todas as possíveis mudanças em condições e valores de variáveis; deve-se considerar entretanto que a simulação exaustiva de um modelo de tamanho médio pode extrapolar o limite aceitável de tempo e espaço de memória. Portanto, se isso ocorrer, os testes exaustivos podem ainda ser usados para modelos pequenos ou para partes pequenas de modelos mais complexos [HARE92].

Statemate possui uma Linguagem de Geração de Documentos com a qual o usuário pode criar documentos com estrutura, conteúdo e aparência definidas pelo mesmo. Statemate fornece relatórios para todas as fases de desenvolvimento do software, tais como: relatórios baseados nos modelos, baseados na análise dos resultados da simulação, e relatórios de alcançabilidade dinâmica, mostrando possíveis caminhos entre configurações.

Tradução da especificação para código fonte de uma linguagem de alto nível, tal como ADA, é feita por um pacote Prototipador encontrado em Statemate. O código produzido não deve ser considerado, entretanto, um produto final, mas sim, um protótipo. A principal vantagem é que ao invés de se ver modelos de uma forma animada, ou seja, ver statecharts e diagramas de atividade transicionando, o que pode ser visto é um protótipo do sistema, o qual está mais próximo do sistema final do que os modelos de especificação. 


\subsection{3 - Argonaute}

O sistema Argonaute possui como base a linguagem gráfica Argos, cuja semântica é baseada na álgebra de processos. Argonaute foi projetado para descrição, especificação e verificaçāo de sistemas reativos, como pode ser visto em [MARA89]. A linguagem Argos fundamenta-se na teoria de autômatos e em conceitos de linguagens baseadas na álgebra de processos clássica, tal como CCS [MILN80] , e linguagens de programação como Esterel [BERR88] e baseia-se também no formalismo de Statecharts. Sistemas reativos podem ser graficamente especificados por Argonaute, e esta especificação pode ser simulada.

A sintaxe gráfica de Argos é derivada do formalismo de Higraphs [HARE88a], tal como o formalismo de Statecharts proposto por Harel. Argos não é, entretanto, uma tentativa de definir outra semântica formal para Statecharts; sua definição baseia-se em álgebra de processos, e o conceito de decomposição hierárquica é adaptado de noções de linguagens do tipo Esterel, pois a álgebra de processos não propicia meios para fazê-lo.

\subsubsection{1 - Linguagem Argos}

Devido ao fato de Argos ser baseada em autômatos, um sistema pode ser descrito através da especificação de estados e transiçōes rotuladas. De maneira similar a Statecharts, o estado inicial é determinado por um pequeno vetor não rotulado. Os rótulos das transições correspondem aos eventos, os quais determinam a evolução do sistema.

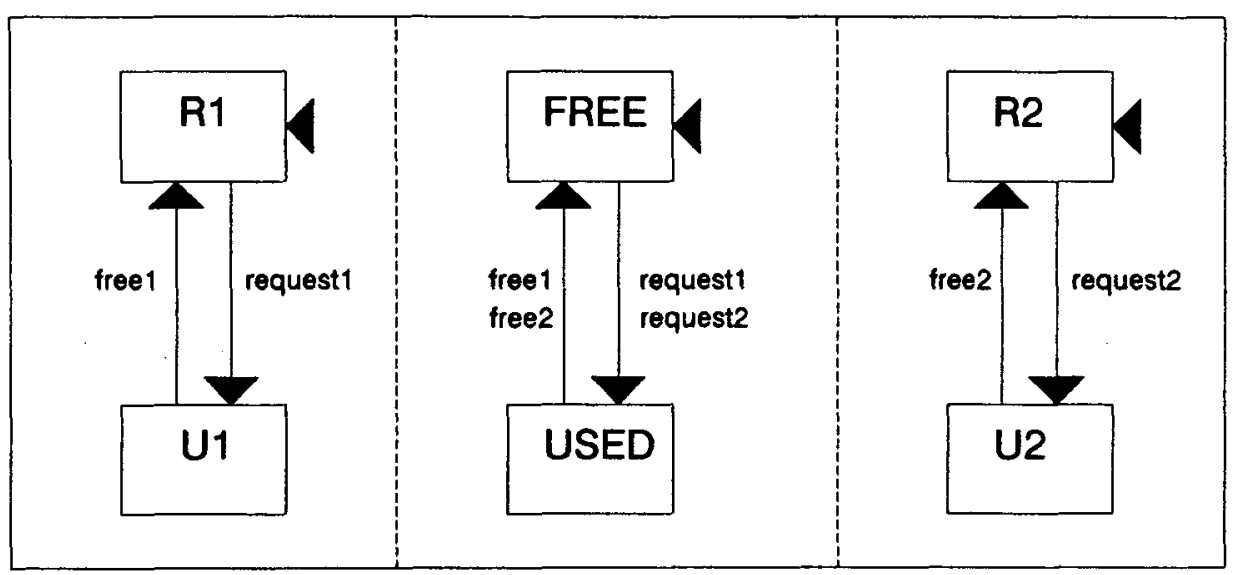

Figura 2.9 - Paralelismo em Argos [MARA89] 
A semántica do operador paralelo da linguagem Argos pode ser entendida da seguinte forma: para qualquer evento, por exemplo alfa, todos os componentes paralelos que possuem alfa devem evoluir juntos, ou seja, alfa só é executado se isso for feito em todos os componentes, caso contrário o mesmo é perdido. Na Figura 2.9 pode-se analisar melhor a semântica do operador paralelo. Seja R1/FREE/R2 a situação inicial e supondo a ocorrência de "request1", a nova situação será U1/USED/R2. Se em seguida ocorre "request2", então nada acontece, pois o mesmo não pode ser ativado no segundo componente.

Outra característica do operador paralelo é a possibilidade de comunicação entre os componentes paralelos, através da propagação de eventos. Esta característica será melhor compreendida através do modelo da Figura 2.10. A situação inicial do modelo é $\mathrm{A} / \mathrm{C} / \mathrm{E}$, e supondo que ocorra alfa, então a transição alfa/beta do primeiro componente gera o evento beta, o qual faz com que o segundo e o terceiro componentes transicionem, chegando portanto à situação B/D/F. Se a partir dessa situação o evento alfa ocorre novamente, então a transição alfa/gama gerará o evento gama, o qual será sentido nos componentes paralelos, mas não poderá ser executado, pois ele aparece nos dois componentes e só pode ser ativado no terceiro.

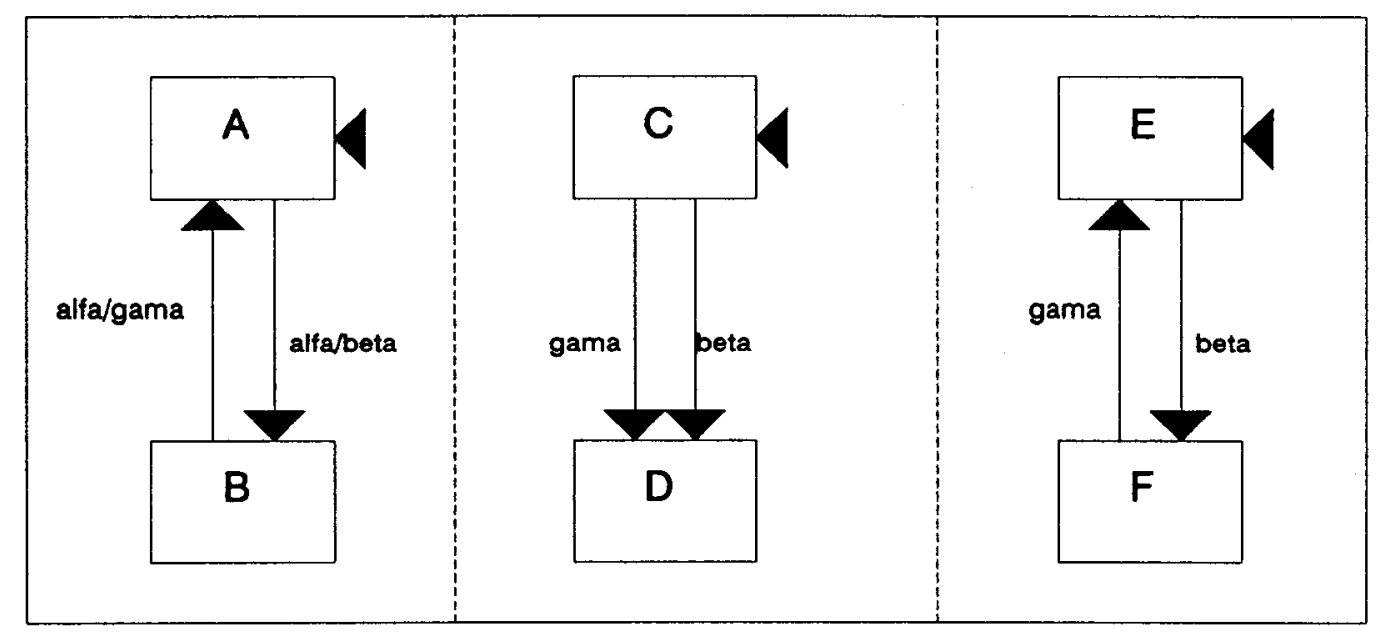

Figura 2.10 - Comunicação em Argos [MARA89]

Note-se que o paralelismo em Argos é determinístico, pois usa a mesma hipótese de sincronismo perfeito de Esterel [BOUS91], o que mostra claramente a fusão entre Esterel e Statecharts, ou seja, o determinismo é oriundo de Esterel, porém a propagação 
de eventos é proveniente de Statecharts, no qual a semântica de eventos gerados é não determinística.

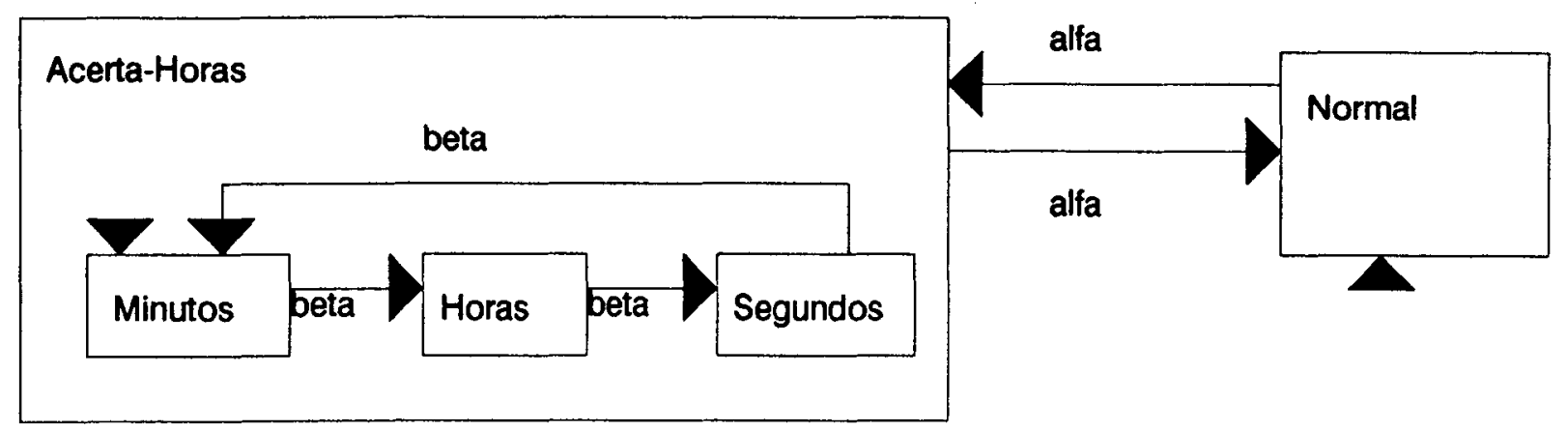

Figura 2.11- Decomposição Hierárquica em Argos (Exemplo 1) [MARA89]

O conceito de decomposição hierárquica em Argos é inspirado no formalismo de Statecharts, pois como foi visto anteriormente, a álgebra de processos não suporta a definição desse conceito. Para entender a semântica da decomposição hierárquica serão dados a seguir dois exemplos.

O primeiro exemplo, o qual pode ser visto na Figura 2.11, corresponde a um relógio, o qual pode estar no estado normal ou pode estar acertando as horas, respectivamente "NORMAL" e "ACERTA-HORAS" no modelo. Sendo "NORMAL" o estado inicial e ocorrendo o evento alfa, transiciona-se para "ACERTA-HORAS" e interno a este encontra-se em "MINUTOS", pois o mesmo é o estado inicial de "ACERTA-HORAS". Em "ACERTA-HORAS", se ocorre beta, vai-se transicionando de "MINUTOS" para "HORAS", de "HORAS" para "SEGUNDOS" e de "SEGUNDOS" para "MINUTOS", porém, se ocorre alfa, transiciona-se de "ACERTA-HORAS" para "NORMAL" e o processo (estado) interno a "ACERTA-HORAS" é morto, seja qual for.

No exemplo da Figura 2.12 o comportamento é similar ao exemplo anterior, só que, supondo que dentro do estado "TENTATIVA DE CONEXĀO", o processo ativo seja "D" e que ocorra o evento "ComConf", então "TENTATIVA DE CONEXÃO" vai para o estado "E", o evento "estabelecida" é gerado e o sistema transiciona de "TENTATIVA DE CONEXÃO" para "TRANSFERE DADOS", matando portanto o processo "E". Situação similar acontece quando, estando em "C", o evento "dt" ocorre. 


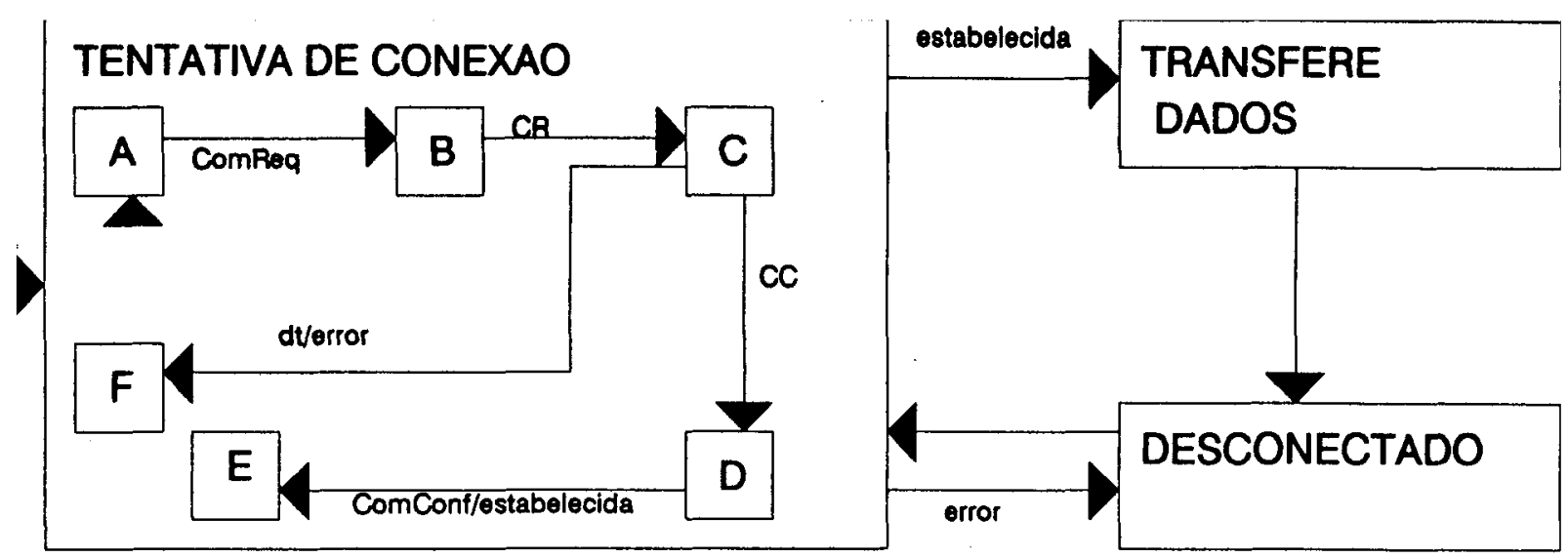

Figura 2.12 - Decomposição hierárquica em Argos (Exemplo 2) [MARA89]

O exemplo acima esclarece a decomposição hierárquica e mostra as diferenças entre Argos e Statecharts, pois, no segundo, os eventos gerados só podem ser sentidos por componentes paralelos.

Os eventos gerados em Argos podem ser definidos como internos. A sintaxe gráfica do operador "internal" pode ser vista na Figura 2.13. Quando beta é gerado dentro do escopo do operador "internal", o mesmo só poderá ser executado dentro desse escopo, tornando-se invisível para o resto do sistema. Um operador semelhante é definido em [HOOM91] para Statecharts. Em Esterel o equivalente do operador "internal" são os sinais locais.

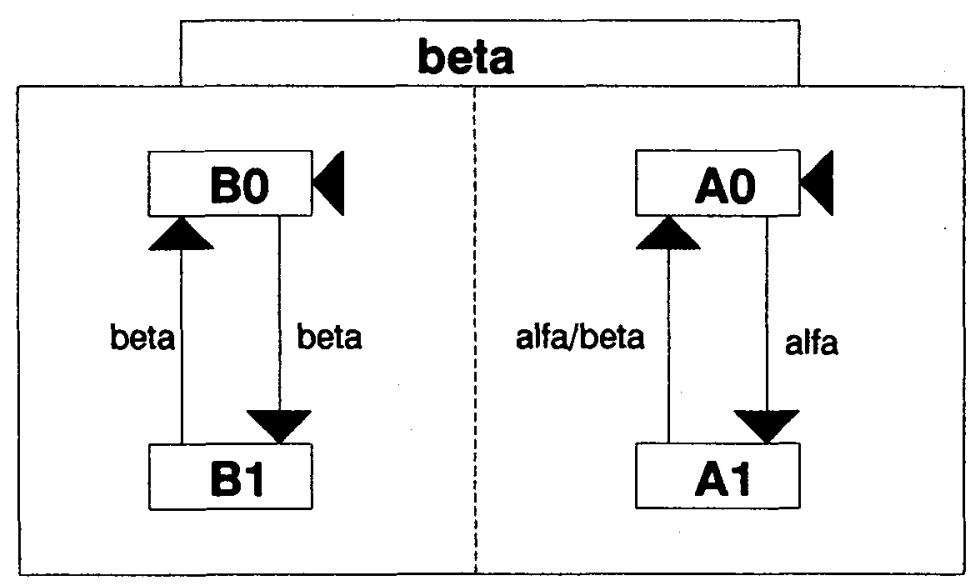

Figura 2.13 - Operador "Internal" de Argos [MARA89]

Não determinismo poderia ocorrer em Argos se duas transiçōes (alfa e beta), possuindo o mesmo estado fonte, pudessem ser selecionadas e só uma pudesse ser 
executada. Porém Argos define uma relação alfa\#beta que impede que os dois eventos possam ocorrer simultaneamente. Esta mesma relação permite a detecção de problemas de "casualidade", como os encontrados em [BOUS91].

\subsubsection{2 - Estrutura Geral de Argonaute}

A organização geral de Argonaute pode ser vista na Figura 2.14. A descrição gráfica do sistema pode ser construída e manipulada na tela pelo ambiente gráfico interativo de Argonaute.

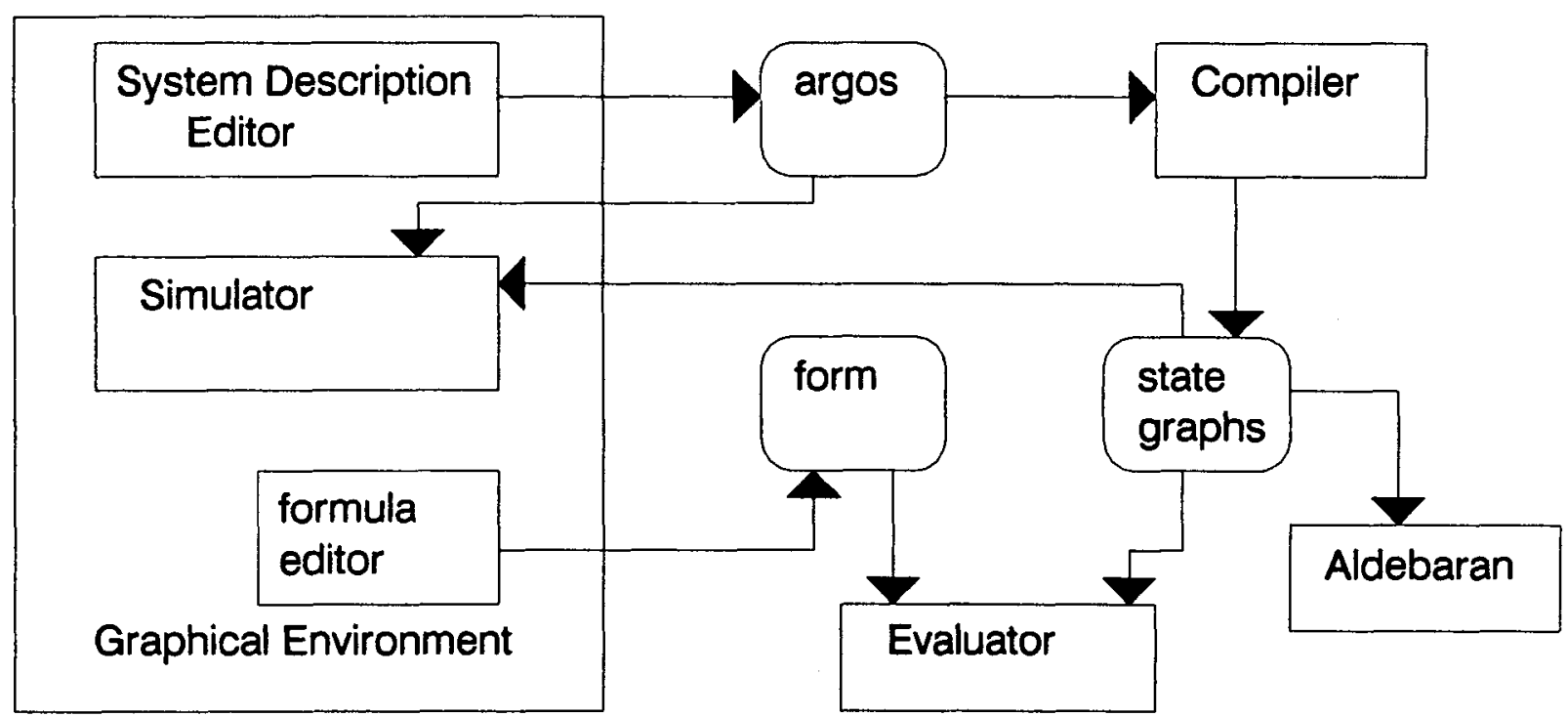

Figura 2.14 - Estrutura geral de Argonaute [MARA89]

Em [MARA89] vê-se que o editor de descrição do sistema permite a construção interativa e controle passo a passo da sintaxe conceitual da linguagem. Depois da descrição do autômato ter acabado, então o sistema ou apresenta um diagnóstico se o autômato não estiver correto, ou libera-o para ser executado. Argonaute possui também um editor de fórmulas, no qual pode-se especificar predicados básicos sobre os objetos da descrição gráfica do sistema, tais fórmula são avaliadas pelo módulo "EVALUATOR".

No momento em que o sistema é compilado, o modelo gráfico é salvo no formato "stategraphs". Este formato é usado pelo avaliador e pelo simulador gráfico, sendo também usado como entrada para a ferramenta de redução "Aldebaran". 
O ambiente Argonaute e a linguagem Argos são, portanto, baseados em conceitos de álgebra de processos e conceitos de linguagens de programação, ou seja, Argos tem por alicerce os conceitos e definições encontradas em Esterel e Statecharts.

\section{4 - Linguagens baseadas em Especificação de Estados}

As técnicas gráficas utilizadas no desenvolvimento de sistemas tornam a especificação mais amigável, tanto para o projetista quanto para o usuário. Se formalismo (sintático e semântico) for aliado a essas técnicas gráficas, então essa união se constitui em poderosa ferramenta para o desenvolvimento de sistemas. São estes alguns dos motivos que levaram ao aparecimento de linguagens baseadas em estados, tais como Esterel e Estelle, descritas a seguir.

\subsection{1 - Esterel}

Esterel é uma linguagem síncrona para programação reativa, originada de um projeto INRIA-ENSMP sobre semântica de paralelismo. No decorrer do projeto da linguagem, a necessidade de uma abordagem formal tornou-se cada vez mais clara. Dessa forma, Esterel é baseada em uma semântica formal, o que propiciou que os programas escritos em Esterel pudessem ser compilados eficientemente em máquinas de estados finitos e código eficiente pudesse ser gerado.

\subsubsection{1 - Características da Linguagem}

Como pode ser visto em [BOUS91], Esterel pode ser caracterizada pela equação a seguir:

$$
\begin{aligned}
\text { Esterel }= & \text { reatividade }+ \text { atomicidade de reações }+ \\
& \text { propagação instantânea }+ \text { determinismo }
\end{aligned}
$$


REATIVIDADE - o modelo básico de Esterel é o modelo reativo no qual a interação entre o ambiente e o sistema ocorre continuamente. Se o sistema é estimulado por um evento de entrada, o mesmo reage produzindo um evento de saída. Em um sistema reativo definem-se "instantes" como momentos em que o sistema reage a estímulos externos e internos. Comandos referentes a instantes são chamados comandos reativos. Por exemplo "await $\mathrm{S}$ " é um comando reativo no qual a execução é paralisada até o primeiro instante em que o sinal $S$ torne-se presente.

ATOMICIDADE DE REAÇõES - Esterel é baseado na hipótese de sincronismo perfeito, que supõe que as reações são instantâneas, de tal forma que a ativação e produção das saídas são síncronas, como se os programas fossem executados em uma máquina infinitamente veloz. Portanto, se uma reação é atômica quer dizer que uma reação particular não interfere em outras reações.

PROPAGAÇÃO INSTANTÂNEA - o operador de paralelismo, denotado por || em Esterel, é análogo a uma comunicação de rádio, onde muitos receptores recebem a mesma informação, isto como conseqüência da característica síncrona do operador paralelo. A comunicação é feita usando sinais que podem ser emitidos, testados por sua presença e terem um valor associado. No mesmo instante em que um sinal é enviado ele pode ser percebido por todos os receptores.

No exemplo a seguir verifica-se a propagação instantânea, pois quando "S" é emitido na segunda sentença, ele já se torna presente na primeira e na última sentença, o que faz com que "T" e "U" sejam emitidos em um mesmo instante.

exemplo :

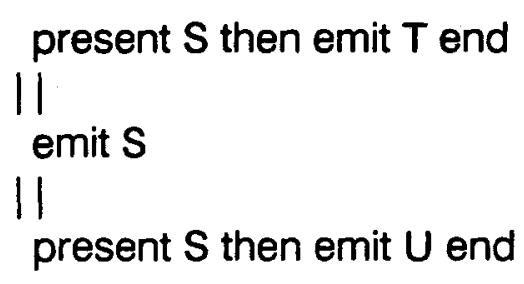

DETERMINISMO - é uma forma de simplificar a programação reativa. Com programas determinísticos o comportamento é reproduzível, o que simplifica as tarefas de teste e validação de programas. 


\subsubsection{2 - Programação em Esterel}

Aqui não será descrita a linguagem Esterel, serão vistos apenas exemplos para mostrar as principais características da linguagem.

Seja o exemplo:

do

await BUTTON

emit ACTION

watching SECOND

timeout emit ALARM

A sentença "await BUTTON" espera até que o sinal "BUTTON" esteja presente, então a sentença "emit ACTION" emite o sinal "ACTION". A sentença "watching SECOND" só é executada se o sinal "SECOND" chegar antes ou ao mesmo tempo que o sinal "BUTTON", desta forma "timeout emit ALARM" emite o sinal "ALARM". Deve-se ressaltar que se o sinal "BUTTON" chegar antes do sinal "SECOND", então "await BUTTON" é executado, caso contrário "watching SECOND" o será.

No exemplo acima ou "ALARM" ou "ACTION" eram emitidos, nunca ambos. Será mostrado agora um exemplo em que os dois podem ser emitidos simultaneamente.

exemplo :

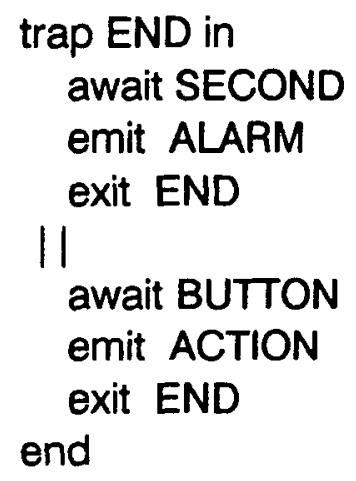

O comando "trap END in" define um bloco que é instantaneamente terminado quando o comando "exit END" é executado. Então o bloco "trap END in" termina tão logo "SECOND", ou "BUTTON", ou ambos, estejam presentes. Caso "SECOND" e "BUTTON" estejam presentes simultaneamente, então "ACTION" e "ALARM" são ambos emitidos, isto como conseqüência da semântica do operador paralelo. 
Um exemplo de um manipulador de mouse simplificado ([BOUS91]) será exibido a seguir. Sejam as duas entradas:

1 - CLICK = pressionar o botão.

2 - TOP $=$ um sinal de unidade de tempo do relogio.

O manipulador de mouse deve registrar o número de clicks (zero, um, mais de um) realizados num intervalo de cinco tops.

O primeiro módulo é o que conta as ocorrências dos CLICKS, quando o sinal "RST" chega, então o módulo "COUNTER" emite o sinal "VAL" cujo valor associado corresponde ao número de clicks.

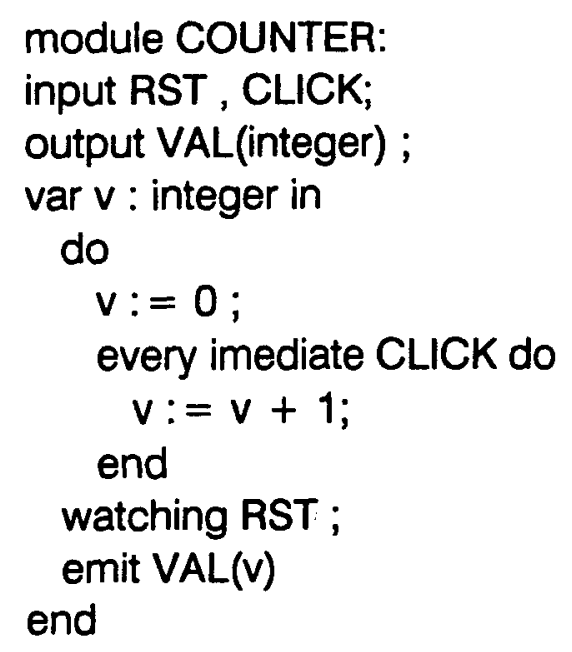

O segundo módulo recebe o sinal "VAL" e, de acordo com o seu valor, emite os sinais "NONE", "SINGLE" ou "MANY".

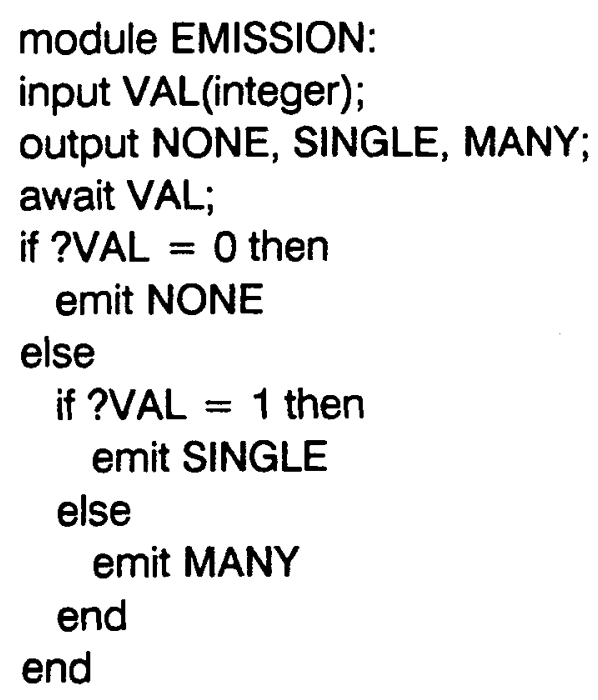


O programa principal (módulo "MOUSE") possui um laço com uma cópia dos módulos "COUNTER" e "EMISSION" e uma sentença que emite "RST" depois de cinco tops recebidos, tudo em paralelo.

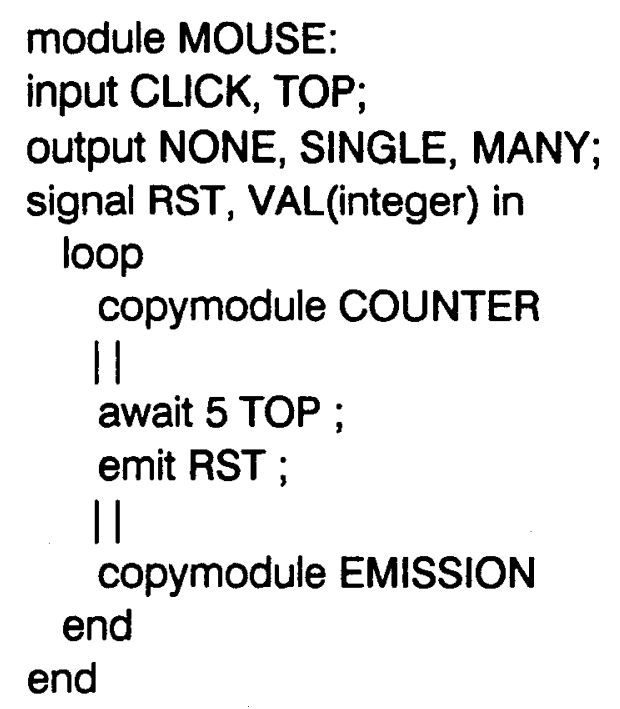

É importante notar que no módulo "MOUSE" a propagação é instantânea, pois quando no segundo bloco é emitido o sinal "RST", este já é sentido no primeiro bloco por "COUNTER", o qual emite "VAL" com o número de clicks, sendo esse sentido por "EMISSION", que emite o sinal de acordo com o valor de "VAL". Todas essas operações são realizadas no mesmo instante.

\subsubsection{3 - Semântica de Esterel}

A sintaxe de Esterel dá liberdade ao programador para que certos "problemas" possam ser gerados durante a programaçāo, tais como "loops instantâneos" e "problemas de casualidade", os quais são detectados em tempo de compilaçāo. Maiores detalhes sobre esses problemas podem ser vistos em [BOUS91]. Deve-se notar, entretanto, que a presença de "deadlocks" não pode ser detectada em tempo de compilação.

O objetivo da semântica formal de Esterel é descrever sem ambigüidade o comportamento dos programas. A abordagem formal foi a principal diretiva para os projetistas do compilador e das ferramentas de validação. 
A semântica comportamental em Esterel manipula transições de acordo com o seguinte formato:

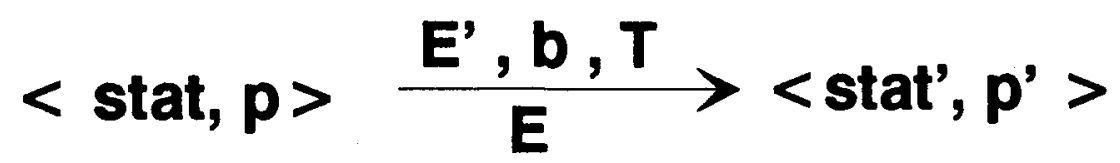

onde:

- p e p' são memórias que alocam as variáveis livres das sentenças stat e stat'.

- Ê é um evento completo. É o conjunto de sinais de entrada e sinais locais visíveis para stat.

- E' é um evento que contém os sinais emitidos por stat e seus valores. É o conjunto de sinais de saída e sinais locais visíveis para stat.

- b é um valor booleano, o qual assume $t$ se stat termina e ff caso contrário.

- T é o conjunto de rótulos dos blocos de comando que contém os rótulos da sentença "exit" executados por stat.

São mostrados a seguir a semântica dos comando de atribuição e do comando "emit", as demais regras podem ser encontradas em [BERR88].

a) regra para comando de atribuição

$$
<\exp , p>\underset{E}{\longrightarrow} v
$$

$$
<X:=\exp , p>\frac{e, t t, \emptyset}{E}><\text { nothing, } p[X \longleftarrow v]>
$$

b) regra para o comando "emit"

$$
<\exp , p>\longrightarrow
$$

$<$ emit $S(\exp ), p>\frac{S(v), t t, \varnothing}{E}><$ nothing, $p>$ 
As regras acima podem ser interpretadas como uma composição de comandos. A parte superior de cada regra indica que uma expressāo foi avaliada e gerou um determinado valor v. A parte inferior mostra o comportamento do comando que está sendo executado, ou seja, se o comando termina ou se ele deixa resíduos; as alteraçōes que o comando executa na memória, etc.

\subsubsection{4 - Compilação e produção de código em Esterel}

Uma das grandes vantagens no uso de Esterel é que a mesma pode, a partir do programa, produzir um autômato finito equivalente. A construção do autômato é baseada na semântica comportamental. Para cada sentença "stat", as transiçōes são ativadas pelos eventos de entrada, e ocorre a transição para a sentença residual "stat". Como o autômato produzido é seqüencial, fica eliminado desta forma o paralelismo e os sinais locais de comunicação. Eficiência é obtida no código gerado, justamente pelo fato do mesmo ser seqüencial, pois não ocorrem gastos de tempo com gerenciamento de processos, comunicação e sincronização de sinais. Outro fator importante é que o máximo tempo de transição de um autômato é previsível, o que é de grande valia em sistemas de tempo real. A descriçāo textual seqüencial do exemplo do manipulador de mouse visto anteriormente pode ser encontrada em [BOUS91].

\subsubsection{5 - O ambiente Esterel}

Dois grupos de ferramentas estão disponíveis no ambiente Esterel. O primeiro é composto pelas ferramentas de Verificação e Validação, as quais consideram a estrutura interna do autômato compilado. Essas ferramentas permitem a comparação com a especificação e a visualização total ou parcial de estados e transições. Como muitas vezes o autômato produzido é demasiadamente grande, as ferramentas executam a redução do mesmo. Desta forma o autômato fica reduzido somente às partes relevantes para a sua verificação e validação. 
O segundo grupo é composto por ferramentas de simulação e desenvolvimento, que consideram programas em Esterel como caixas reativas e permitem ao usuário ativá-las interativamente, registrando as reações correspondentes.

Esterel é portanto uma linguagem próxima da especificaçāo, o que facilita o desenvolvimento, produz código eficiente, pois não gerencia processos e nem sincronização, e por fim, ainda determina o máximo tempo de transição, o que é muito importante para sistemas reativos. Esterel é dessa forma adequada para o desenvolvimento de sistemas de tempo real, pois além das características dadas acima, ainda possui um ambiente com ferramentas de apoio à verificação, validação, simulação e desenvolvimento de sistemas.

\subsection{2 - Estelle}

O desenvolvimento de sistemas distribuídos é bem mais problemático do que o desenvolvimento de sistemas convencionais (seqüenciais). A especificação de sistemas distribuídos evidencia, ainda mais, a necessidade da utilização de técnicas formais, pois sem elas a validação e verificação dos sistemas torna-se mais difícil. Estelle é uma linguagem para especificação de sistemas distribuídos voltada para uma aplicaçāo em especial: protocolos de comunicação e serviços. Estelle possui sintaxe e semântica formalmente definidas, que a inclui como uma técnica de descrição formal. Uma especificação em Estelle descreve a estrutura de comunicação do autômato de estados, cujas ações internas são definidas por comandos em Pascal (com algumas restriçōes e expansões).

\subsubsection{1 - Principais características de Estelle}

a) Task - uma especificação em Estelle dá a visão de um conjunto de componentes de comunicação, chamados de instâncias de módulos (tasks). Uma "task" é representada graficamente por um retângulo e possui um número de pontos de acesso de entrada e saída, chamados pontos de interação, os quais são externos, caso estejam localizados na fronteira 
do retângulo; ou internos, se estiverem no interior do retângulo. Um exemplo de "task" e pontos de interação pode ser observado na Figura 2.15.

Uma task é ativa se sua especificação possui pelo menos uma transição, caso contrário ela é inativa. Uma task possui um dos seguintes atributos de classe:

- "systemprocess".

- "systemactivity".

- "process".

- "activity".

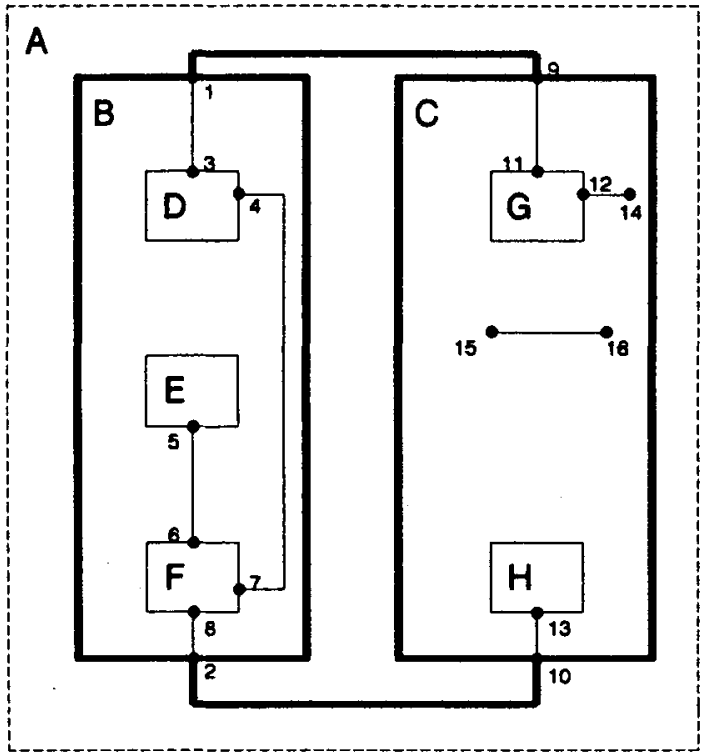

Figura 2.15 - Tasks e Pontos de Interação em Estelle [BUDK87]

b) Estruturação - a estrutura hierárquica das tasks pode ser representada graficamente de duas maneiras, como mostram as Figuras 2.16a e 2.16b. A relação pai/filho é representada por arestas ou caixas aninhadas. Existem certos princípios que devem ser observados na hierarquização das tasks, os quais podem ser vistos em [BUDK87].

As estruturas de comunicação são representadas graficamente por segmentos de linha, os quais unem os pontos de interação das tasks. Quando um ponto de interação externo de uma task é unido com um ponto de interação externo da task pai, diz-se que esses pontos estão ligados (attached). Dois pontos de interação estão conectados (connected) se:

- ambos são pontos de interação externos de tasks no mesmo nível hierárquico; 
- Um é um ponto de interação interno de uma task e o outro é um ponto de interação externo de uma task filha;e

- ambos são pontos de interação internos da mesma task.

(a)

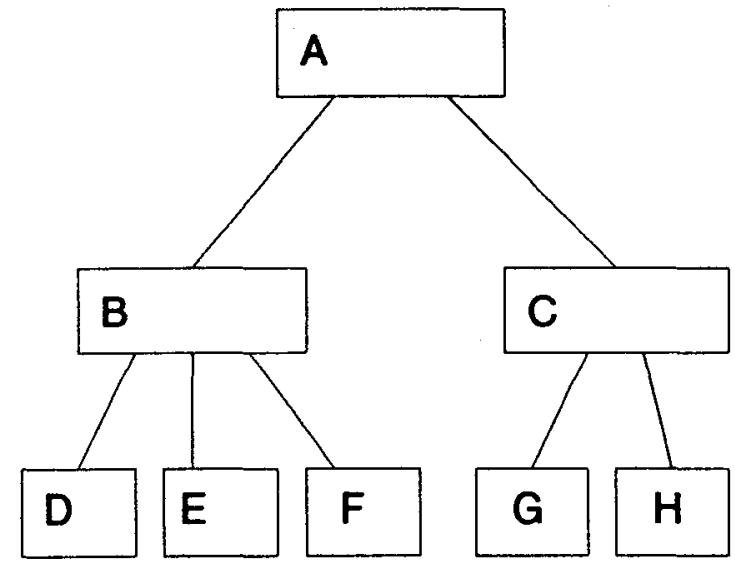

(b)

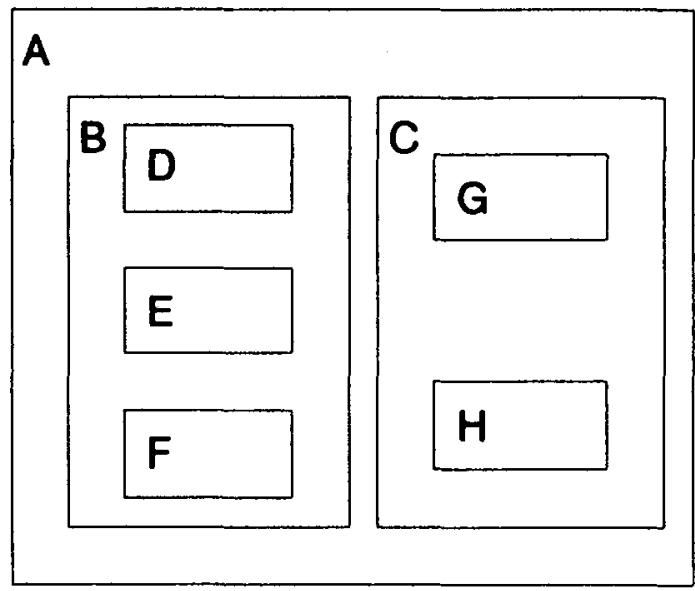

Figura 2.16 - Hierarquia das Tasks em Estelle [BUDK87]

Certas restrições são impostas para se fazer a união entre pontos de interação, as quais sāo descritas em [BUDK87].

Uma linha composta de exatamente um segmento "connected" e zero ou mais segmentos "attached" formam um "link" entre dois pontos de interação. Os "links" especificam que duas tasks podem se comunicar por troca de mensagens (bidirecional) através deles. Os "links" e demais componentes de um sistema são representados por:

- linhas tracejadas, que são usadas para tasks englobando "subsystems";

- linhas mais espessas, que representam "tasks system" e "links" de comunicação entre estas; e

- linhas normais, que representam o restante das "tasks" e "links".

c) Comunicação - Estelle faz uso de dois mecanismos de comunicação entre as tasks:

1) troca de mensagens: tasks trocam mensagens (interações). Uma task pode enviar uma interação para outra task através de um "link" de comunicação previamente estabelecido. Uma interação recebida por uma task é adicionada a uma fila FIFO ilimitada, portanto a comunicação é não bloqueante, associada ao ponto de interação. A fila FIFO 
pode ser individual (caso pertença a um único ponto de interação) ou comum (caso seja compartilhada com outros pontos de interação).

2) compartilhamento restrito: variáveis podem ser compartilhadas entre uma task e sua task pai. $O$ acesso simultâneo a essas variáveis pelas tasks pai e filho é exclusivo, pois a execução de ações da task pai é sempre prioritária.

d) Paralelismo - o paralelismo entre duas tasks em Estelle pode ser expresso por:

- paralelismo assíncrono: permitido somente entre subsystems, ou mais precisamente, entre ações de diferentes tasks pertencentes a diferentes subsystems.

- paralelismo síncrono: permitido somente dentro de um subsystem, ou melhor, entre açōes de diferentes tasks pertencentes ao mesmo subsystem.

e) Comportamento Global - o estilo operacional foi usado para descrever o comportamento de um sistema especificado através de Estelle. O comportamento é definido por um conjunto de todas as possíveis seqüências de "situaçōes globais" geradas de uma situação inicial. Duas situações globais consecutivas correspondem à execução de uma transição. A semântica operacional de Estelle descreve a maneira como esta seqüência é gerada, ou seja, a forma como as transições do sistema podem permutar para modelar de forma adequada o paralelismo síncrono dentro de subsistemas, combinado com o paralelismo assíncrono entre eles.

\subsubsection{2 - Semântica de Estelle}

Estelle é baseada em uma semântica operacional, ou seja, a relação próximo-estado é definida sobre o conjunto de estados globais do sistema, chamados "situação global", em Estelle. A relação próximo-estado especifica todas as possíveis situações que podem ser diretamente alcançadas de uma dada situação. Caracteriza-se o comportamento de um sistema especificado em Estelle por um conjunto de todas as seqüências de situações globais que podem ser geradas de uma certa situação inicial. 
A execução dos subsistemas é dada por uma sucessão de passos de computação. Um passo de computação começa com a seleção de transições a serem executadas nesse passo. $O$ passo termina quando todas as transiçōes selecionadas forem executadas; porém, deve-se notar que a execução de transiçōes em um passo não pode ser considerada simultaneamente, pois o resultado pode depender do fato de uma outra transição terminar primeiro.

Situação Global - cada situação global de transiçōes do sistema é composta por informações sobre a estrutura hierárquica do sistema, a estrutura das ligações, estados locais de cada task e o conjunto de transiçōes que estão em execução paralela. Essas informações estão incluídas em uma descrição instantânea global (Gid(SP), onde SP indica "Sistema Especificado") do sistema. O conjunto de transições paralelas para o i-ésimo subsistema é denotado por:

Ai ( $\mathrm{i}=1, \ldots, \mathrm{n}$, onde $\mathrm{n}$ é o número de subsistemas).

Denota-se a situação global por:

sit $=(\operatorname{Gid}(\mathrm{SP}) ; \mathrm{A} 1, \ldots, \mathrm{An})$

A situação global é inicial se $\mathrm{Gid}(\mathrm{SP})$ é inicial e $\mathrm{Ai}=0, \forall \mathrm{i}$. Gid(SP) é inicial se este resulta da parte de inicialização da especificação de SP.

Se dada uma situação global, temos $A \dot{i}=0$, então o i-ésimo subsistema está em fase de gerenciamento, onde um novo conjunto de transições a serem executadas em paralelo está sendo selecionado.

Caso $A i \neq 0$, então o i-ésimo subsistema está em execução.

Relação Próxima-Situação - dada uma situação global arbitrária, esta relação define a situação sucessiva.

Para $i=1,2, \ldots, n$, a relação é definida por:

1) Se, na situação corrente $A i=0$, entāo a próxima situação é dada por (Gid(SP);A1,...,AS(Gid(SP)/i),..,An) onde AS(Gid(SP)/i) é o conjunto de transições selecionadas para execução pelo i-ésimo subsistema.

2) $\mathrm{Se}$, na situação corrente $\mathrm{A} i \neq 0$, então para cada transição t de $\mathrm{Ai}$, a próxima situação é:

$(\mathrm{t}(\mathrm{Gid}(\mathrm{SP})) ; \mathrm{A} 1, \ldots, \mathrm{Ai}-\{\mathrm{t}\}, \ldots, \mathrm{An})$, ou seja, depois de t ser executada ela é removida do conjunto Ai.

A execução de uma transição t de uma "task":

- pode causar uma mudança no estado local da "task"; e 
- não pode influenciar a escolha de transições já selecionadas por outros subsistemas, nem a escolha de transiçōes dentro do mesmo subsistema.

A escolha do conjunto AS(Gid(SP)/i) é regulada pelo princípio da prioridade pai/filho e pelos atributos das "tasks". As regras aplicadas para uma "task" dentro de um subsistema podem ser formuladas por: se a "task" tem transições a oferecer e estas estão prontas para ativar, entâo elas serão selecionadas de acordo com a prioridade; de outra forma, se a "task" é um "process" ou um "systemprocess" todas as transições oferecidas são selecionadas, e se a "task" é uma "activity" ou uma "systemactivity" somente uma das transições oferecidas será selecionada.

\subsubsection{3 - Um Exemplo de Estelle}

Não será feita aqui nenhuma descrição da sintaxe de Estelle, a qual pode ser encontrada em [BUDK87] com um nível de detalhes não muito grande. $O$ exemplo apresentado aqui não ilustra uma situação real, e também pode ser visto em [BUDK87] com mais variações dos atributos de módulos e da especificação. Seja o exemplo:

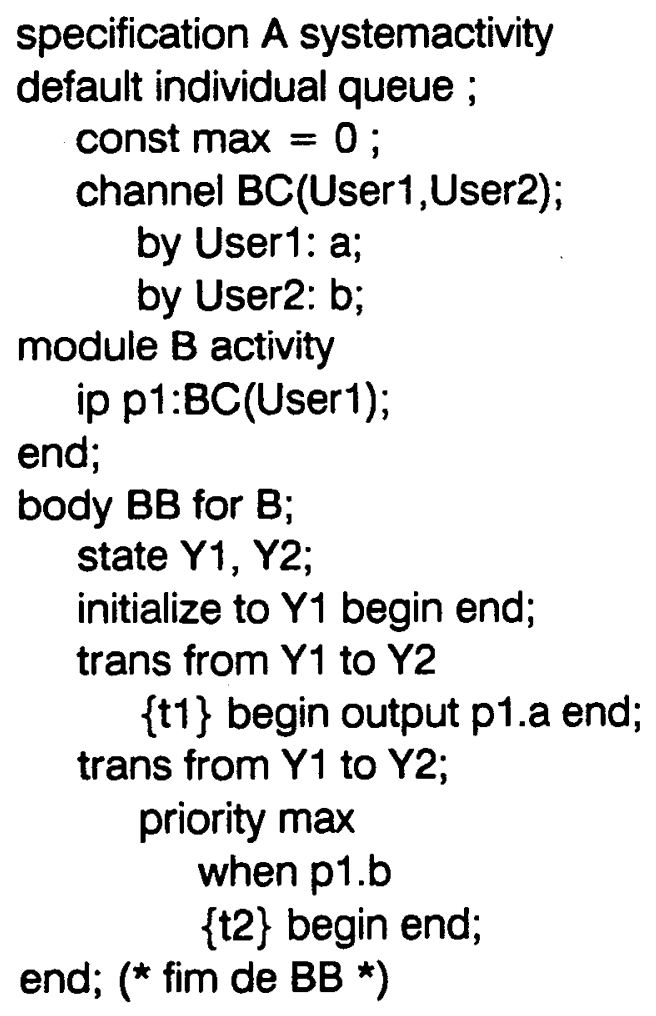




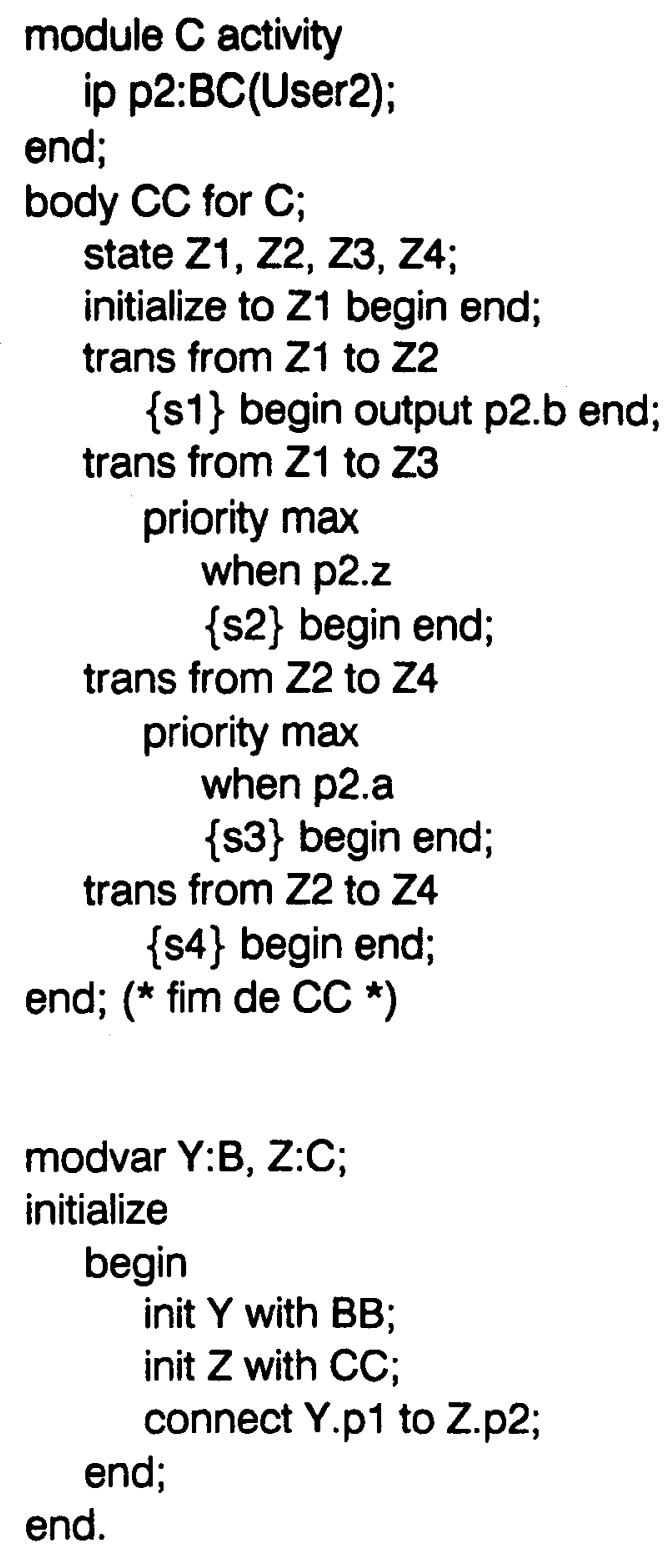

A representação gráfica do exemplo é dada na Figura 2.17 e o diagrama de estados dos módulos B e C pode ser visto na Figura 2.18.

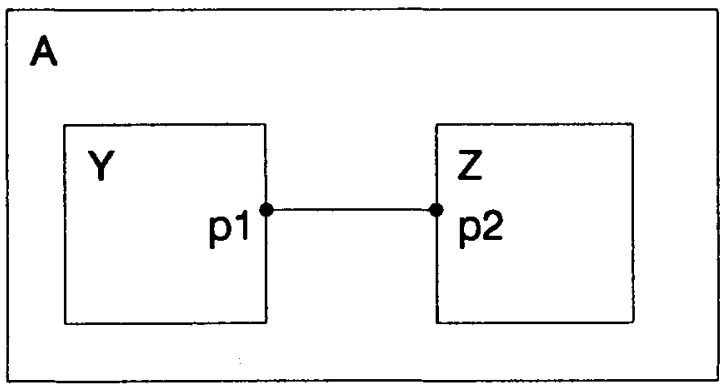

Figura 2.17 - Representação Gráfica do Exemplo de Estelle [BUDK87] 

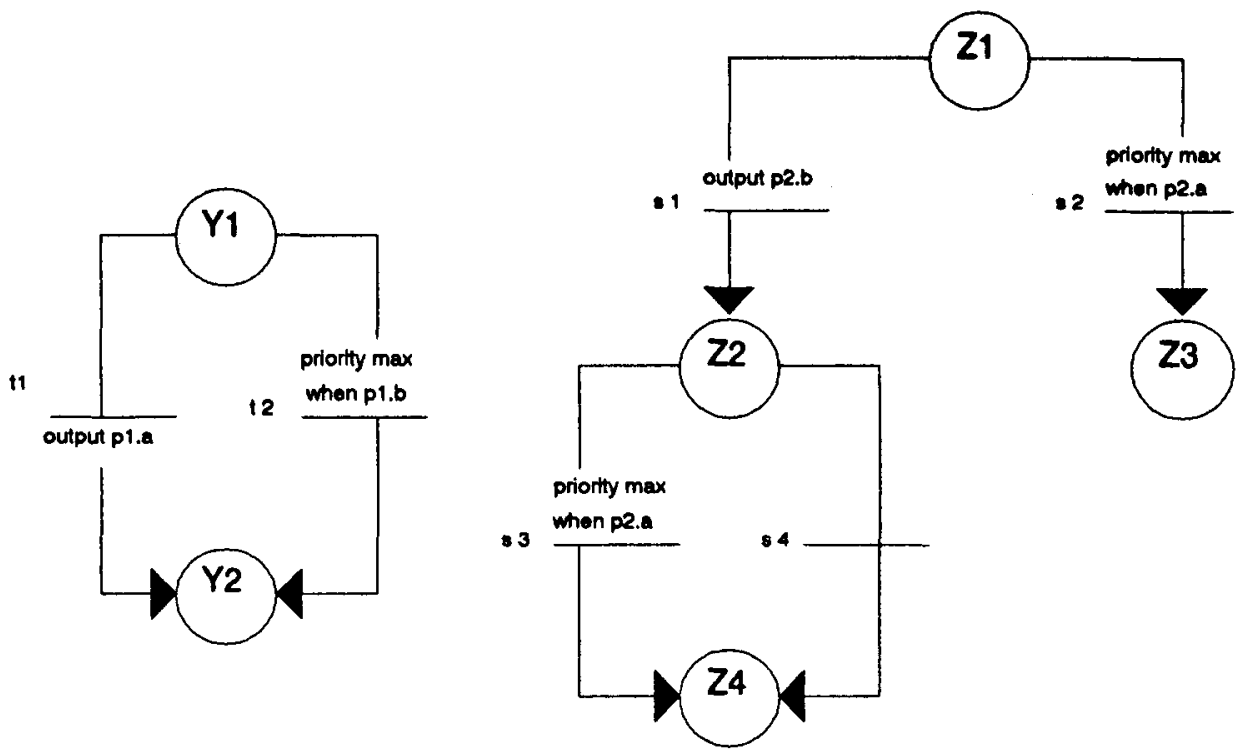

Figura 2.18 - Dlagrama de Estados dos Módulos 8 • C do Exemplo de Estelle [BUDKB7]

Como o sistema specification A possui atributo "systemactivity", então o conjunto de transições ou é vazio ou possui uma única transição. O estado inicial é o seguinte:

- Y está no estado Y1;

- Z está no estado Z1;

- as filas p1 e p2 estão vazias; e

- o conjunto de transições está vazio.

Dada a situação inicial acima, ou a transição $t 1$ de $\mathrm{Y}$ ou a transição $\mathrm{s} 1$ de $\mathrm{Z}$ pode ser selecionada. Suponha primeiro que $t 1$ foi selecionada, desta forma a interação "a" é posta na cabeça da fila p2, e a única transição possível em $\mathrm{Z}$ é s2 (devido à prioridade). Logo s2 é executada e a seqüência de transiçōes é $\mathrm{t} 1, \mathrm{~s} 2$.

Suponha, entretanto, que ao invés de $t 1$, seja selecionada s1. A interação "b" será enviada para a cabeça da fila $\mathrm{p} 1 \mathrm{e}$, conseqüentemente, na task $\mathrm{Y}$ será executada $\mathrm{t} 2$ (pela prioridade). Obtém-se dessa maneira a situação Y $2 \mathrm{em} \mathrm{Y} \mathrm{e} \mathrm{Z2} \mathrm{em} \mathrm{Z,} \mathrm{portanto} \mathrm{somente} \mathrm{a}$ transição 44 poderá ser selecionada. Deve-se notar também que a transição 44 poderia ter ocorrido antes de $\mathrm{t} 2$. As seqüências obtidas da escolha inicial de $\mathrm{s} 1$ são portanto: $\mathrm{t} 1, \mathrm{t} 2, \mathrm{~s} 4$ e t1,s4,t2.

Foram tratados neste exemplo somente módulos e especificaçōes com atributos "activity" e "systemactivity", mas existem mais dois casos em que, variando-se os atributos de A, B e C, geram-se seqüências de transições diferentes. Essas duas variações são vistas e discutidas em [BUDK87]. 


\section{5 - Linguagens de Simulação}

As linguagens de simulação surgiram para facilitar a programação de modelos de simulação, pois algumas características são comuns a quase todos os modelos, tais como:

- geração de números aleatórios;

- geração de variáveis aleatórias para uma distribuição probabilística especificada;

- controle do tempo de simulação; e

- geração de relatórios dos resultados da simulação.

Junto com a necessidade de se programar um modelo vem a decisão de qual linguagem utilizar para fazê-lo. Algumas vantagens que as linguagens de simulação possuem em relação às linguagens de propósito geral são:

- linguagens de simulação fornecem a maioria das características necessárias para programação de um modelo de simulação, resultando em possível diminuição do tempo de programação;

- a tradução do modelo para a linguagem é mais natural;

- alterações no modelo são feitas com maior facilidade;

- linguagens de simulação fornecem alocação dinâmica de memória; e

- os erros de programação são poucos e detectados com mais facilidade.

As vantagens citadas acima, bem como as vantagens em se utilizar uma linguagem de propósito geral, dadas abaixo, podem ser vistas em [LAW82].

As vantagens em se usar uma linguagem de propósito geral são:

- a maioria dos modeladores já conhece uma linguagem de propósito geral;

- linguagens de propósito geral (Fortran, Basic, Pascal, etc) estão disponíveis na maioria dos computadores;

- um programa escrito em uma linguagem de propósito geral pode ser mais rápido do que um escrito em uma linguagem de simulação; $e$

- linguagens de propósito geral são mais flexíveis.

Serão dadas a seguir algumas características das linguagens de simulação SimscriptII.5, Slam e GPSS, sendo que uma maior ênfase será dada à última, que é uma das linguagens de simulação mais usada atualmente. 


\subsection{1 - Simscript}

Simscript $\epsilon$ uma linguagem de programação especialmente projetada para simulação de modelos de eventos discretos, porém pode ser utilizada como uma linguagem científica, sendo tão poderosa quanto Fortran, Algol ou Pascal. Os comandos em Simscript são bastante semelhantes ao inglês e podem ser escritos em um estilo de formato livre. Devido a essas características, os programas escritos em Simscript não necessitam de uma documentação adicional muito rigorosa. Simscript executa a manutenção automática da lista de eventos futuros e algoritmos para escalonamento de eventos e controle do tempo de simulação, fornecendo também geradores de variáveis aleatórias para uma grande variedade de distribuições probabilísticas.

A modelagem de um sistema, utilizando Simscript, consiste de entidades, atributos e conjuntos. Entidades podem ser de dois tipos: permanentes (tais como os servidores de um sistema) e temporários (tais como clientes, chegando e abandonando o sistema). Atributos são valores ou dados que caracterizam as entidades; e conjuntos são coleçōes de entidades com propriedades comuns.

SimscriptII.5, como pode ser visto em [LAW82] e [BANK84], é uma linguagem de simulação bastante poderosa e flexível, cuja programação pode ser mais eficiente do que Fortran. $\mathrm{O}$ alto custo de SimscriptII.5, se comparado com outras linguagens de simulação, faz com que esta seja mais utilizada por organizaçōes que possuam muitas atividades de simulação ou um grande projeto de simulação onde o poder de SimscriptII.5 compense os custos de aquisição e manutenção da linguagem.

\subsection{2 - Slam}

Slam (Simulation Language for Alternative Modeling) é uma linguagem de simulação de alto nivel, baseada em Fortran, que permite a modelagem de sistemas orientados a eventos e/ou orientados a processos. Na modelagem orientada a processos, Slam combina um conjunto de símbolos padrões chamados nodos (nodes) e ramificações (branches), dentro de uma estrutura de rede interconectada, a qual representa o sistema. Um modelo de rede completo em Slam representa todos os possíveis caminhos que uma 
entidade pode percorrer através do sistema. Para executar o modelo o simulador traduz a representação em rede diretamente para comandos da linguagem, os quais são as entradas para o processador Slam.

Assim como Simscript, Slam também possui algoritmos para escalonamento de eventos e controle de tempo de simulação, geração de números e variáveis aleatórias para grande variedade de distribuições probabilísticas, controle de entrada e saída de entidades no sistema, etc.

Um exemplo de simulação de uma fila com um único servidor, modelado em Slam, é encontrado em [BANK84].

\section{5 .3 - GPSS}

GPSS (General Purpose Simulation System) é uma linguagem de simulação altamente estruturada, fazendo uso da abordagem orientada a processos e especializada na simulação de modelos de filas. O alto nível de abstração de GPSS/H torna-a mais legível do que linguagens como Simscript, Fortran e Slam. O sistema a ser modelado é descrito por meio de um diagrama de blocos, no qual fluem as transaçōes (entidades temporárias), ou seja, as entidades são geradas, percorrem um determinado caminho no diagrama de blocos, até o momento em que abandonam o sistema. Ao contrário de Simscript, GPSS não é uma linguagem procedimental, mas sim um método estruturado para descrição de certos tipos de sistemas.

Apesar de ser a linguagem de simulação de maior uso, GPSS possui algumas desvantagens, tais como: cálculos numéricos complexos são praticamente impossíveis de serem feitos; possui gerador de variáveis aleatórias para poucas distribuiçōes probabilísticas; e a seqüência de números aleatórios produzida é sempre a mesma.

O diagrama de blocos de um modelo de fila com um único servidor pode ser observado na Figura 2.19, sendo que o mesmo foi extraído de [BANK84]. Nesse modelo pode-se observar alguns dos 40 blocos padróes existentes no GPSS, por exemplo:

- GENERATE - gera transações em intervalos de tempo especificados pela distribuição probabilística associada ao mesmo; 
- SEIZE - representa a aquisição de um recurso. Se o recurso estiver livre, ele é adquirido, caso contrário a transação fica esperando no bloco anterior a SEIZE;

- ADVANCE - representa uma atividade. O tempo de serviço desta atividade é computado pela distribuição probabilística referenciada no bloco; e

- RELEASE - libera o recurso adquirido pela transação.

Maiores detalhes sobre esses e outros blocos do GPSS podem ser vistos em [BANK89] e [SCHR91].

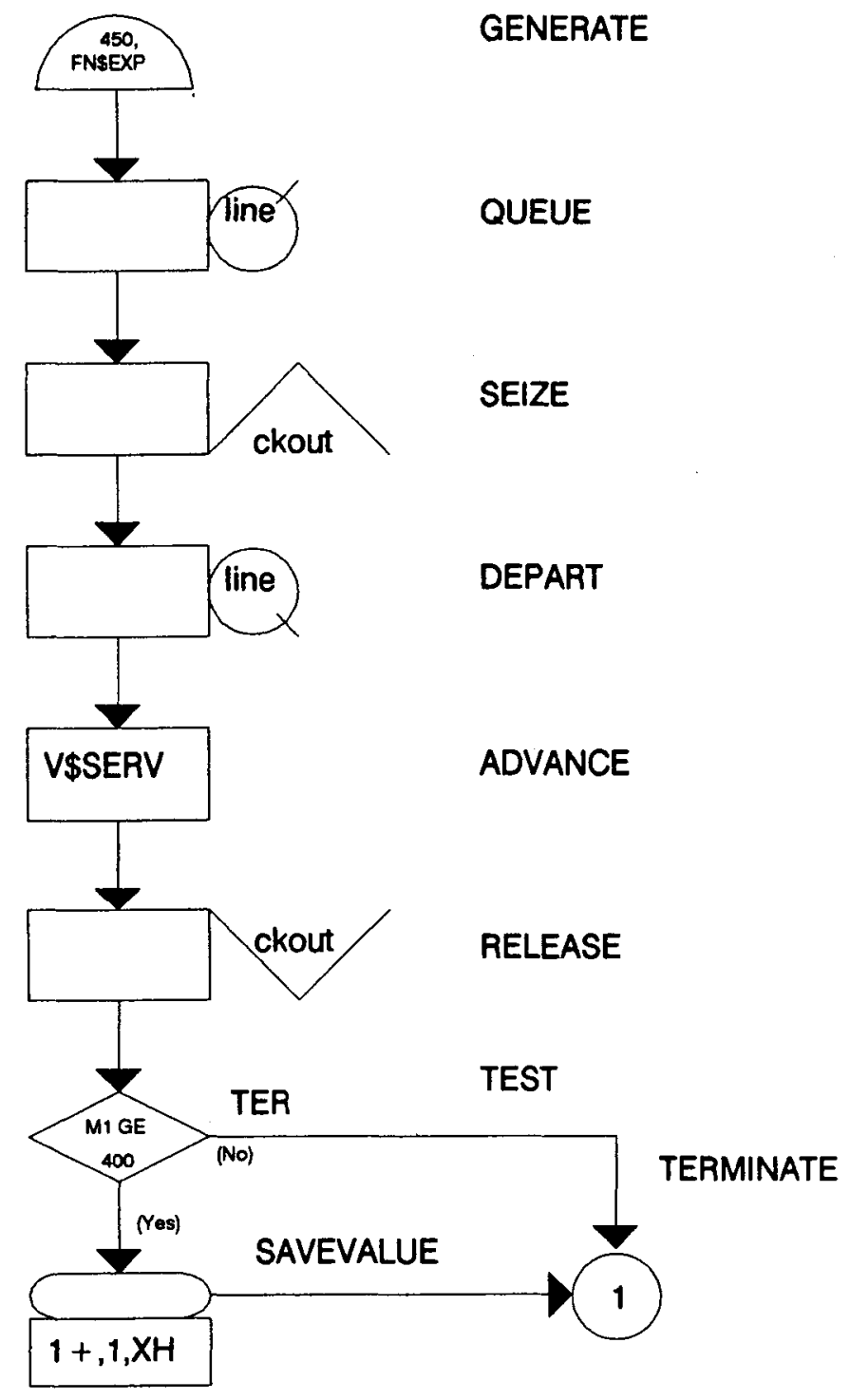

Figura 2.19 - Diagrama de Blocos do GPSS/H [SCHR91] 
Comparados com Fortran e Simscript, os modelos em GPSS são menores e mais legíveis. Em compensação, GPSS é menos flexível e poderosa do que Fortran e Simscript, mas apesar disto tem sido usada com sucesso em um grande número de projetos de simulação.

A escolha de qual linguagem de simulaçāo utilizar depende de uma série de fatores, como por exemplo:

- Portabilidade da linguagem;

- Custo de instalação e manutenção;

- Qualidade da documentação da linguagem; e

- Facilidade de aprendizagem.

Os fatores listados acima não influenciam somente a decisão de escolha entre as três linguagens vistas anteriormente, mas juntamente com outros fatores, podem determinar qual ou quais linguagens de simulação se deve adquirir e qual utilizar para um determinado modelo. Tabelas comparativas de algumas linguagens de simulação podem ser encontradas em [BANK84] e [LAW82], e em [SWAI91] uma tabela comparativa de muitas das linguagens de simulação existentes é apresentada.

\section{6 - Outras Técnicas de Execução de Modelos}

No desenvolvimento de sistemas através de técnicas convencionais, a primeira versão executável corresponde à própria implementação do sistema. Portanto, a existência de linguagens ou ferramentas que propiciem a execuçāo de modelos de um sistema, para que dessa forma o comportamento do mesmo possa ser simulado, permite que erros sejam detectados em fases iniciais do projeto e que a solução dos problemas não seja mais adiada para os estágios finais do desenvolvimento. São brevemente descritos a seguir modelos executáveis para Máquinas de Estados Finitos, Redes de Petri e PAISLey, a qual é uma linguagem para execução de modelos.

Um modelo executável para máquinas de estados finitos pode ser encontrado em [WANG88]. Apesar de ser baseado em máquinas de estados finitos, que são seqüenciais por natureza, o modelo apresentado por WANG é concorrente. O sistema é dividido em subsistemas ou visões, onde cada visão é na verdade um sistema completo. O sistema 
interage com o ambiente através da troca de sinais. Quando um sinal é recebido, todas as visões (subsistemas) para as quais o sinal é relevante executam suas açōes em paralelo.

Wang, em [WANG88], propōe uma linguagem de especificação de propósito geral, denominada SXL, a qual é executável. O usuário pode simular o sistema acionando transições interativamente, se a transição não for possível, o usuário recebe uma mensagem de erro. A interação do usuário com um sistema descrito em SXL é textual. Um exemplo de um "Chaveador de Telefone" com duas visōes é visto em [WANG88].

Em [JENS87] é encontrado um estudo sobre ferramentas para construção, modificação e análise de Redes de Petri. Segundo Jensen, o usuário necessita de várias ferramentas para trabalhar eficientemente com aplicações práticas de Redes de Petri, entre as quais citam-se: editores gráficos, editores textuais e recursos para análise das Redes de Petri.

Os recursos para análise das Redes de Petri citados acima consistem na aplicação de diferentes técnicas de análise para se obter informaçōes sobre propriedades de Redes de Petri. Simulação é uma das técnicas importantes pois permite a detecção de erros em fases iniciais do desenvolvimento de sistemas. A simulação pode ser interativa (usuário seleciona transições interativamente) ou automática (transições são selecionadas automaticamente por meio de um gerador de números aleatórios). Nos dois casos, estatísticas podem ser fornecidas e as marcações das Redes de Petri podem ser vistas textual ou graficamente.

PAISLey é uma linguagem para descrição de sistemas digitais que possui características como: paralelismo síncrono e assíncrono livre de problemas de exclusão mútua; especificaçōes podem ser exècutadas, mesmo que incompletas e inconsistências são detectadas por checagem automática [ZAVE86]. Essas características, entre outras, fazem de PAISLey uma linguagem de especificação bastante poderosa para $o$ desenvolvimento de Sistemas Reativos.

PAISLey é uma linguagem textual, ao contrário de Redes de Petri e Máquinas de Estados Finitos, mas apesar disso apresenta um alto grau de simplicidade. A execução de uma descrição em PAISLey corresponde a simular (interativamente) o comportamento do sistema descrito. 


\section{7 - Avaliação das Referências Revisadas}

Foi apresentada neste capítulo uma breve introdução à sintaxe e semântica de statecharts, seguida da descrição de alguns ambientes para desenvolvimento de software baseados nessa técnica. Será feita agora uma análise comparativa dos ambientes StatSim, Statemate e Argonaute. Esta analise tem por objetivo identificar as ferramentas que podem ser inseridas em um ambiente que não as possua, ou mesmo identificar ferramentas que não estão incluídas em nenhum dos ambientes.

TABELA 2.1 - Comparação entre os Ambientes Statemate, Statsim e Argonaute

\begin{tabular}{|c|c|c|c|}
\hline Características & Statemate & Statsim & Argonaute \\
\hline Editor Gráfico & $x$ & $x$ & $\mathrm{x}$ \\
\hline Editor Textual & $\mathrm{x}$ & $x$ & $\mathrm{x}$ \\
\hline$\rightarrow$ Especificação Comportamental & $\mathrm{x}$ & $\mathrm{x}$ & $\mathrm{x}$ \\
\hline$\rightarrow$ Especificação Funcional & $\mathrm{x}$ & $\mathrm{x}$ & -- \\
\hline$\longrightarrow$ Especificação Estrutural & $\mathrm{x}$ & -- & -- \\
\hline Verificação Sintática & $\mathbf{x}$ & $x$ & $\mathrm{x}$ \\
\hline Simulação Interativa & $x$ & $x$ & $\mathrm{x}$ \\
\hline Simulação Não-Interativa & $\mathbf{x}$ & $x$ & -- \\
\hline Simulação Programada & $x$ & - & -- \\
\hline Geração de Relatórios & $\mathbf{x}$ & -- & -- \\
\hline Detecção de Deadlock & $\mathrm{x}$ & $\mathrm{x}$ & $\mathrm{x}$ \\
\hline Deteç̧ão de Não-Determinismo & $x$ & $x$ & $\mathrm{x}$ \\
\hline Teste Exaustivo & $\mathrm{X}$ & $x$ & -- \\
\hline Teste de Alcançabilidade & $\mathbf{x}$ & $x$ & -- \\
\hline Teste de Vivacidade & $\mathrm{x}$ & $\mathrm{x}$ & -- \\
\hline Teste de uso de Transições & $\mathbf{x}$ & $x$ & .- \\
\hline Geração de Código (Protótipo) & $\mathbf{x}$ & -- & -- \\
\hline Redução da Especificação & -- & -- & $\mathbf{x}$ \\
\hline
\end{tabular}

Em relação à edição de statecharts, os três ambientes possuem editores gráficos e textuais. Nos ambientes StatSim e Statemate a checagem sintática é feita a cada novo elemento inserido na especificação, enquanto que em Argonaute um diagnóstico só é apresentado quando a descrição do autômato está terminada.

Ferramentas para verificação da especificação são mais completas em Statemate, sendo que Argonaute fornece poucos recursos para testes da especificação. Testes para 
detecção de deadlock e não determinismo estão presente nos três ambientes; Statemate e StatSim também fornecem meios para se fazer testes de alcançabilidade, vivacidade e uso de transiçōes. Testes exaustivos podem ser efetuados em Statemate e em StatSim, porém deve-se ressaltar que estes são aplicados somente a pequenos modelos ou a partes isoladas de modelos maiores.

Oúnico ambiente que permite ao desenvolvedor a geração de relatórios que apóie o ciclo de desenvolvimento de sistemas é Statemate, que também possibilita a especificação dos aspectos funcionais e estruturais da especificação. A especificação funcional também é encontrada no ambiente StatSim [TUTU92]. Argonaute não fornece meios para a especificação funcional e nem para a estrutural.

A simulação interativa, na qual o usuário interage diretamente com o sistema, ativando eventos e alterando condições, entre outros recursos, está disponível em todos os ambientes aqui descritos. A simulação não interativa, onde o usuário determina uma seqüência de eventos, alterações de variáveis e condições, que são executadas automaticamente, bem como a execução programada, onde eventos e condições são geradas aleatoriamente, de acordo com distribuições probabilísticas especificadas e onde resultados estatísticos são colhidos, estão disponíveis nos ambientes Statemate e StatSim.

Statemate possui um pacote para geração de código, o qual traduz o diagrama de atividades e os statecharts em código fonte de linguagens de alto nível, tal como ADA. Deve-se notar entretanto, que o código gerado não é um produto final, mas sim um protótipo, cujo objetivo maior é a validação do sistema. Nem StatSim e nem Argonaute possuem ferramentas para geração de código.

O sistema especificado pelo usuário (desenvolvedor) pode ser demasiadamente grande, tornando-se necessária a redução do mesmo, de forma a facilitar a verificação e validação do sistema. Argonaute é o único ambiente que fornece uma ferramenta para redução da especificação. Apesar de StatSim e Statemate não possuírem tal ferramenta, estes são bem mais poderosos, em relação a testes, do que Argonaute, o que de uma certa forma compensa a falta de uma ferramenta para redução.

A análise geral dos ambientes comparados mostra Statemate como o mais completo, mesmo porque este é o único disponível comercialmente, sendo que os outros dois ambientes são projetos acadêmicos. Com exceção da ferramenta de redução, Statemate possui todas as características dos outros dois ambientes. As principais vantagens de Statemate, em relação a StatSim e Argonaute, consistem nos pacotes para 
especificação funcional e estrutural, nos meios para simulação não interativa e programada e na geração de código e relatórios de apoio.

\section{8 - Considerações Finais}

Neste capítulo foi feita uma introdução a statecharts, que são uma técnica para especificação de sistemas reativos complexos. A Linguagem de Controle de Execução (LCE) proposta neste trabalho é executada com base na semântica formal de statecharts.

Como a LCE deve ser integrada ao ambiente StatSim, foram apresentadas a descrição deste e de mais dois ambientes para desenvolvimento de sistemas reativos baseados em statecharts: Statemate e Argonaute, comparando-os entre si, conforme é exibido na Tabela 2.1 .

O estudo de linguagens baseadas em especificação de estados e de linguagens de simulação enriqueceram a proposta da LCE, pois serão extraídas dessas linguagens características adequadas aos requisitos da linguagem aqui especificada.

A execução de modelos não é uma técnica recente, mas é até certo ponto inexplorada. Alguns trabalhos sobre execução de modelos têm sido elaborados ([WANG88], [ZAVE86], [JENS87]). A execução de modelos é feita interativamente (na maioria das vezes), sem recursos para a execução programada. Isso ocorre em vários ambientes e linguagens, o que motivou a se inserir no ambiente StatSim uma linguagem dessa natureza.

Atualmente, o único ambiente baseado em Statecharts que possui execução interativa, não-interativa e programada dos modelos é Statemate, porém o acesso aos meios como estas linguagens foram desenvolvidas é restrito à i-Logix, Inc., pelos direitos autorais reservados. Tem-se por objetivo desenvolver linguagens que se assemelhem, em resultados fornecidos ao usuário, às encontradas em Statemate, além de inserir recursos adicionais.

Com o estudo dos tópicos presentes neste capítulo, pode-se então partir para a definição da Linguagem de Controle de Execução, que será discutida no capítulo seguinte. 


\section{Capítulo 3}

\section{Uma Linguagem de Controle de Execução para Statecharts}

\section{1 - Considerações Iniciais}

Os requisitos que a LCE deve satisfazer são definidos neste capítulo. Uma arquitetura para sistemas reativos é apresentada, descrevendo-se o papel desempenhado pela LCE nessa arquitetura. Apresenta-se em seguida a definição da sintaxe e da semântica da LCE.

A sintaxe da LCE é descrita informalmente, mas a descrição formal da linguagem em BNF [FISC88] encontra-se no Apêndice A.

A semântica da LCE é baseada em uma semântica operacional similar à de Esterel, vista em [BERR88] e [BOUS91]. A importância de se definir formalmente, tanto a sintaxe quanto a semântica, é devido ao fato de que a utilização de técnicas formais elimina, em grande parte, os problemas de ambigüidade, incompleteza e inconsistência da especificação [WING90].

O formato da semântica e o conteúdo das memórias que esta manipula são descritos neste capítulo, seguido pela definição semântica de todos os comandos e funções da LCE. 


\section{2 - Requisitos da Linguagem de Controle de Execução (LCE)}

No capítulo anterior foi feita uma breve descrição da linguagem de simulação GPSS/H, a qual é bastante adequada para a modelagem de sistemas de filas. Alguns dos requisitos da Linguagem de Controle de Execuçāo, aqui estabelecidos, foram extraídos de características do GPSS/H. Note-se que enquanto o GPSS/H é uma linguagem que modela o sistema, isto não ocorre na LCE, pois a modelagem é feita através dos Statecharts, e a linguagem serve para executar o modelo e obter resultados do mesmo.

Outro ponto a ser considerado é que nem todos os requisitos foram extraídos do GPSS/H, pois se isto tivesse ocorrido ter-se-ia ficado restrito à modelagem de certos tipos de sistemas, e sabendo que Statecharts podem modelar sistemas reativos complexos para as mais variadas aplicações, isto restringiria o poder do ambiente StatSim. Dessa forma, outros requisitos foram inseridos baseados em outras linguagens, em outros ambientes e em necessidades que foram surgindo no decorrer do trabalho.

A LCE controla a execução de modelos especificados através de statecharts pelo ambiente StatSim. A função que a LCE desempenha no desenvolvimento de sistemas reativos é aqui estabelecida baseada em uma arquitetura que permite a visualização do processo controlado e o ambiente no qual o mesmo está inserido e o interfaceamento deste com o sistema controlador [CANG92a].

\subsection{1 - Requisitos Estatísticos da Linguagem}

Os requisitos estatísticos da LCE foram extraídos do GPSS/H, que é especializado na modelagem de sistemas de filas. Portanto fez-se uso de um sistema de filas para se obter esses requisitos.

Para modelar uma fila, um dos primeiros critérios que pode ser considerado é a chegada de clientes na fila. No GPSS/H essa chegada é produzida pelo bloco "GENERATE", sendo que distribuições probabilísticas são associadas a este bloco para modelar a chegada de clientes. Num modelo de fila em Statecharts, a chegada de um cliente poderia corresponder à ocorrência de um determinado evento, ou seja, quando o evento 
ocorre significa que um novo cliente entra no sistema. Portanto, é conveniente que a Linguagem de Controle de Execução possua um gerador de eventos e que funçōes de distribuiçōes probabilísticas, tais como distribuiçôes Exponencial, Normal e Uniforme, sejam acopladas a esse gerador. $O$ gerador de eventos não é útil somente para modelar chegadas em uma fila, ele pode ser usado para outros tipos de sistemas, onde a probabilidade de ocorrência de um determinado evento seja conhecida.

Em um sistema de fila, o tempo de atendimento corresponde ao tempo que um cliente fica de posse de um servidor. Em statecharts o tempo de atendimento poderia corresponder ao número de passos que um estado que denote a ocupação do servidor permanece ativo, sem que nenhuma transição que abandone o estado seja executada, mesmo que essa retorne ao próprio estado. Nesse caso, as distribuições probabilísticas também podem ser usadas para determinar o número de passos em que o estado fica ativo, ou seja, o número de passos em que uma transição que abandone o estado é executada.

Um fator muito importante em linguagens de simulação e linguagens de execução de modelos é o controle dos passos de simulação, o qual deve ser feito automaticamente pela linguagem. No caso da Linguagem de Controle de Execução os passos de simulação correspondem, de acordo com o sistema, a unidades de tempo do relógio de uma linguagem de simulação, como o GPSS/H. O controle desses passos indica em que passo um determinado evento é gerado, ou uma variável tem seu valor alterado, etc., além de possibilitar a coleta de dados estatísticos, tal como o valor médio de variáveis.

Assim como no GPSS/H, onde os blocos "SAVAIL" e "SUNAVAIL", fazem com que um ou mais servidores tornem-se disponíveis ou não, na Linguagem de Controle de Execução devem existir funções que façam com que um evento se torne disponível ou não. Uma utilidade dessas funçōes ocorre quando um modelo atinge uma configuração específica e, nesse caso, certos eventos não devem mais ocorrer, sendo desabilitados (tornados indisponíveis) até que sejam novamente tornados disponíveis em outro passo de simulação.

O fato do usuário poder obter o valor de uma variável, ou mesmo a sua média, é bastante importante. Portanto, funções para exibir o valor instantâneo ou o valor médio de uma variável devem ser especificadas como: "SHOW_VAR" ou "SHOW_CONTROL_VAR".

Para finalizar os requisitos estatísticos da Linguagem de Controle de Execução deve-se ter a geração de um relatório estatístico de saída. Tal relatório deve fornecer ao usuário uma série de resultados coletados durante os passos de simulação e que são de 
grande importância para a validação de certos modelos. Uma descrição mais detalhada deste relatório será dada posteriormente.

\subsection{3 - Requisitos "Computacionais" e Aspectos Gerais da LCE}

Existe a possibilidade de que, atingindo um certo estado ou um certo valor de uma variável, ou mesmo um certo passo, a simulação pare e passe o controle do sistema ao usuário, o qual poderá acionar eventos e modificar variáveis e condiçōes e devolver o controle à "Execução Programada", quando desejado.

Para que se possa verificar se a execução do Statechart atingiu um certo estado, ou se uma variável atingiu um certo valor, faz- se necessária a inclusão de uma sentença condicional na linguagem. Tal sentença deve verificar se a condição é verdadeira e se for, executar o comando.

O controle dos passos de simulação pode ser estendido para que o usuário especifique determinadas ações em determinados passos, ou seja, se no passo 100 o usuário deseja que o controle da simulação passe a ser interativo, ele pode especificar um comando tal como: "AT STEP 100 INTERACTIVE". Outra possibilidade é a de que o usuário, por exemplo, deseje ver o valor das variáveis a cada 30 passos, uma sentença do tipo "FOR STEP 1 EACH 30 STEPS DO SHOW_VAR" deverá ser especificada, juntamente com a sentença anterior.

Um dos aspectos gerais é que o usuário tenha a possibilidade de escolher entre a execução animada (gráfica) ou a textual. No primeiro caso o usuário poderá ver o comportamento do modelo diretamente na tela; e no segundo caso, um arquivo de saída dos passos de simulação é gerado. Detalhes sobre esse arquivo de saída serão dados posteriormente. $\mathrm{O}$ usuário poderá especificar o tipo de execução através de comandos como "VISUAL" ou "TEXT".

A depuração de modelos é uma tarefa de grande importância, pois muitos erros na especificação podem ser encontrados através dessa técnica. Portanto, é importante adicionar à Linguagem de Controle de Execução características que facilitem a depuração de modelos. Uma dessas características pode ser a simulação passo a passo, ou seja, o usuário especifica se ele deseja a simulação passo a passo, através de um comando como "CONTROLLED". Caso o comando seja omitido, então a simulação é feita 
continuamente, por default. Esse mecanismo de execução passo a passo só estará disponível para a simulação gráfica, pois na textual, o usuário pode analisar toda a execução, passo a passo, através do arquivo gerado.

Várias formas encontradas em linguagens de programação e linguagens baseadas na especificação de estados devem ser introduzidas na LCE com o objetivo principal de lhe dar uma maior flexibilidade. Algumas dessas formas são as operaçōes com expressões numéricas e os comandos de repetição.

\subsection{3 - Função da LCE numa Arquitetura para Sistemas Reativos}

Statecharts são utilizadas para modelar sistemas reativos e StatSim é um ambiente para desenvolvimento de sistemas reativos baseado em statecharts. Diante disso, o MEP (Módulo de Execução Programada) deve se enquadrar neste contexto e desempenhar uma função no mesmo. Este contexto é aqui representado por uma Arquitetura para Sistemas Reativos.

A Figura 3.1 apresenta uma Arquitetura para Sistemas reativos, podendo-se ver o Ambiente e o Processo Controlado, o qual possui sensores (S) que emitem sinais e atuadores (A) que recebem sinais e executam determinadas tarefas [CANG92a]. As atividades servem como uma interface entre o Processo Controlado e o Processo Controlador, pois de acordo com os sinais recebidos dos sensores, as Atividades colocam eventos na fila de eventos. Estes eventos são captados pelo Processo Controlador, o qual É um statechart, que a cada passo de tempo processa os eventos da fila de eventos. A ocorrência de eventos faz com que transiçōes sejam disparadas no statechart, e este atinja uma nova configuração de estados ativos. Cada estado ativo faz com que as Atividades relacionadas sejam ativadas e estas Atividades enviam sinais para os Atuadores do Processo Controlado. A tarefa executada pelos sensores e atividades, ou seja, os sinais proveniente dos sensores recebidos pelas atividades, faz com que os eventos sejam colocados na fila de eventos e processados pelo Processo Controlador.

Com a utilização da LCE, o usuário pode abstrair-se do Processo Controlado, indicando distribuições probabilísticas para a ocorrência dos eventos. Há outras alternativas na LCE para a especificaçāo da ocorrência de eventos, tais como percentagens fixas e entrada direta através de um arquivo. 


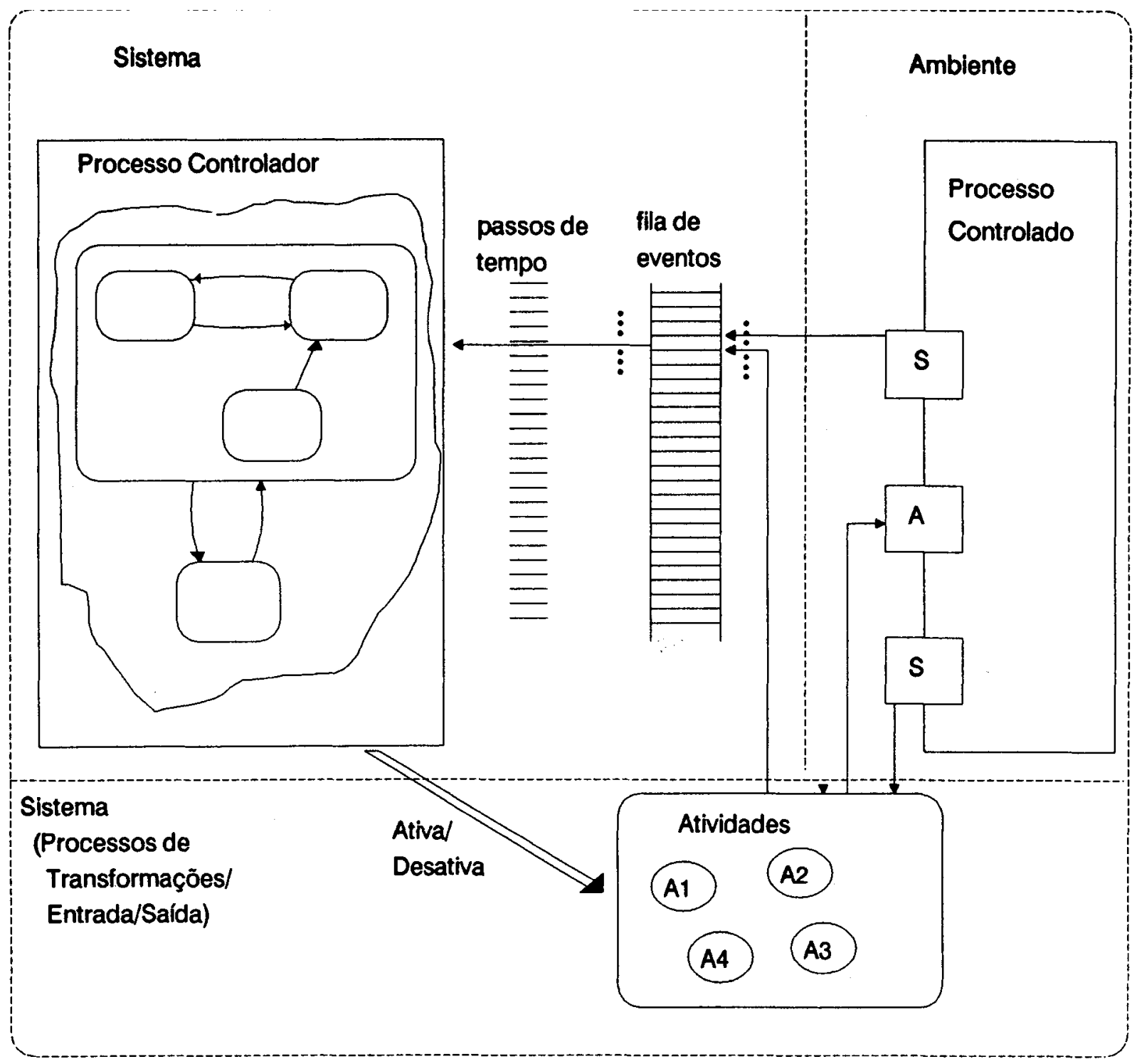

Figura 3.1 - Uma Arquitetura para Sistemas Reativos

Como a Execução Programada apenas simula o Processo Controlado e as Atividades, esses são representados na LCE pela geração de eventos e pela configuração de estados ativos, respectivamente. Em relação ao tempo que cada atividade demora para ser executada, na LCE este tempo é representado pelo número de passos que o estado permanece ativo. Caso um gerador de código estivesse disponível e as atividades pudessem realmente ser executadas, ter-se-ia dessa forma um protótipo bem mais próximo do sistema final. 


\section{3 - Sintaxe da LCE}

A Linguagem de Controle de Execução (LCE) foi dividida, principalmente por motivos estruturais, em três partes. A primeira parte diz respeito aos parâmetros globais da execução, tal como o número de passos e a configuração inicial do modelo; a segunda parte trata da declaração das variáveis de controle e das declarações para geração de eventos; e por fim, a terceira parte executa o controle da simulação, através dos laços, sentenças condicionais e controle dos passos, entre outros comandos. Cada uma das três partes citadas acima será descrita a seguir.

\subsection{1 - Parâmetros Globais da LCE}

Os parâmetros globais da LCE são opcionais, ou seja, não é estritamente necessário que os mesmos sejam especificados; dessa forma, aqueles que forem omitidos serāo inicializados com os valores defaults pré-determinados.

Os parâmetros são os seguintes:

NUMBER_OF_STEPS $=$ valor

Especifica o número de passos que serão executados, sendo que o valor deve ser um número natural. O valor default deste parâmetro é 100, ou seja, se o parâmetro for omitido o modelo será executado por cem passos.

\section{SIMULATION_RESULT $\boldsymbol{=}$ modo}

Este parâmetro especifica o modo de execução, o qual pode ser:

- VISUAL - a execução será apenas visual (animada), não será gerado o relatório de passos.

- TEXT - a execução será apenas textual, ou seja, não haverá animação e será gerado o relatório de passos da simulação.

- COMPLETE - corresponde ao valor default do parâmetro, e indica que a execução será tanto visual, através da animação na tela, quanto textual, através da geração do relatório de passos. 


\section{SIMULATION_TYPE $=$ tipo}

A simulação animada pode ser executada de duas formas, a primeira corresponde ao tipo "CONTROLLED", em que a cada passo executado o ambiente fica esperando que o usuário forneça uma confirmação para prosseguir, e a segunda forma corresponde ao tipo "FREE", no qual os passos são executados continuamente, sem a intervenção (a cada passo) do usuário. Caso o parâmetro seja omitido, o tipo default será "FREE".

\section{INITIAL_CONFIGURATION = configuração}

Este parâmetro indica a configuração de estados ativos na qual a execução será iniciada. O valor default é "DEFAULT", no qual o modelo a ser simulado será inicializado pelos estados defaults do statechart. Uma configuração específica deve ser constituída de uma lista dos nomes dos estados atômicos, os quais serão ligados juntamente com os seus ancestrais.

\section{STATECHART $=$ modelo}

Este parâmetro indica qual statechart será executado, sendo o valor default o statechart que já estiver carregado na memória.

\subsection{2 - Declaraçōes da LCE}

As declarações da LCE podem ser de dois tipos: as primeiras são as declaraçōes das variáveis de controle, as quais são variáveis inteiras e possuem o símbolo "\%" precedendo seus nomes identificadores. As variáveis são declaradas da seguinte forma:

CONTROL_VAR \%nome1,$\%$ nome $2, \ldots, \%$ nomeN

As declarações relativas a eventos não significam que os mesmos estão sendo especificados, ou seja, o que essas declarações fazem é determinar a forma como os eventos serão gerados nos passos de simulação, mas não especificam novos eventos. Todos os* eventos citados nas declarações devem corresponder a eventos existentes no statechart a ser executado.

A forma como os eventos podem ser gerados são as seguintes: 


\section{READ_FILE(arquivo)}

Dado 0 arquivo, cada linha desse representa os eventos que serão disparados em um passo da simulação. Portanto esse arquivo deve obedecer a um determinado formato, como por exemplo:
$a, b, c$
$\mathrm{c}, \mathrm{a}$
d,b
$b, g$

O arquivo acima indica que no primeiro passo serão disparados os eventos "a", "b" e "c", no segundo passo os eventos "c" e "a" serão disparados, e assim sucessivamente, até que se chegue ao final do arquivo.

\section{EVENTS e1,...,en distribuiçāo}

Esta declaração especifica que os eventos e1,...,en serão gerados seguindo uma distribuição probabilística, a qual pode ser exponencial, normal ou uniforme. Um exemplo destas distribuições pode ser:

EVENTS e1 EXPO(1.4)

EVENTS e2, e3 NORMAL(1.2,0.5)

EVENTS \&4 UNIF $(3,0.4)$

\section{EVENTS e1,...,en X\%}

Através desta declaração tem-se que os eventos especificados possuem uma probabilidade $\mathrm{X}$ de ocorrer. Seja o exemplo:

EVENTS e1,e2 $30 \%$

EVENTS $\mathrm{e} 3 \quad 80 \%$

No exemplo tem-se que e1 e e 2 possuem $30 \%$ de chance de ocorrerem em um passo e que e3 possui $80 \%$ de chance de ser disparado em um passo.

\section{EVENTS e1,...,en FROM STEP s1 TO s2 EACH s3 STEPS}

Esta declaração indica que os eventos $\mathrm{e} 1, . .$, ,en serão disparados a partir do passo s1 até o passo s2 a cada s3 passos. Se a parte "TO s2" for omitida, o fim irá corresponder ao número de passos, e se a parte "FROM STEP s1" for omitida, o passo inicial será o passo 1 (um). 


\subsection{3 - Controle de Simulação da LCE}

A parte referente ao controle de simulação da LCE tem inicio com a palavra reservada "SIMULATION" e termina com "END_SIMULATION". Esta parte da linguagem especifica as atividades que serão executadas nos passos. As sentenças que controlam a simulação e auxiliam nas tarefas de verificação e validação do modelo são vistas a seguir.

\section{AT STEP s1 \\ BEGIN \\ comandos}

END

Esta sentença determina que no passo s1 os comandos delimitados por BEGIN...END sejam executados. Se existir apenas um comando a ser executado, então BEGIN...END pode ser omitido.

\section{ALL STEPS \\ BEGIN \\ comandos}

END

Esta sentença determina que os comandos especificados serão executados em todos os passos da simulação. Assim como na sentença anterior, se o comando for único, BEGIN...END pode ser omitido. Na LCE, em todas as sentenças que possuírem os delimitadores BEGIN...END, o mesmo poderá ser omitido, desde que o comando seja único.

FOR STEP s1 TO s2 EACH s3 STEPS DO

BEGIN

comandos

END 
Iniciando do passo $\mathrm{s} 1$ até o passo s2, os comandos delimitados por BEGIN e END serão executados a cada s3 passos. Caso a parte "TO s2" da sentença seja omitida, então o limite será estabelecido pelo número de passos a ser simulado.

As sentenças especificadas acima determinam o controle dos passos. Dessa forma, as mesmas não podem ser aninhadas, ou seja, uma composição de sentenças, como no exemplo mostrado abaixo, não é permitida.

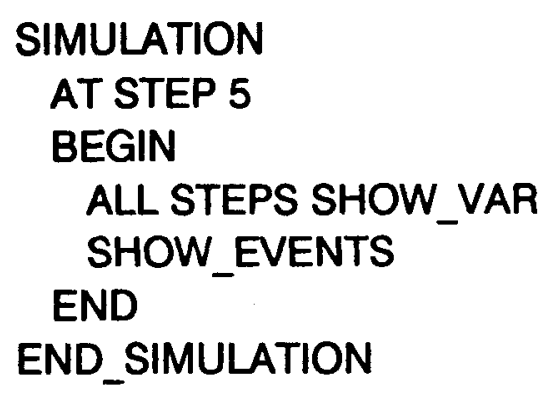

Porém, se as mesmas são colocadas seqüencialmente, a construção torna-se correta, como abaixo.

\section{SIMULATION \\ AT STEP 5 SHOW EVENTS \\ ALL STEPS SHOW_VAR \\ END_SIMULATION}

Os comandos da LCE que podem ser aninhados são especificados a seguir.

\section{IF condição THEN \\ BEGIN \\ comandos \\ END \\ ELSE BEGIN \\ comandos \\ END}

Se na sentença acima a condição for verdadeira, então os comandos da parte "THEN" serão executados, caso contrário, os comandos da parte "ELSE" o serão. Se não existirem comandos a serem executados na parte "ELSE", então o mesmo pode ser omitido. 
FOR \%vc1 $=$ expressão1 TO expressão2 DO

\section{BEGIN}

comandos

END

A sentença determina que os comandos internos ao laço sejam executados n vezes, onde $\mathbf{n}=$ expressão2 - expressão1. Somente variáveis de controle podem ser especificadas como contadores do laço, no caso \%vc1.

\section{WHILE condição DO}

\section{BEGIN}

comandos

END

Esta sentença especifica que os comandos internos a ela serão executados enquanto a condição especificada possuir o valor "true".

$\mathrm{v}:=$ expressão2

\%vc : = expressão1

Esta sentença determina que uma variável ou uma variável de controle receberão o valor determinado pela expressão.

A sintaxe das funções disponíveis ao usuário, bem como uma breve descrição das mesmas é dada a seguir.

\section{SHOW_VAR}

Função para exibir o valor instantâneo e médio das variáveis do statechart.

\section{SHOW_CONTROL_VAR}

Função para exibir o valor (médio e instantâneo) das variáveis de controle declaradas pelo usuário.

\section{SHOW_EVENTS}

Função para exibir os eventos disparados no passo corrente de simulação.

\section{INTERACTIVE}


Função que faz com que a execução volte a ser interativa.

\section{EVENTS(e1,...,en,parâmetro)}

Função que determina que os eventos pertencentes à lista de eventos especificada sejam disparados de acordo com o valor de "parâmetro", o qual pode ser:

- omitido, então os eventos serão disparados no passo corrente;

- um número natural n, então os eventos serâo disparados a n passos do passo corrente. Ex: EVENTS(a,b,5); e

- uma distribuição probabilística, então os eventos serão disparados a $n$ passos do passo corrente, sendo que n será determinado para cada evento da lista, de acordo com a distribuicao especificada. Ex: EVENTS(a,b,EXPO(l)).

AVAIL(e1,...,en)

Determina que os eventos passados como parâmetro tornem-se disponíveis para serem disparados.

UNAVAIL(e1,...,en)

Determina que os eventos passados como parâmetro fiquem indisponíveis para serem disparados.

\section{MESSAGE(mensagem,\%vc)}

Esta função imprime a mensagem, passada como parâmetro, no relatório de passos, em todo passo que a mesma for executada. A mensagem pode ser composta de cadeias de caracteres e valores das variáveis de controle.

SET_CONFIGURATION $=$ DEFAULT ou

SET_CONFIGURATION $=$ configuração

Reinicializa o statechart por default, ou de acordo com a configuração especificada.

Nos comandos acima foram citadas condições e expressões. As primeiras são compostas de operadores relacionais, variáveis, variáveis de controle, números, além das funções:

\section{ACTIVE(estado)}


Tabela 3.1 - Comandos, Paråmetros e Funções da LCE

\begin{tabular}{|c|c|}
\hline Comando & ção \\
\hline \multicolumn{2}{|c|}{ Paråmetros Globais } \\
\hline $\begin{array}{l}\text { NUMBER_OF_STEPS } \\
\text { SIMULATION_RESULT } \\
\text { SIMULATION_TYPE } \\
\text { STATECHART } \\
\text { INITIAL_CONFIGURATION }\end{array}$ & $\begin{array}{l}\text { Determina o número de passos } \\
\text { Determina o resultado da simulação } \\
\text { Determina o tipo da simulaçăo } \\
\text { Determina o modelo a ser simulado } \\
\text { Determina a configuraçăo inicial do modelo }\end{array}$ \\
\hline \multicolumn{2}{|c|}{ Declaração de Variáveis de Controle e Eventos } \\
\hline $\begin{array}{l}\text { CONTROL_VAR } \\
\text { READ_FILE } \\
\text { EVENTS e } 1, . ., \text { en distribuição } \\
\text { EVENTS e1,...,en X\% } \\
\text { EVENTS e } 1, \ldots, \text { en FROM }\end{array}$ & $\begin{array}{l}\text { Declara varíaveis de controle } \\
\text { Coloca os eventos do arquivo na fila de eventos } \\
\text { Especifica uma dist. prob. para a geração de eventos } \\
\text { Especifica uma probabilidade de ocorrencia dos eventos } \\
\text { Especifica os passos de ocorrencia dos eventos }\end{array}$ \\
\hline \multicolumn{2}{|c|}{ Comandos e Funções } \\
\hline AT STEP $s 1, \ldots, s n$ & Especifica os comandos a serem exec. nos passos s1,..,sn \\
\hline ALL STEPS & Especifica os comandos a serem exec. em todos os passos \\
\hline FOR STEP & Especifica os comandos a serem exec. nos passos espec. pelo FOR \\
\hline IF & Comando condicional \\
\hline FOR & Comando de repetiçăo \\
\hline WHILE & Comando de repetição \\
\hline SHOW VAR & Exibe as variáveis do statechart \\
\hline SHOW_CONTROL_VAR & Exibe as variáveis de controle \\
\hline SHOW_EVENTS & Exibe os eventos disparados no passo corrente \\
\hline INTERĀCTIVE & Retorna para a execução interativa \\
\hline EVENTS(paråmetro) & Dispara os eventos passados como paråmetro \\
\hline AVAIL & Habilita os eventos passados como paråmetros \\
\hline UNAVAIL & Desabilita os eventos passados como parámetros \\
\hline MESSAGE & Emite a mensagem especificada \\
\hline SET_CONFIGUIRATION & Reconfigura o statechart \\
\hline ACTIVE & Verififica se os estados especificados estão ativos \\
\hline CONFIGURATION & Verifica se a configuraçăo especificada está ativa \\
\hline
\end{tabular}


Retorna o valor "true" se o estado estiver ativo e "false" caso contrário.

\section{CONFIGURATION(configuração)}

Retorna "true" se a configuração no passo corrente for igual à especificada, e "false" caso contrário.

No caso das expressões, estas podem ser compostas de operadores $\left(+,-/,{ }^{*}\right)$, variáveis, variáveis de controle e números.

A Tabela 3.1 apresenta os comandos e funções da LCE, bem como uma descrição da função de cada comando.

\section{4 - Semântica da LCE}

\subsection{1 - Notação da Semântica}

A semântica da $L C E$ segue o formato abaixo, o qual indica que uma sentença, ou termina sua execução, ou deixa resíduos a serem executados. A sentença também pode alterar os conteúdos das memórias. Seja:

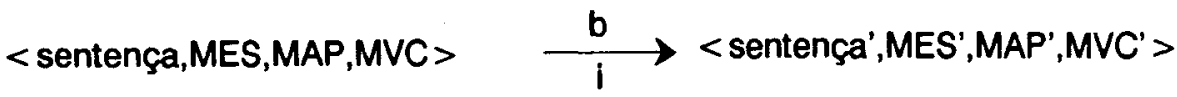

Onde:

- sentença e sentença' são comandos e ou funçōes da linguagem e seus resíduos, respectivamente;

- MES e MES' correspondem à Memória de Especificação do Statechart (antes e depois da sentença ser executada) e contém informaçōes sobre os estados, eventos e variáveis do statechart;

- MAP e MAP' correspondem à Memória de Atividades por Passo (antes e depois da sentença ser executada), contendo informaçōes sobre os eventos a serem ativados em cada passo e as variáveis a serem exibidas, entre outras; 
- MVC e MVC' correspondem à Memória das Variáveis de Controle (antes e depois da sentença ser executada), as quais podem ser externas, se forem definidas pelo usuário, ou internas, se corresponderem a variáveis para controle do número de passos, do passo atual, etc;

- bé um valor booleano que assume "true" se a sentença termina e "false" caso contrário; e

- i é um valor inteiro que indica o passo corrente da simulação.

\subsection{2 - Memória de Especificação do Statechart (MES)}

A MES é composta de informaçōes sobre três conjunto de dados:

- Estados: onde informações sobre a situação do mesmo (ligado ou desligado) são vistas pela decomposiçāo MES_EST_LIG; MES_EST_DEF fornece informaçōes sobre os estados defaults; e MES_MOD determina o statechart que está carregado na memória;

- Eventos: onde informações sobre a condição do evento (diponível ou não) são obtidas pela decomposição MES_EVE_DISP; e

- Variáveis: onde informações sobre seus valores são obtidas do item de dado MES_V.

Alguns parâmetros e funções da LCE que se relacionam diretamente com consultas e alteraçōes na MES são vistos a seguir.

INITIAL_CONFIGURATION $=$ Configuração

$\forall$ est $\in$ Configuração, MES_EST_LIG(est) $\leftarrow$ true

\section{INITIAL_CONFIGURATION $\boldsymbol{=}$ DEFAULT}

$\forall$ est $\mid($ MES_EST_DEF $($ est $)=$ true $) \Rightarrow$ MES_EST_LIG(est) $\leftarrow$ true

obs: os estados defaults devem ser ligados a partir da raiz, ou seja, do superestado mais externo. Um subestado default somente deve ser ligado se o seu ancestral imediato estiver ligado. 
SET_CONFIGURATION(configuração)

$\forall$ est $\in$ configuração, MES_EST_LIG(est) + true

ACTIVE(est) $\leftarrow$ MES_EST_LIG(est)

CONFIGURATION(configuração) $\leftarrow$ false se :

$\forall$ est $\in$ configuração, $\exists$ est $\mid$ MES_EST_LIG(est) $=$ false

CONFIGURATION (configuração) $\leftarrow$ true se :

$\forall$ est $\in$ configuração, MES_EST_LIG(est) = true.

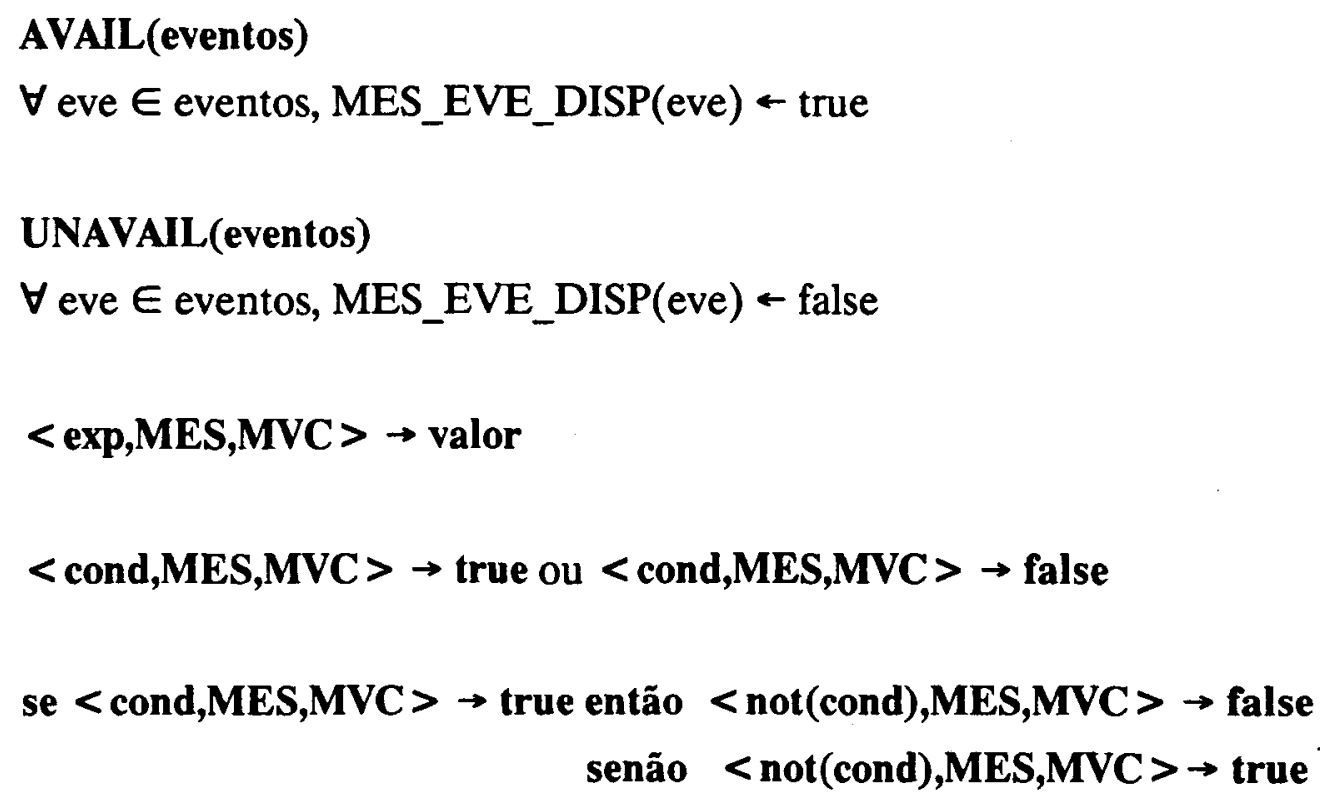

Onde:

- est representa um estado, e configuração representa um conjunto de estados atômicos do statechart. Esta configuração deve ser valida, ou seja, deve estar de acordo com a sintaxe e semântica definidas por Harel;

- exp é uma expressão que pode conter variáveis do statechart, variáveis de controle e números inteiros; $\mathrm{e}$

- eventos representa uma lista de eventos, onde cada elemento é denominado eve.

A cada passo, as novas configurações são obtidas, baseadas na semântica formal de statecharts, descrita por Harel em [HARE87]. Aqui se ficará restrito a especificar a 
nova configuração a cada passo por MES_EST_LIG(est) $\leftarrow$ true, $\forall$ est $E$ Nova_Configuração.

Onde Nova_Configuração é a configuração de estados ativos obtida pela execução das transições no passo corrente.

\subsection{3 - Memória de Atividades por Passo (MAP)}

A Memória de Atividades por Passo (MAP) é composta de variáveis para controle de algumas funções e controle dos eventos a serem disparados em cada passo.

As variáveis da MAP que controlam as funções são:

- MAP_SV

- MAP_SCV

- MAP_SE

- MAP_INT

Estas variáveis recebem o valor true se a função correspondente for ativada no passo, caso contrário recebem false por default.

A descrição do significado dessas e de outras variáveis da MAP , e também da MES e da MVC é encontrada na Tabela 3.2. A variável MAP_MES(i,mensagem) especifica que no passo i a mensagem será impressa no relatório de passos da simulaçāo.

O controle dos eventos a serem disparados em cada passo, os quais são determinados por alterações na memória, segue o seguinte formato:

\section{MAP_EVE[ $]_{1}^{\mathrm{j}, \mathrm{k}} \leftarrow_{\text {disp }} \mathbf{e}_{1}, \ldots, \mathbf{e}_{\mathrm{n}}$}

Onde especifica-se que partindo do passo i até o passo $\mathrm{j}$, a cada $\mathrm{k}$ passos, os eventos e1,...,en serão disparados de acordo com disp, que representa:

- uma distribuição probabilística exponencial, normal ou uniforme;

- uma probabilidade de ocorrência em cada passo especificado; e

- um arquivo de entrada especificando os eventos a serem disparados em cada passo. 
Tabela 3.2 - Conteúdo das Memórias do MEP (Módulo de Execução Programada)

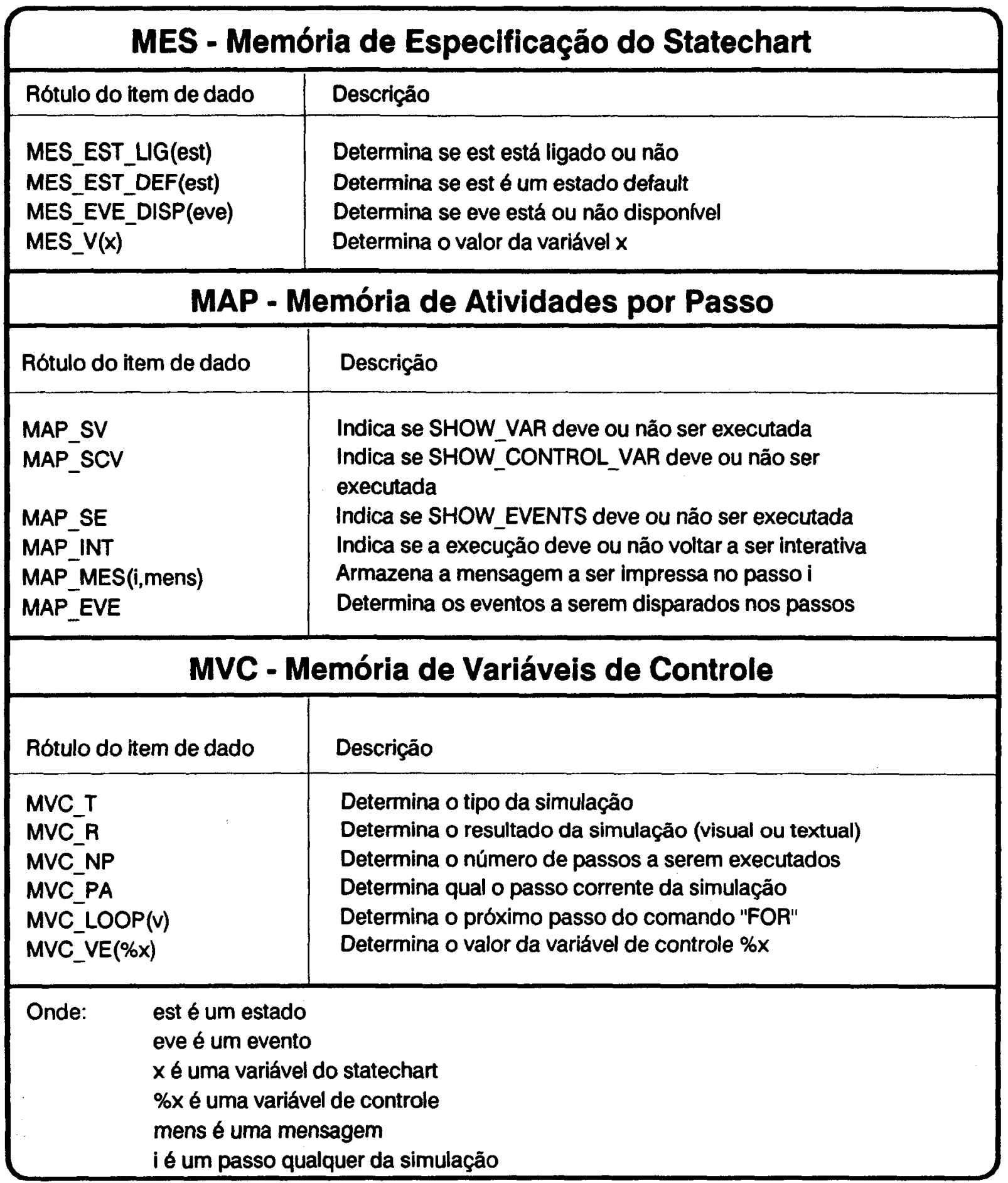


Caso disp seja omitido, os eventos e1,..,,en serão disparados em todos os passos especificados.

\subsection{4 - Memória das Variáveis de Controle (MVC)}

A Memória das Variáveis de Controle (MVC) pode ser dividida em dois grupos. O primeiro grupo corresponde às variáveis de controle internas, as quais controlam alguns parâmetros; o laço "FOR" para controle de passos; e os passos de simulação propriamente ditos. $O$ segundo grupo são as variáveis de controle externas, que correspondem as variáveis declaradas pelo usuário.

As variáveis de controle internas que correspondem aos parâmetros são: $M V C_{-} T$, que pode assumir os valores "FREE" ou "CONTROLLED", e MVC_R, que pode assumir os valores "VISUAL", "TEXT" ou "COMPLETE".

Os passos de simulação são controlados por: MVC_NP, que indica o número de passos que serão executados, e MVC_PA, que indica qual o passo corrente da simulação.

Cada laço, ou melhor, cada comando "FOR STEP s1 TO s2 EACH s3 STEPS DO" possui uma variável de controle associada (MVC_LOOP(vc)), a qual indica como os passos vão avançando até atingirem o passo final (s2).

As variáveis de controle externas correspondem àquelas declaradas pelo usuário, sendo que cada variável declarada é acrescentada à MVC_VE.

As alterações nos conteúdos das variáveis de controle internas e externas são feitas por simples atribuições como:

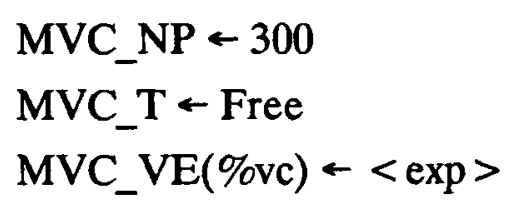


3.4.5 - Semântica dos Comandos e Funções da LCE

3.4.5.1 - Regras para Definição dos Parâmetros Globais da LCE 3.4.5.1.1 - NUMBER_OF_STEPS

$<$ Number_Of_Steps $=v$, MES,MAP,MVC $>\underset{0}{\stackrel{\text { true }}{\longrightarrow}}<<$ nothing,MES,MAP, MVC_NP $\leftarrow v>$

\subsubsection{2 - SIMULATION_RESULT}

$<$ Simulation_Result $=m$, MES,MAP,MVC $>\underset{0}{\stackrel{\text { true }}{0}}<<$ nothing,MES,MAP, MVC_R $\leftarrow \mathrm{m}>$ Onde $m=$ (Nisual ou Text ou Complete)

\subsubsection{3 - SIMULATION_TYPE}

$<$ Simulation_Type $=t$, MES,MAP,MVC $>\quad \stackrel{\text { true }}{0}<<$ nothing,MES,MAP, MVC_T $\leftarrow$ t $>$ Onde $\mathrm{t}=$ (Controlled ou Free)

\subsubsection{4 - STATECHART}

$<$ Statechart $=$ arq, MES,MAP,MVC $>\frac{\text { true }}{0} \rightarrow<$ nothing,MES_MOD $\leftarrow$ arq,MAP,MVC $>$ 
3.4.5.2 - Regras para Declaração de Eventos e Variáveis de Controle

\subsubsection{1 - CONTROL_VAR}

$<$ Control_Var \%v1,...,\%vn,MES,MAP,MVC $>\frac{\text { trug }}{0}<n t, M E S, M A P, M V C \_V E U \% v 1, \ldots, \% v n>$ Onde $\mathrm{nt}=$ nothing

\subsubsection{2 - EXPONENCIAL}

$<$ Events e1,...,en Expo(v) ,MES,MAP,MVC > $\underset{0}{\stackrel{\text { true }}{\rightarrow}}$

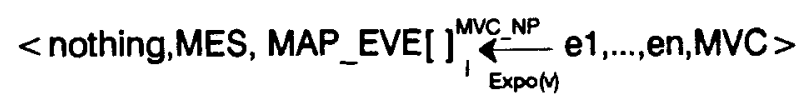

\subsubsection{3 - NORMAL}

$<$ Events e1,...,en Normal(v1,v2), MES,MAP,MVC> $\underset{0}{\stackrel{\text { true }}{\rightarrow}}$

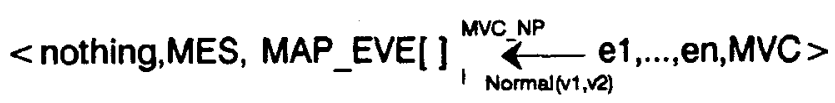

\subsubsection{4 - UNIFORME}

$$
\begin{aligned}
& <\text { Events e1,...,en Unif(V1,V2), MES,MAP,MVC > } \underset{0}{\stackrel{\text { true }}{\longrightarrow}}
\end{aligned}
$$

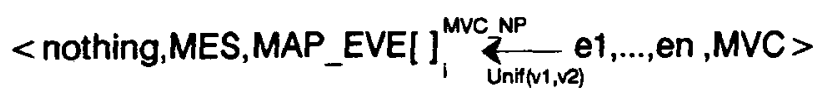




\subsubsection{5 - ARQUIVO DE ENTRADA}

$<$ Read_File arq,MES,MAP,MVC $>\underset{0}{\stackrel{\text { true }}{\rightarrow}}$

$<$ nothing,MES, MAP_EVE[ ] ${ }_{1}^{\text {MVC }} \stackrel{\text { NP }}{\leftarrow}$ arq ,MVC >

\subsubsection{6 - PERIÓDICO}

<Events e1,...,en From Stet s1 To s2 Each s3 Steps, MES,MAP,MVC> $\underset{0}{\stackrel{\text { true }}{\longrightarrow}}$

$<$ nothing,MES, MAP_EVE[ ] ${ }_{\mathrm{s} 1}^{s 2,83} \longleftarrow \mathrm{e} 1, \ldots, \mathrm{en}, \mathrm{MVC}>$

\subsubsection{7 - PROBABLILISTICO}

\footnotetext{
$<$ Events e1,...,en v1\%,MES,MAP,MVC> $\frac{\text { true }}{0}$

< nothing,MES, MAP_EVE[ ] ${ }_{1}^{M V C} \underset{V 1 \%}{\text { NP }}$ e1,...,en,MVC >
} 


\subsubsection{3 - Regras para Comandos e Funçōes da LCE}

\subsubsection{1 - AT STEP}

se i $\notin\{v 1, \ldots, v n\}$

<At Step v1,...,vn begin < sentença > end, MES, MAP, MVC> $\underset{1}{\stackrel{\text { false }}{\longrightarrow}}$
<At Step v1,...,vn begin < sentença > end, MES, MAP, MVC>

se $i \in\{v 1, \ldots, v n\}$

< sentença,MES,MAP,MVC > $\underset{\mathbf{i}}{\stackrel{\mathrm{b}}{\longrightarrow}}$ < sentença',MES',MAP',MVC' >

< At Step v1,...,vn begin < sentença > end, MES, MAP, MVC> $\underset{i}{\stackrel{\text { false }}{\longrightarrow}}$

< At Step v1,...,vn begin < sentença'> end ,MES',MAP',MVC'>

Comentário: No primeiro caso ( $\mathrm{i} \notin\{\mathrm{v} 1, \ldots, \mathrm{vn}\})$, nada ocorre, pois o passo corrente (i) não está entre os passos especificados (v1,...,vn) no comando. No segundo caso (i $\in\{\mathrm{v} 1, \ldots, \mathrm{vn}\})$ ocorre uma composição de definições, ou seja, o comando "AT STEP" é executado juntamente com os comandos internos a este (sentença, a qual resulta em sentença'). 


\title{
3.4.5.3.2 - FOR STEP v1 TO v2 EACH v3 STEPS DO
}

\author{
se $\mathbf{i} \neq \mathbf{v} \mathbf{1}$
}

< For Step v1 to v2 Each v3 Steps Do, MES,MAP,MVC > begin < sentença > end

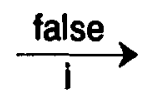

< For Step v1 to V2 Each V3 Steps Do, MES,MAP,MVC > begin < sentença > end

$$
\text { se } i=v 1 e(v 1+v 3) \leq v 2
$$

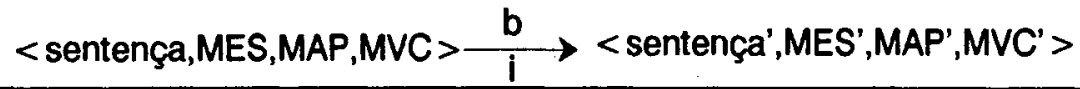

$<$ For Step v1 to v2 Each v3 Steps Do, MES,MAP,MVC > false
begin < sentença $>$ end

< For Step v1 to v2 Each v3 Steps Do, MES',MAP',MVC_LOOP(v1) -v1 + v3 > begin < sentença' > end

$$
\text { se } i=v 1 e(v 1+v 3>v 2 \text { ou v1 }=v 2)
$$

< sentença,MES,MAP,MVC > $\underset{\mathrm{i}}{\stackrel{\mathrm{b}}{\longrightarrow}}$ < <entença',MES',MAP',MVC'> < For Step v1 to v2 Each v3 Steps Do, MES,MAP,MVC>
begin < sentença > end

< sentença',MES',MAP',MVC'>

Comentário: Quando $i \neq v 1$, então nada deve ser feito. Quando $\mathrm{i}=\mathrm{v} 1$ e não é o último passo do comando (v1 + v3 $\leq \mathrm{v} 2)$, então: v1 é incrementado de v3; sentença é executada e resulta em sentença' e o comando "FOR" será novamente executado no passo $\mathrm{v} 1+\mathrm{v} 3$. Quando $\mathrm{i}=\mathrm{v} 1$, mas é o último passo do comando $((\mathrm{v} 1+\mathrm{v} 3)>\mathrm{v} 2$ ou $(\mathrm{v} 1=\mathrm{v} 2)$ ) então a sentença é executada e resulta em sentença', mas o comando "FOR" não será executado novamente. 


\subsubsection{3 - ALL STEPS}

< sentença,MES,MAP,MVC > $\underset{\mathbf{b}}{\longrightarrow}$ < sentença',MES',MAP',MVC' >

<All Steps begin < sentença > end, MES, MAP, MVC> talse $\underset{1}{\longrightarrow}$

< sentença',MES',MAP',MVC' >

\subsubsection{4 - IF condição THEN comandos \\ ELSE comandos}

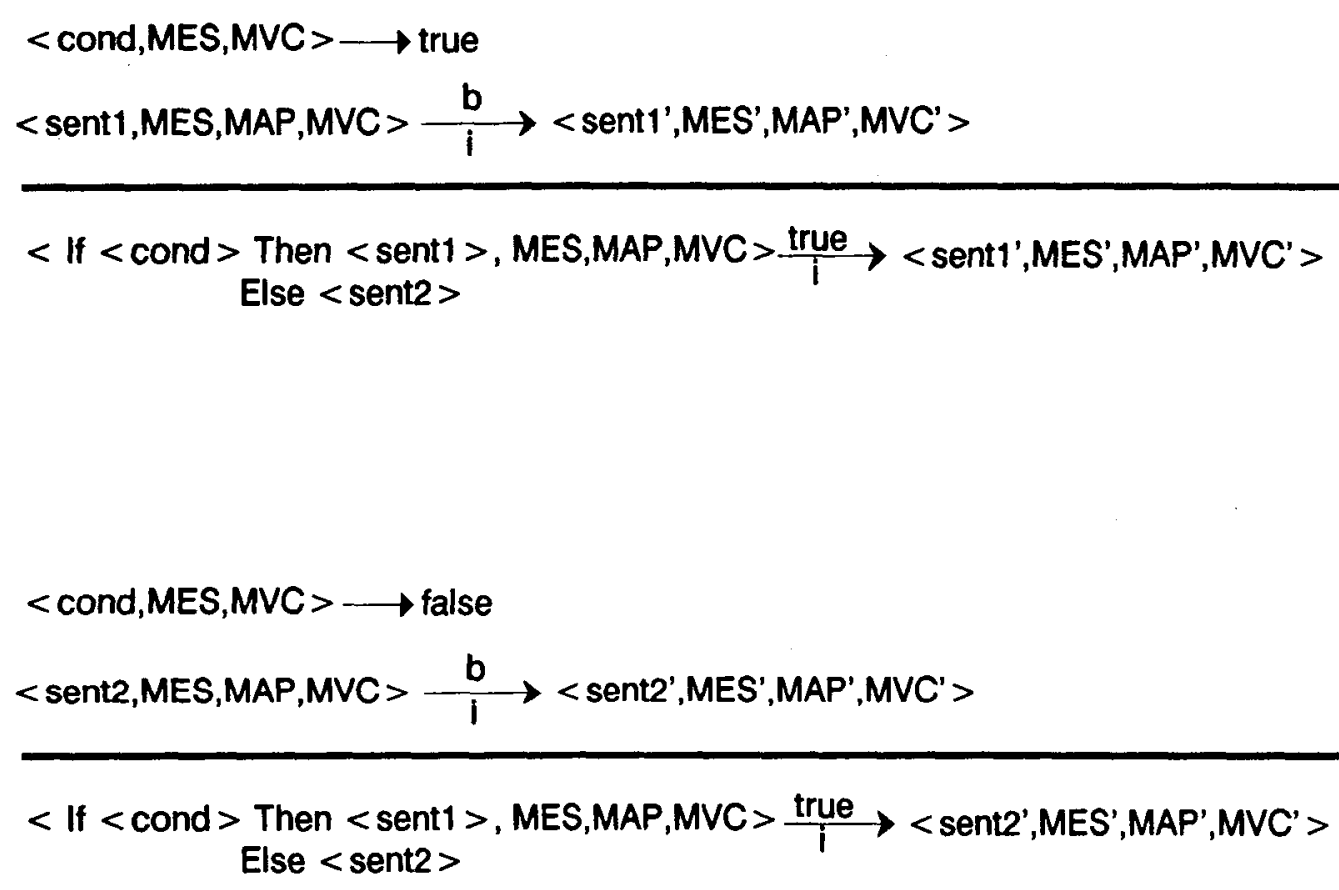

Comentário: No primeiro caso, como a condição é satisfeita, então sent1 é executada. No segundo caso sent 2 é executada, pois a condição não foi satisfeita. 


\subsubsection{5 - WHILE condição DO comandos}

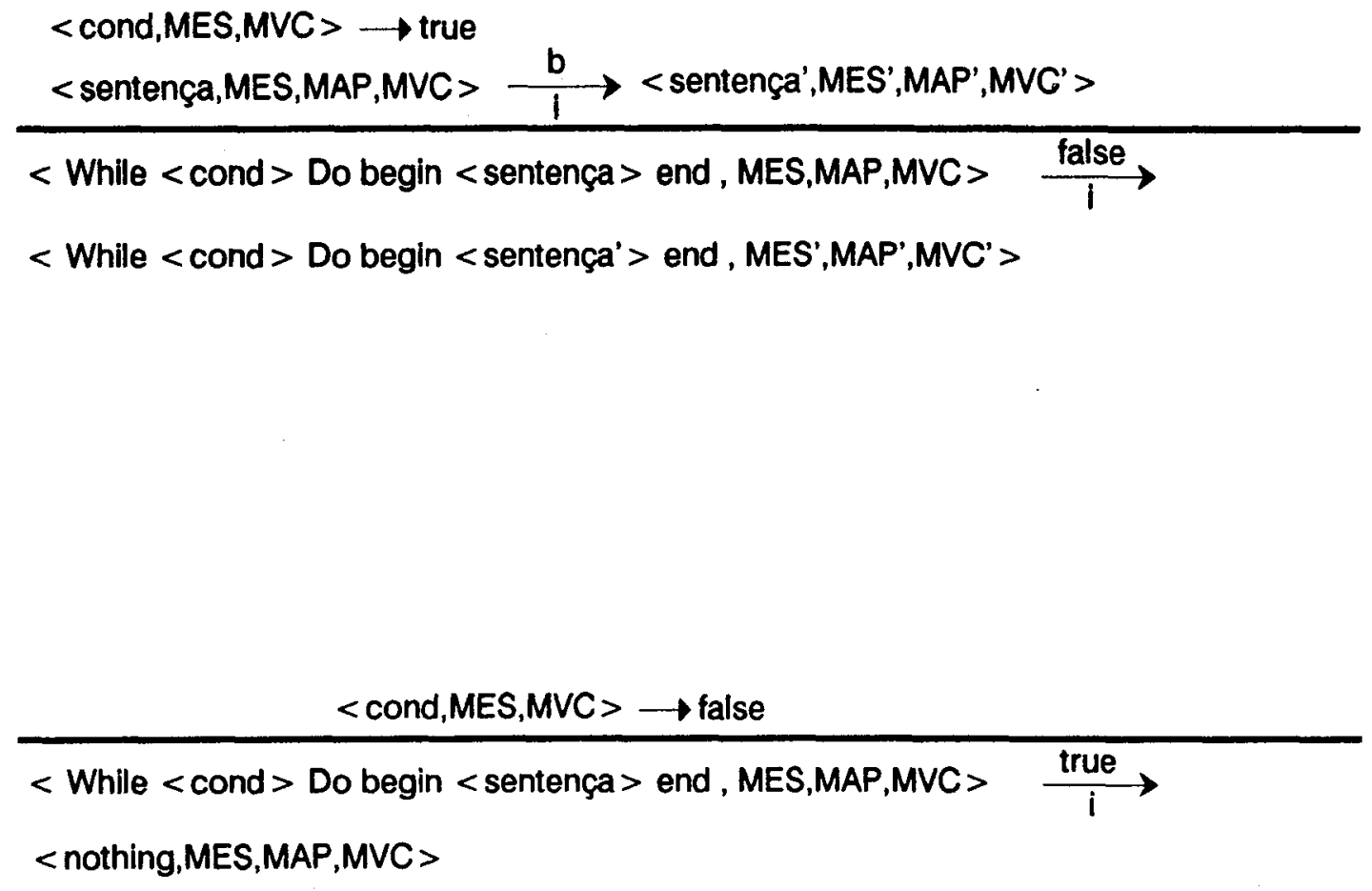

Comentário: Na primeira definição, pelo fato da condição ser verdadeira, então o comando "WHILE" é executado, juntamente com os comandos internos a este, resultando como resíduo o próprio comando "WHILE" e sentença', que é o resíduo de sentença. Na segunda definição, como a condiçāo não é satisfeita, então o comando termina. 


\subsubsection{6 - FOR \%vc $=$ expressão1 TO expressão2 DO comandos}

se $v<$ v1

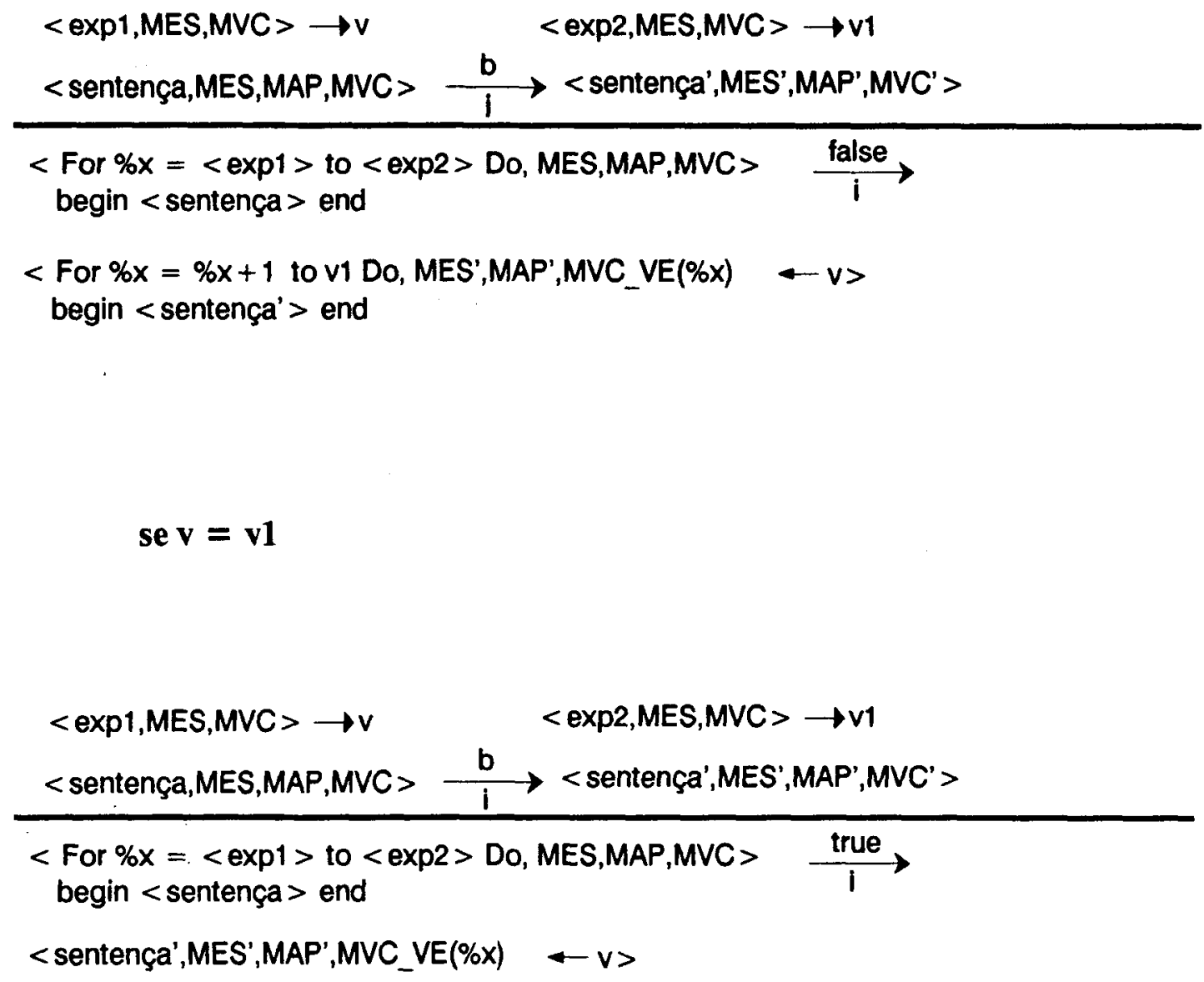

Comentário: Quando a primeira expressão gera um valor menor do que a segunda, então o comando "FOR" é executado, em composição com sentença, mas como o "FOR" não termina, obtém-se o resíduo do "FOR" e sentença', que é o resíduo de sentença. Quando a primeira expressão gera um valor igual ao da segunda, então o comando "FOR" é executado pela última vez, restando apenas o resíduo de sentença, ou seja, sentença'. 


\subsubsection{7 - Atribuição de Variável do Statechart}

$$
<\exp , M E S, M V C>\rightarrow V
$$

$<x:=<\exp >$,MES,MAP,MVC $>\frac{\text { true }}{i}<<$ nothing, MES_V $(x) \leftarrow V, M A P, M V C>$

Comentário: a variável "x" do statechart recebe um valor, o qual é gerado por, então a atribuição termina e é feita uma alteração na MES.

\subsubsection{8 - Atribuição de Variável de Controle}

$\frac{<\exp , M E S, M V C>\rightarrow V}{<\% x:=<\exp >, \text { MES,MAP,MVC }>\frac{\text { true }}{i} \rightarrow<\text { nothing, MES,MAP,MVC_VE }(\% X) \leftarrow V>}$

Comentário: Similar à atribuiçāo de variável do statechart. 


\subsubsection{9 - EVENTS(e1,...en,parâmetro)}

se parâmetro for omitido

$<$ EVENTS $(e 1, \ldots, e n)$, MES,MAP,MVC $>\quad \underset{\text { true }}{i}$

<nothing,MES, MAP_EVE[ ] ${ }_{i}^{1} \longleftarrow e 1, \ldots$, en,MVC >

se parâmetro for um número natural

$<$ EVENTS $(e 1, \ldots$, en, num $)$, MES,MAP,MVC > $\quad \stackrel{\text { true }}{i}>$

<nothing,MES, MAP_EVE[ ] $i+$ num $e 1, \ldots$, en,MVC >

se parâmetro for uma distribuição probabilística

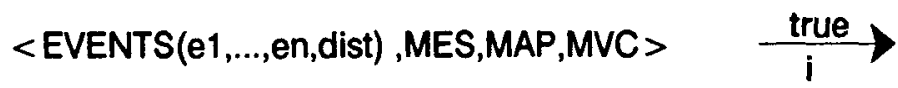

< nothing,MES, MAP_EVE[ ] $\leftarrow_{\text {dlst }} e 1, \ldots$, en,MVC >

Onde dist pode ser uma distribuição Exponencial, Normal ou Uniforme

Comentário: Quando os parâmetros da função EVENTS são somente eventos, então esses são colocados na MAP_EVE para serem disparados no passo corrente da simulação. Caso o último parâmetro da função seja um número n, então os eventos serão colocados na MAP_EVE para serem disparados em n passos a partir do passo corrente. Se o último parâmetro for uma distribuição probabilística, entāo os eventos irão compor a MAP_EVE de acordo com os números gerados por essa distribuição. 


\subsection{0 - SHOW_VAR}

$<$ SHOW_VAR,MES,MAP,MVC> $\stackrel{\text { true }}{i}$ < $<$ nothing,MES,MAP_SV $\leftarrow$ true, MVC >

Comentário: é realizada apenas uma alteração na MAP, a qual indica que a função SHOW_VAR deve ser executada.

\subsection{1 - SHOW_CONTROL_VAR}

$<$ SHOW_CONTROL_VAR,MES,MAP,MVC $>\stackrel{\text { true }}{\mathrm{i}}<$ nt,MES,MAP_SCV -true, MVC $>$

Onde $\mathrm{nt}=$ nothing

Comentário: é realizada apenas uma alteração na MAP, a qual indica que a função SHOW_CONTROL_VAR deve ser executada.

\subsection{2 - SHOW_EVENTS}

$<$ SHOW_EVENTS,MES,MAP,MVC > $\stackrel{\text { true }}{i}<$ nothing,MES,MAP_SE $\leftarrow$ true, MVC >

Comentário: é realizada apenas uma alteração na MAP, a qual indica que a função SHOW_EVENTS deve ser executada. 


\subsection{3 - SIMULATION}

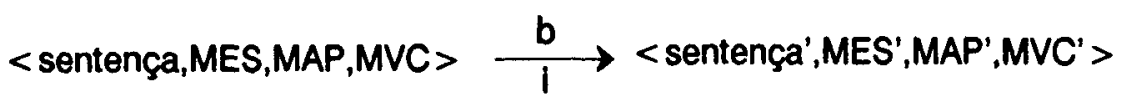

< Simulation < sentença > End_Simulation, MES,MAP,MVC >

$<$ <sentença' > ,MES,MAP,MVC >

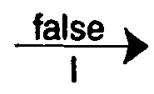

\subsection{4 - END_SIMULATION}

$$
\text { se i }<\text { MVC_NP }
$$

$<$ End_Simulation,MES,MAP,MVC $>\stackrel{\text { false }}{\longrightarrow}$

$<$ Simulation,MES - Nova_Configuração,MAP,MVC_PA 4 MVC_PA + $1>$

$$
\text { se } \mathrm{i}=\text { MVC_NP }
$$

$<$ End_Simulation,MES,MAP,MVC $>\underset{\mathrm{i}}{\stackrel{\text { true }}{\longrightarrow}}<$ <nothing,MES,MAP,MVC $>$

Comentário: Quando i < MVC_NP, ou seja, não foi executado o último passo, então o resíduo de END_SIMULATION é SIMULATION, e o passo corrente é incrementado de $1(\mathrm{um})$, mas quando $\mathrm{i}=$ MVC_NP, significa que o último passo já foi executado, então a simulação termina. Quando END_SIMULATION é executado, então, de acordo com os eventos que foram disparados pelo Simulador, o statechart alcança uma nova configuração. 


\subsection{5 - INTERACTIVE}

$<$ INTERACTIVE,MES,MAP,MVC $>\stackrel{\text { true }}{i}><$ nothing,MES,MAP_INT 4 true,MVC $>$

Comentário: INTERACTIVE determina que a simulação voltará a ser interativa até que o usuário decida voltar à execução programada. Deve-se ressaltar que durante a execução interativa o usuário só poderá alterar o conteúdo da MES, pois os conteúdos da MAP e da MVC são de controle exclusivo da execução programada.

\subsection{6 - MESSAGE}

$<$ MESSAGE(mensagem),MES,MAP,MVC > $\underset{i}{\stackrel{\text { true }}{\rightarrow}}$ < nothing,MES,MAP_MES(i,mensagem),MVC >

Comentário: Esta definição especifica que a mensagem será impressa no passo i do relatório de passos da simulação.

\section{5 - Considerações Finais}

Os conceitos extraídos de linguagens baseadas em especificação de estados e de linguagens de simulação serviram para estabelecer os requisitos que a LCE deve satisfazer. Estes requisitos, acoplados à função que a LCE desempenha em um sistema reativo, levaram à definição sintática e semântica da LCE.

A definição precisa da sintaxe e da semântica de qualquer linguagem é uma atividade indispensável para o desenvolvimento de um interpretador para essa linguagem. Portanto, a descrição informal da sintaxe feita neste capítulo e, principalmente, a definição 
em BNF feita no Apêndice A foram necessárias, juntamente com a definição semântica de todos os comandos e funções da LCE (Linguagem de Controle de Execução) [CANG92b].

Com base na semântica e na sintaxe da LCE definidas neste capítulo, será apresentada, no próximo capítulo, a implementação de um interpretador para a LCE, o qual trabalha basicamente em cima de alteraçōes nas três memórias disponíveis, cujo conteúdo pode ser visto na Tabela 3.2.

O motivo do interpretador se restringir, um pouco, a alterações nas memórias, é justificado pelo fato de que as tarefas de simulação são executadas pelo "Simulador" já existente no ambiente StatSim, ou seja, o interpretador altera as memórias, e estas alterações determinam mudanças no comportamento do modelo que está sendo executado pelo "Simulador". 


\section{Capítulo 4 \\ O Módulo de Execução Programada (MEP)}

\section{1 - Considerações Iniciais}

Neste capítulo são vistos principalmente os aspectos de implementação do MEP (Módulo de Execução Programada), o qual está inserido no ambiente StatSim. Para situar o leitor, apresenta-se primeiro uma visão geral da evolução do ambiente StatSim, mostrando-se um panorama do ambiente desde o início de seu desenvolvimento até a situação anterior à inclusão do MEP.

A arquitetura do ambiente StatSim é então apresentada com o MEP já incluído, podendo-se perceber como ele se integra ao ambiente. Em seguida são apresentados detalhes de mais baixo nível a respeito da implementação do MEP, tais como: as restrições que a LCE possui; o esforço de programação despendido; e uma descrição da interface do MEP.

Depois da apresentação dos detalhes de implementação apresenta-se neste capítulo o exemplo de um sistema de fila única com dois servidores, sendo apresentada a descrição do modelo em statecharts e os resultados da simulação, ou seja, o relatório estatístico e o relatório de passos da simulação. O programa em LCE para o sistema de fila também é apresentado. O capítulo termina com considerações finais sobre a implementação do MEP e sobre o exemplo apresentado. 


\section{2 - Evolução do Ambiente StatSim}

O desenvolvimento do ambiente StatSim teve início com o projeto de uma Linguagem de Especificação de Statecharts, denominada LES, e um compilador para a mesma. Em seguida foram desenvolvidos um simulador textual, baseado na LES, e um editor gráfico de statecharts.

Com a implementação do compilador e do simulador para a LES, o usuário pode especificar o statechart de uma forma textual e os erros na especificação são detectados pelo compilador. Se o statechart for corretamente especificado, uma base de dados é gerada pelo compilador da LES, contendo todas as informações necessárias para que a simulação seja executada.

Com a base de dados gerada pelo compilador da LES, o usuário pode realizar a simulação textual do statechart, acionando eventos externos que farão com que o modelo seja reconfigurado. A semântica da simulação é a definida por Harel em [HARE87].

A simulação é baseada em intervalos de tempo $I_{i}=\left[\sigma_{i}, \sigma_{i}+1\right]$. Uma configuração do sistema num determinado instante de tempo $\sigma_{1}$ é definida como sendo a quadrupla $(\mathrm{X}, \Pi, \Theta, \xi)$. Onde $\mathrm{X}$ é a configuração de estados ativos no instante $\sigma_{\mathrm{l}}, \Pi$ é o conjunto de eventos ocorridos em $\sigma_{\mathrm{i}}, \Theta$ é o conjunto de condições primitivas cujo valor é true nesse instante e $\xi$ é uma função que associa a cada variável $\mathrm{v}$, o seu valor no instante $\sigma_{\mathrm{k}}, \mathrm{k} \geq \mathrm{i}$.

Assim, no instante $\sigma_{i}+10$ statechart reage aos eventos externos que ocorreram no intervalo $I_{i}$, mudando da configuração de estados $X_{i}$ para a configuração $X_{i}+1$.

Durante a simulaçâo textual, o usuário interage com três campos visuais na tela: uma janela superior, que contém a configuração dos estados ativos; uma janela inferior , que contém os passos da simulação; e, à direita, um menu dos eventos disponíveis para a simulação, acompanhado de um botão de disparo dos mesmos.

A ocorrência dos eventos externos se dá quando o usuário seleciona um ou mais dos eventos disponíveis e em seguida pressiona o botão de seleçāo "Disparar". Com este disparo, as duas janelas são preenchidas com as informações resultantes dos efeitos da simulação. Na sub-janela superior apresenta-se a configuração de estados ativos, visualisando-se o nome dos estados de uma forma tabulada segundo a hierarquia de estados do statechart. $\mathrm{Na}$ sub-janela inferior encontra-se um registro de acompanhamento (arquivo de log), relacionando cada passo a cada disparo de eventos e os respectivos efeitos 
na configuração dos estados, através da lista de nomes dos estados "ligados" e da lista de nomes dos estados "desligados" [FORT91] [MASI91].

Com relação à base de dados gerada pelo compilador, ficam armazenadas na memória principal as informações relativas aos estados, eventos e transições, podendo essas informações também serem armazenadas na memória secundária. A hierarquia de estados está implementada como uma árvore do tipo e/ou, e fisicamente é indexada por um vetor de endereços.

As transições estão organizadas em uma lista. Quando a transição tem mais de um estado fonte ou destino, esses ficam armazenados em sub-listas. Cada transição possui também um apontador para a tabela que contém a expressão polonesa dos eventos e condições. Existe também uma tabela de eventos, onde cada entrada aponta para um evento individual e este, para uma lista de transiçōes onde ele aparece. Maiores informaçōes a respeito da base de dados pode ser vista em [FORT91a].

A ferramenta que seguiu ao desenvolvimento do analisador da LES e da simulação textual foi o editor gráfico, com o qual o usuário ao invés de especificar textualmente o statechart, pode editá-lo graficamente na tela. No editor, praticamente toda a edição é feita com a utilização do mouse para manipulação direta de objetos, quer seja para selecionar operaçōes a executar, quer seja para construir os elementos gráficos que compōem um statechart. As informações textuais, tais como os rótulos de arcos, ações, eventos e variáveis, são fornecidas via teclado. Mensagens de erro são emitidas sempre que alguma informação sintática ou semântica incorreta for inserida. A base de dados criada pelo editor gráfico é essencialmente a mesma criada pelo compilador da LES, a menos das informaçōes gráficas. O editor gráfico faz uso também de partes do analisador da LES, como por exemplo os módulos que realizam a análise de expressōes lógicas e aritméticas [BATI91] [MASI91].

Depois da implementação do editor gráfico, foi feita a integração deste com o simulador, ou seja, o editor gráfico foi interfaceado com o simulador e o resultado da simulação passou a ser animado e não textual, apesar de ainda ser possível analisar a simulação textualmente através do "log" gerado.

O modelo especificado em statecharts é editado no editor gráfico e na simulação o modelo é carregado na memória para ser simulado. A animação é percebida pelo usuário da seguinte forma: se o estado ativo é atômico, ou seja, não possui subestados, este apresenta o seu interior colorido; e caso o estado ativo seja um superestado, este 
apresentará o seu contorno tracejado. O interfaceamento do editor gráfico com o simulador é encontrado em [TUTU91].

A partir do momento que a simulação passou a ser animada, o interesse no ambiente ficou voltado para a inserção de uma série de características dos statecharts que ainda não haviam sido implementadas. Uma das principais características dos statecharts que o ambiente StatSim não suportava era a reação em cadeia ou comunicação entre os componente paralelos (broadcast), essa foi implementada por este autor, juntamente com a implementação dos operadores cr (current) e ny (not yet) que são os operadores sensíveis à reação em cadeia [HARE87].

Outros operadores e eventos internos foram inseridos no ambiente por Furuuti, tais como: ex (exit), en (entered), tr (true), fs (false), t_out (time out), hide/clousure e clear history. Ele também implementou a execução não interativa, na qual o usuário especifica um arquivo com a seqüência de eventos que deve ser disparada e observa o comportamento animado do modelo. Detalhes sobre a implementação dos operadores e da simulação não interativa são encontrados em [FURU92a] e [FURU92b].

Foi desenvolvido também um conjunto de algoritmos para análise dos statecharts editados; esses algoritmos são baseados em uma árvore de alcançabilidade similar a árvore de alcançabilidade para Redes de Petri. Os algoritmos detectam deadlock, alcançabilidade entre configuraçōes, uso de transições e validade de sequência de eventos. A árvore de alcançabilidade gerada permite a análise de todas as possíveis configurações do modelo, ou seja, a análise exaustiva. Deve-se ressaltar entretanto, que as restriçōes de memória e de tempo impedem a análise exaustiva de modelos maiores e mais complexos. $O$ projeto e implementação da árvore de alcançabilidade e dos algoritmos citados acima são encontrados em [BOAV92].

Apesar do ferramental de análise descrito no parágrafo acima fazer parte do ambiente StatSim, este ferramental não se encontrava integrado à mesma interface que as outras ferramentas do ambiente. $O$ trabalho de junção na mesma interface do simulador de statecharts e dos algoritmos de análise foi também realizado pelo autor.

Com isso, as características sintáticas e semânticas formalmente definidas por Harel em [HARE87] foram todas implementadas e o ambiente StatSim vem sendo usado para modelar sistemas, como por exemplo células de manufatura, aquecedores de ambientes e protocolos de comunicação de redes [CANG92b], entre outros, o que demonstra a sua utilidade e versatilidade na modelagem do aspecto de controle de sistemas reativos diversos. 


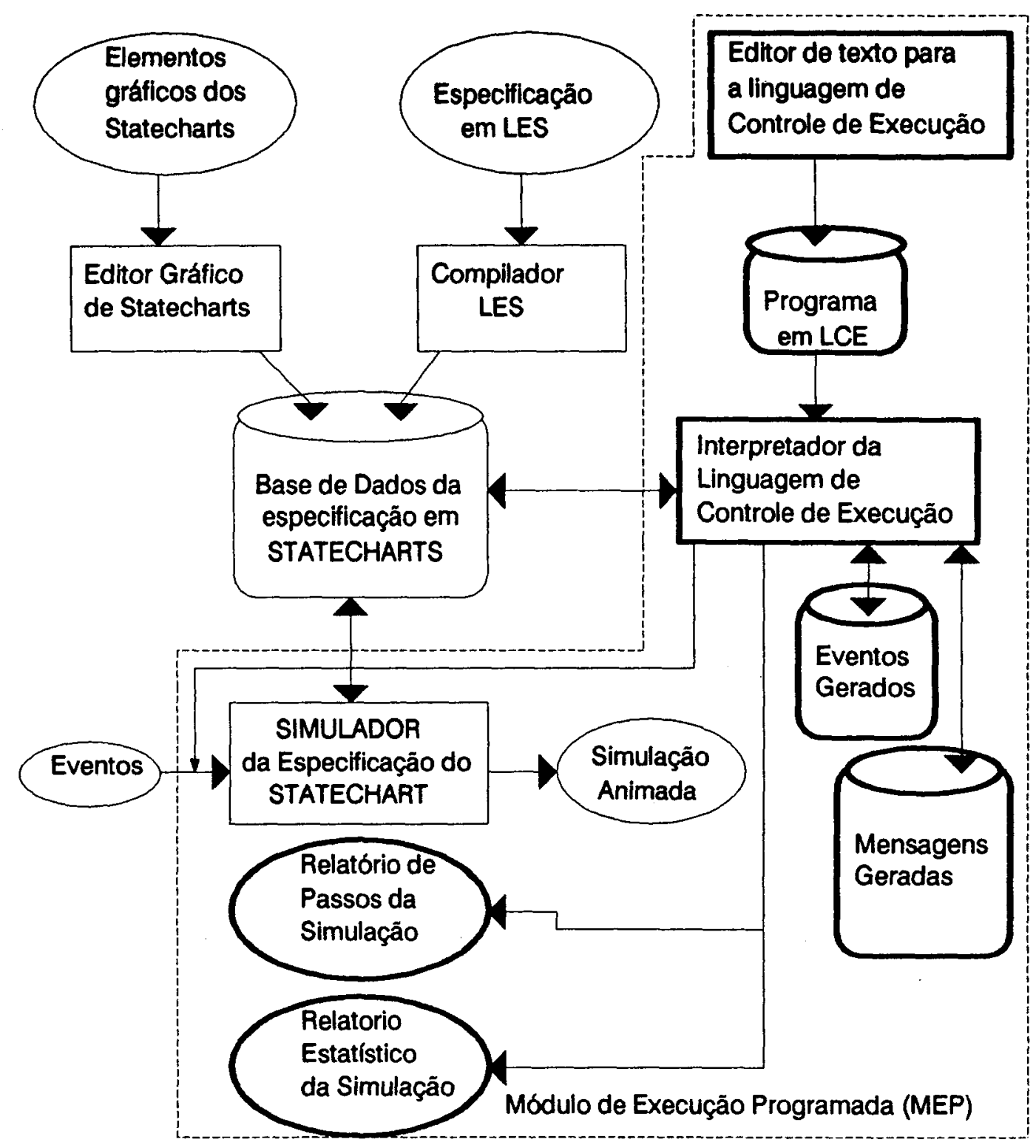

Figura 4.1 - Arquitetura do Módulo de Execução Programada

\section{3 - Arquitetura do Módulo de Execução Programada (MEP)}

O Módulo de Execução Programada (MEP) consiste de elementos para edição de programas, interpretação dos mesmos e execução dos modelos de acordo com os programas escritos. A Figura 4.1 apresenta a arquitetura do MEP, a qual também está inclusa na arquitetura do ambiente StatSim (Figura 2.4). 
Os elementos que possuem o contorno mais expesso na Figura 4.1 correspondem àqueles que foram inseridos para complementar o MEP, cuja arquitetura é constituída, portanto, de elementos já pertencentes ao ambiente StatSim e de novos elementos inseridos. Na figura o Módulo de Execução Programada está delimitado por uma linha tracejada.

O usuário escreve seus programas através de um editor de textos que está disponível no ambiente. Esses programas alimentam o interpretador da Linguagem de Controle de Execução (LCE), o qual também possui acesso à base de dados dos statecharts para fazer certas verificações, tal como: verificar se um certo evento ou variável especificada no programa faz parte do statechart a ser executado.

Durante a interpretaçāo das especificações (declarações) de eventos, o interpretador da LCE armazena os eventos a serem disparados em cada passo. $\mathrm{Na}$ simulação, a cada passo, o interpretador retira os eventos por ele armazenados e coloca-os na entrada do simulador. Assim, de acordo com os eventos, o modelo atinge uma nova configuração e o resultado da simulação será animado, textual (relatório de passos da simulação) ou ambos, dependendo da especificação do usuário.

O relatório de passos da simulação é alimentado a cada passo pelo interpretador e pelas mensagens armazenadas por este. $O$ relatório estatístico é gerado no final da simulação, porém deve-se notar que grande parte dos cálculos vão sendo executados durante a simulação. O relatório estatístico é gerado cada vez que um programa escrito na LCE for executado, independente de especificações do usuário.

\section{4 - Implementação do Módulo de Execução Programada (MEP)}

A descrição da implementação do MEP (Módulo de Execução Programada) será feita a seguir, inicialmente através da descrição estrutural dos módulos que compõem o interpretador da LCE, seguida da descrição dos detalhes de implementação de mais baixo nível e finalizando com uma descrição da interface do MEP. 


\section{Interpretador da LCE}

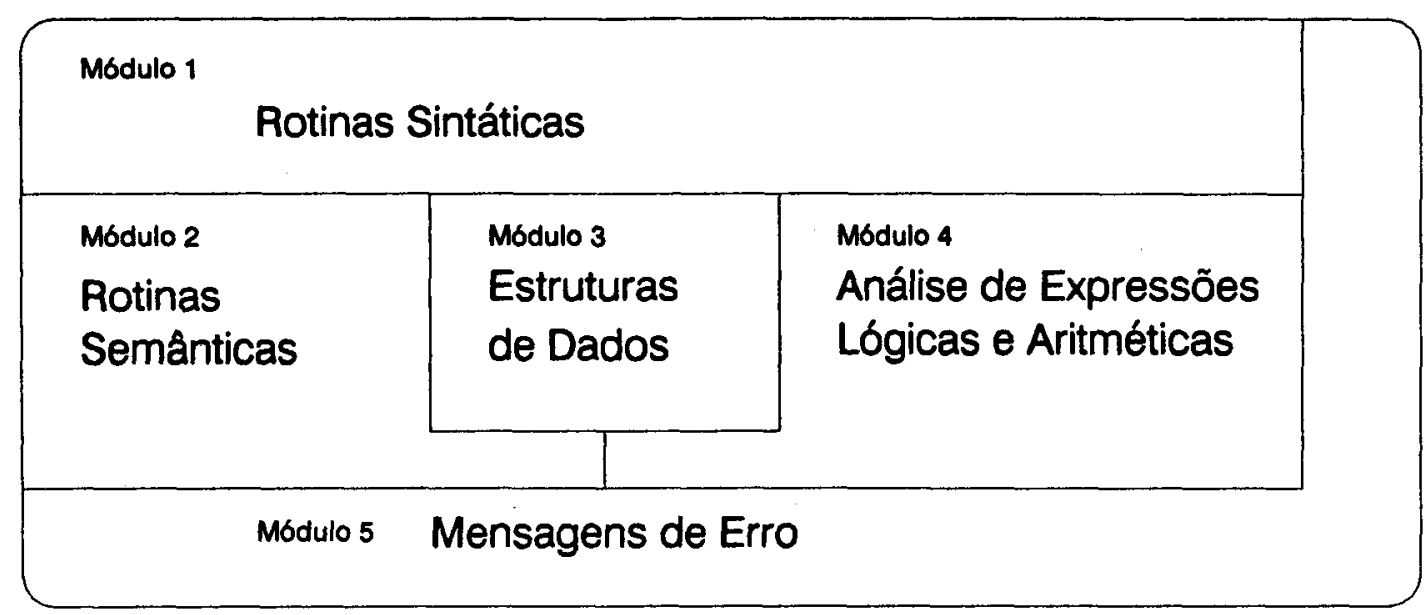

Figura 4.2 - Estrutura do Interpretador da LCE

\subsection{1 - Estrutura do MEP}

No contexto do ambiente StatSim, o MEP está inserido no módulo que especifica a interface da simulação e possui chamadas para rotinas que executam a execução interativa, não-interativa, exaustiva e programada, além de outras funções disponíveis no ambiente. Com isto, pode-se agora descrever o interpretador da LCE, que é o elemento principal do MEP, e é composto por cinco módulos, como pode ser visto na Figura 4.2.

O módulo principal, que gerencia os demais módulos do interpretador, é o módulo referente às rotinas sintáticas. Neste módulo pode-se ver a descriçāo da interface do MEP e uma série de rotinas básicas utilizadas pelo interpretador da LCE. Além da interface e das rotinas básicas, este módulo contém as rotinas de interpretação dos comandos da LCE, juntamente com as rotinas que geram o relatório estatístico e o relatório de passos da simulação.

O módulo referente à análise das expressões é composto de rotinas para a análise sintática e semântica de expressōes lógicas e aritméticas da LCE.

O módulo de mensagens de erro contém apenas uma rotina, a qual de acordo com o número do erro passado, imprime a mensagem de erro correspondente, indicando em que linha do programa fonte tal erro ocorreu e por fim termina a execução do programa. 
O módulo 2 da digura 4.2 representa as rotinas semânticas da LCE, ou seja, as rotinas que realmente executam os comandos da LCE que foram interpretados pelos procedimentos do módulo 1 (rotinas sintáticas).

O módulo 3 contém a definição das estruturas de dados que são utilizadas pelos demais módulos do interpretador. Neste módulo tem-se: a definição das variáveis de controle internas, especificadas no capítulo anterior; as estruturas para armazenamento das variáveis de controle que podem ser declaradas pelo usuário; as estruturas de dados utilizadas para a análise sintática dos programas em LCE; e, a declaração de variáveis que auxiliam no controle das rotinas do interpretador da LCE; entre outras estruturas.

Na Figura 4.2 percebe-se que o módulo 5 (mensagens de erro) é diretamente acessado pelos módulos das rotinas sintáticas, semânticas e análise de expressões (módulos 1,2 e 4), pois são estes que reconhecem algum erro nos programas, e se comunicam com o módulo 5 para que a mensagem correspondente ao erro seja emitida. As estruturas de dados (módulo 4) também são acessadas diretamente pelos módulos 1, 2 e 4, pois estes se utilizam das estruturas de dados para a análise sintática e semântica dos comandos da LCE. No interpretador da LCE, os únicos módulos que nāo se comunicam são as estruturas de dados e as mensagens de erro, pois no módulo 3 não é feita nenhuma análise para que alguma mensagem de erro possa ser gerada.

E importante notar que a estrutura do Interpretador da LCE apresentada na Figura 4.2 se enquadra na arquitetura do MEP (Figura 4.1), realizando as mesmas comunicações, porém estas comunicações não foram especificadas na Figura 4.2.

\subsection{2 - Detalhes de Implementação do MEP}

O Módulo de Execução Programada foi desenvolvido em estações de trabalho SUN, utilizando C como linguagem de programação e as rotinas da biblioteca XView para desenvolvimento da interface.

Em relação ao volume de programaçāo, foram desenvolvidas aproximadamente 95 rotinas, as quais totalizam em torno de 5.000(cinco mil) linhas de código fonte. Algumas rotinas foram aproveitadas do ambiente StatSim, com algumas alterações. $O$ tempo despendido no desenvolvimento destas rotinas foi de aproximadamente 3.5 meses. 
Deve-se notar que o autor já estava completamente familiarizado com os módulos do ambiente StatSim e isso contribuiu bastante para o rápido andamento do projeto.

São comentadas agora algumas das restriçōes e limites que o MEP possui. Em relação aos parâmetros globais a principal restrição é o número de passos, ou seja, qualquer modelo pode ser executado pelo MEP no máximo por 1000(mil) passos. Os programas fontes escritos em LCE também não podem exceder 100.000 (cem mil) caracteres, que são suficientes para se descrever um programa relativamente grande com relação ao porte da LCE.

As variáveis de controle declaradas pelo usuário não podem ultrapassar o limite de 30(trinta) declarações. O comando "FOR STEP" utiliza-se de variáveis de controle internas, então este também possui um limite, ou seja, no máximo 30(trinta) comandos "FOR STEP" podem aparecer em um programa fonte em LCE.

Apesar dessas restrições, o protótipo implementado não fica comprometido, pois acredita-se que em poucos casos os limites acima serão extrapolados. Por outro lado, essas restriçōes podem ser facilmente alteradas no código fonte do MEP, na maioria das vezes, mudando-se apenas o valor de constantes.

Com relação aos testes realizados durante e após a implementação do MEP, foram feitos testes de unidade à medida que os procedimentos eram implementados. Como foi utilizada uma abordagem top-down para a implementação, ou seja, foram implementados primeiro os procedimentos de mais alto nível, descendo na hierarquia até chegar à implementação dos procedimentos de mais baixo nível, desta mesma forma foi realizada a integração dos procedimentos.

Depois de terminada a implementação foram elaborados vários casos de testes, baseados em vários modelos especificados no ambiente. Entre os modelos que foram utilizados para testar o MEP, pode-se citar: o modelo de fila; o manipulador de mouse; o jantar dos filósofos; o controle remoto de uma televisão; além de modelos preparados especificamente para testar características específicas do MEP.

\subsection{3 - Descrição da Interface do MEP}

A interface do MEP apresenta em primeiro lugar, um campo textual no qual o usuário deve especificar qual o programa fonte em LCE que será executado. Os cinco 
campos a seguir correspondem aos parâmetros globais da LCE, ou seja, nesses campos especifica-se: o número de passos da simulação; o tipo de simulação; o resultado da simulação; a configuração inicial que o statechart deve possuir; e por fim, um campo que indica qual statechart será simulado.

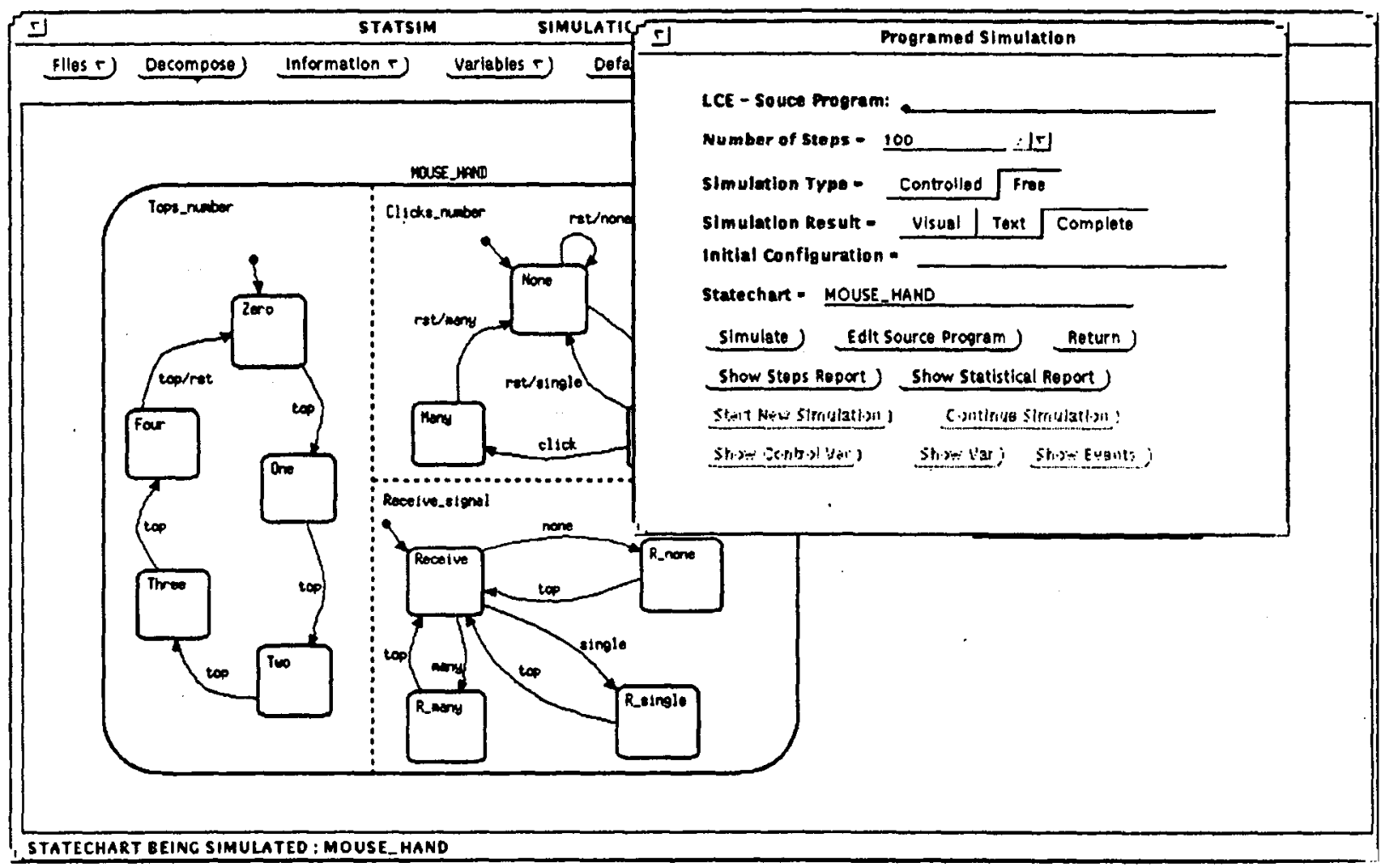

Figura 4.3 - Tela Inicial do MEP

Um ponto importante a considerar em relação aos parâmetros globais da LCE é que se os mesmos forem omitidos no programa fonte, então os valores especificados na interface são assumidos, e se os parâmetros também forem omitidos na interface, então os valores defaults serão assumidos. Desta forma, a especificação dos parâmetros globais no programa fonte possui a maior prioridade, seguida pela interface e pelos valores defaults, respectivamente. Deve-se ressaltar que alguns campos da interface são inicializados com os valores defaults dos parâmetros.

Depois dos parâmetros globais, a interface apresenta um botão, o qual é utilizado para dar início à simulação. Ao lado do botão de início da simulação encontra-se, respectivamente, o botâo que, se pressionado, executa a chamada de um editor para os 
programas fontes em LCE, e um botão que retorna à tela de simulação anterior do ambiente StatSim. A tela inicial do MEP e a tela na qual o editor de programas fontes pode ser visto, são exibidas nas Figuras 4.3 e 4.4, respectivamente.

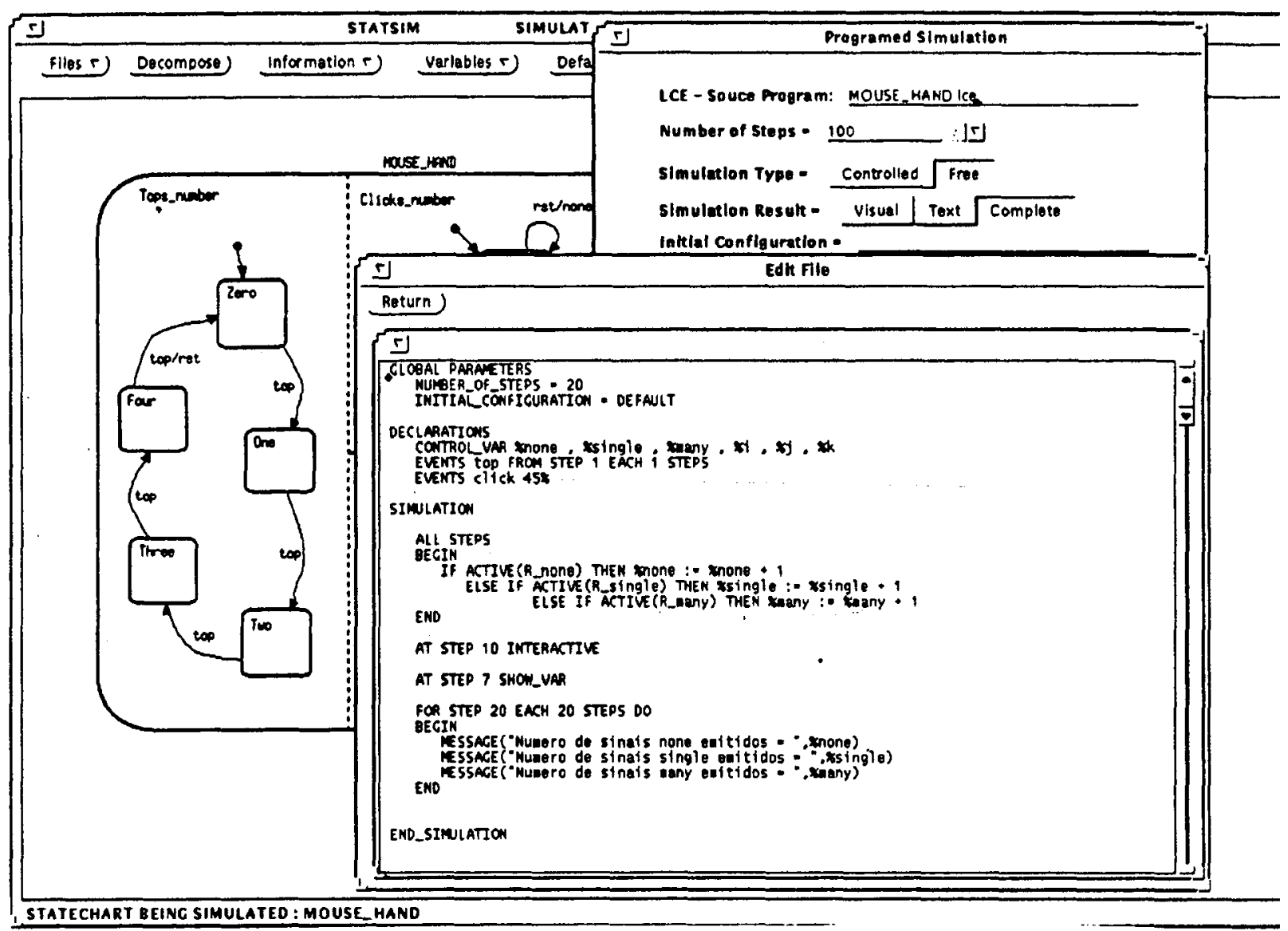

Figura 4.4 - Editor de Programas Fonte em LCE

Os próximos botões da interface são "Show Steps Report" e "Show Statistical Report" que, acionados, apresentam as telas para visualização do relatório de passos da simulação e do relatório estatístico. Estas telas podem ser vistas nas Figuras 4.5 e 4.6.

Se durante a simulação, o interpretador encontrar um dos comandos "SHOW_VAR", "SHOW_CONTROL_VAR" ou "SHOW_EVENTS", então a simulação é parada no final do passo corrente, e o menu de opções do MEP volta a ser visualizado na tela, nas seguintes condiçōes: os únicos botões que podem ser acionados são "Continue Simulation" e os botões que se referem aos comandos "SHOW_CONTROL_VAR", "SHOW_VAR" e "SHOW_EVENTS". Assim, se no programa fonte existir uma sentença: 


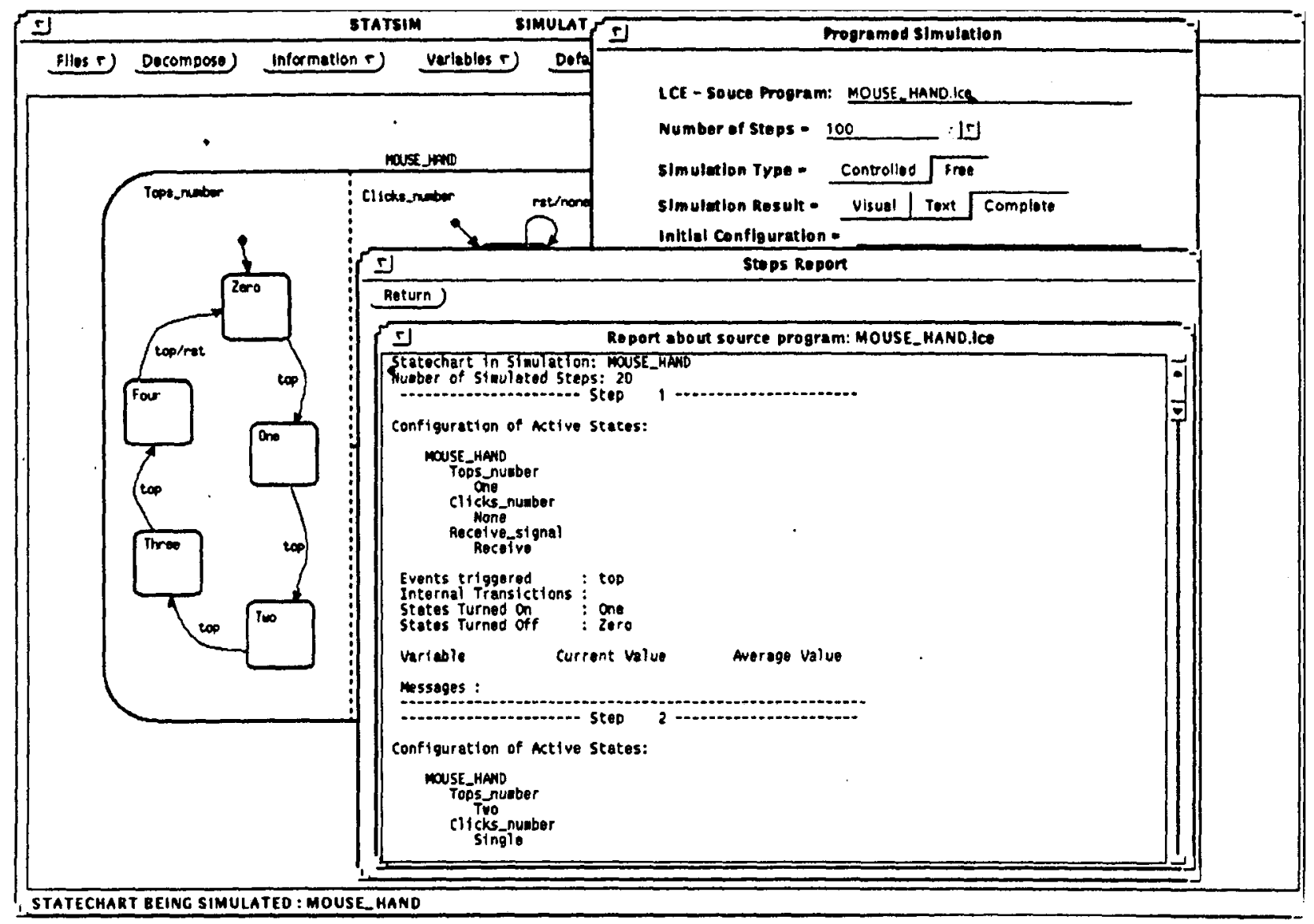

Figura 4.5 - Tela de Visualização do Relatório de Passos

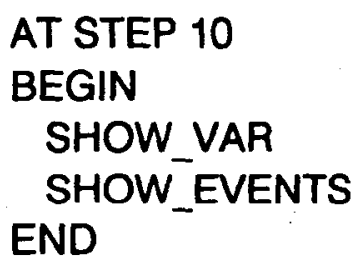

A simulaçāo será interrompida no final do passo $10(\mathrm{dez})$ e os botōes da interface que estão disponíveis ao usuário serão: "Continue Simulation", "Show Var" e "Show Events". Um exemplo da interface nessa situação pode ser visto na Figura 4.7.

Quando um comando "INTERACTIVE" é encontrado em um programa fonte, em um dos passos, então o simulador tem de interromper a execução para voltar à execução interativa. Nesse caso a simulação para no final do passo e a interface se apresenta ao usuário somente com os botões "Return", "Start New Simulation" e "Continue Simulation" possíveis de serem acionados. Se o usuário pressionar o botão "Return", então volta-se à simulação interativa e o usuário poderá fazer as alteraçōes desejadas e depois retornar à 
simulação programada. Caso o usuário pressione o botão "Start New Simulation", então a interface retornará à tela inicial (Figura 4.3) e as estatísticas da simulação serào zeradas. Caso o usuário pressione o botão "Continue Simulation", entāo a simulaçāo continuará a partir do passo no qual a mesma tinha parado. Na Figura 4.8 vê-se um exemplo da interface do MEP na situação descrita acima.

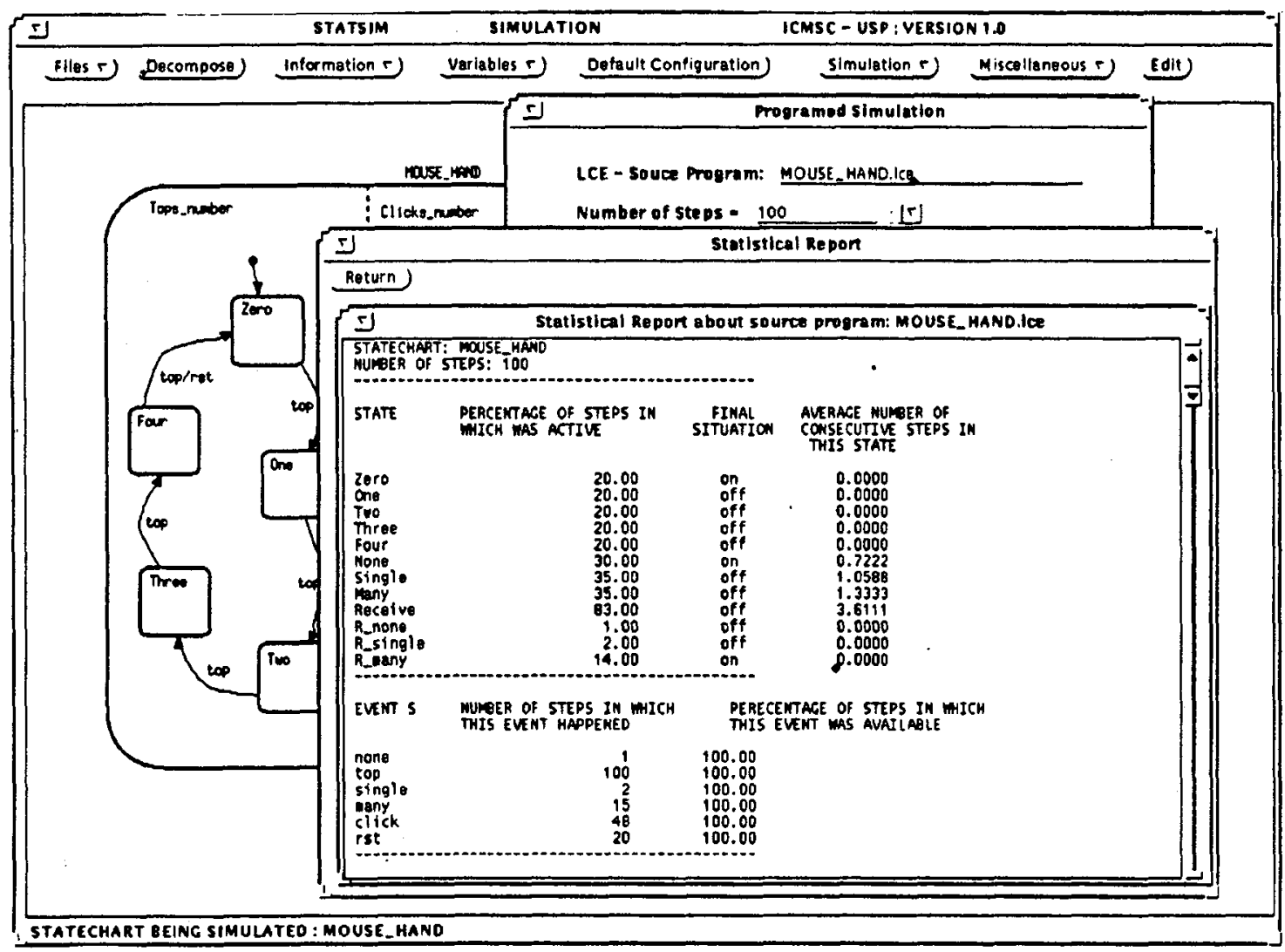

Figura 4.6 - Tela de Visualização do Relatório Estatístico

Um fato que deve ser notado é que durante a simulação a interface do MEP desaparece, para que dessa forma o usuário possa acompanhar a evolução animada do statechart na tela. Quando a simulação termina, a interface do MEP volta a aparecer. As Figuras 4.9a e 4.9b mostram a evolução do manipulador de mouse em dois passos; no primeiro passo o statechart está na configuração inicial; e no segundo passo a configuração apresentada corresponde ao fato dos eventos "top" e "click" terem sido gerados pela LCE e fazerem com que as transiçóes, que eram relevantes e consistentes, fossem disparadas. 


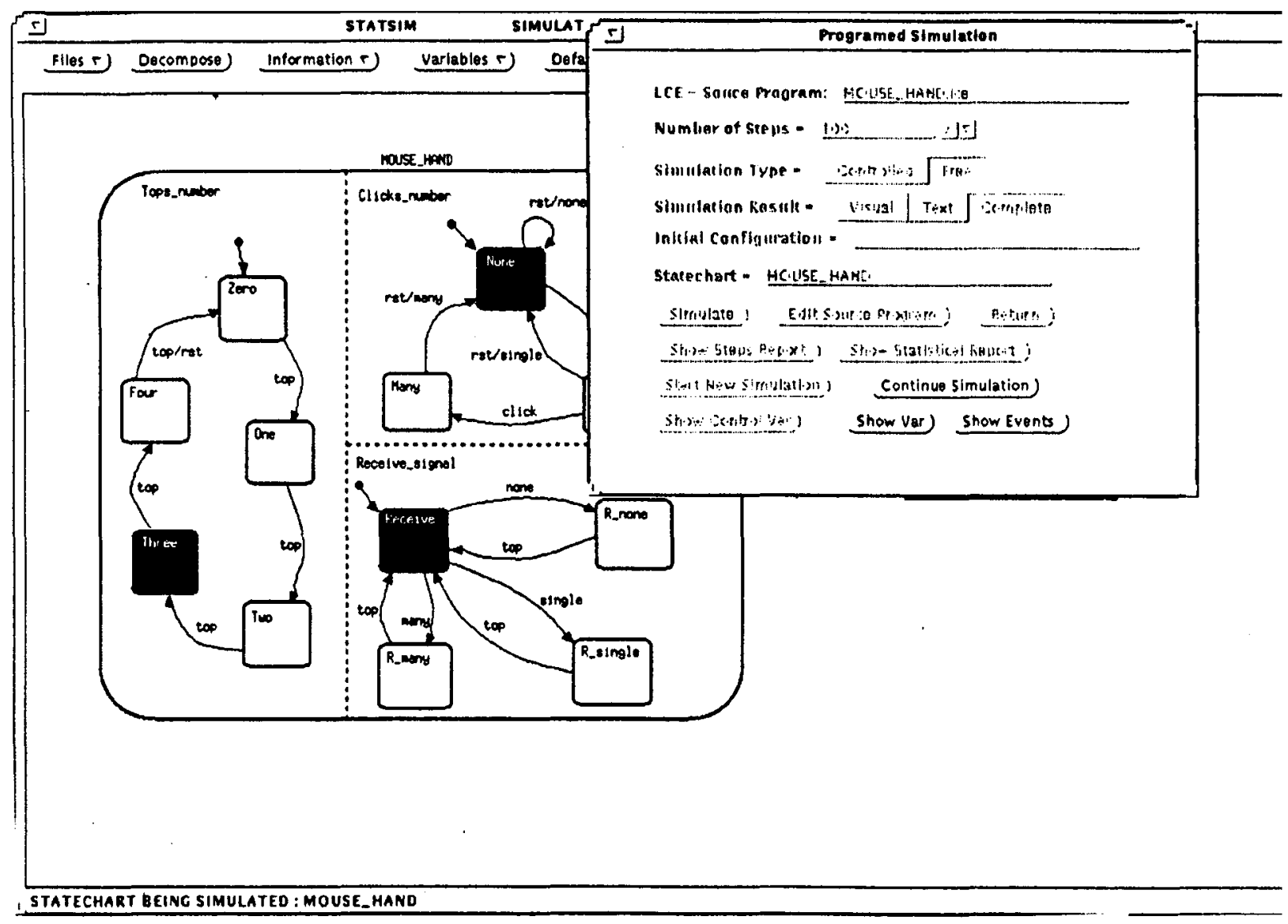

Figura 4.7 - Tela com as Opçōes Show Var e Show Events Disponíveis 


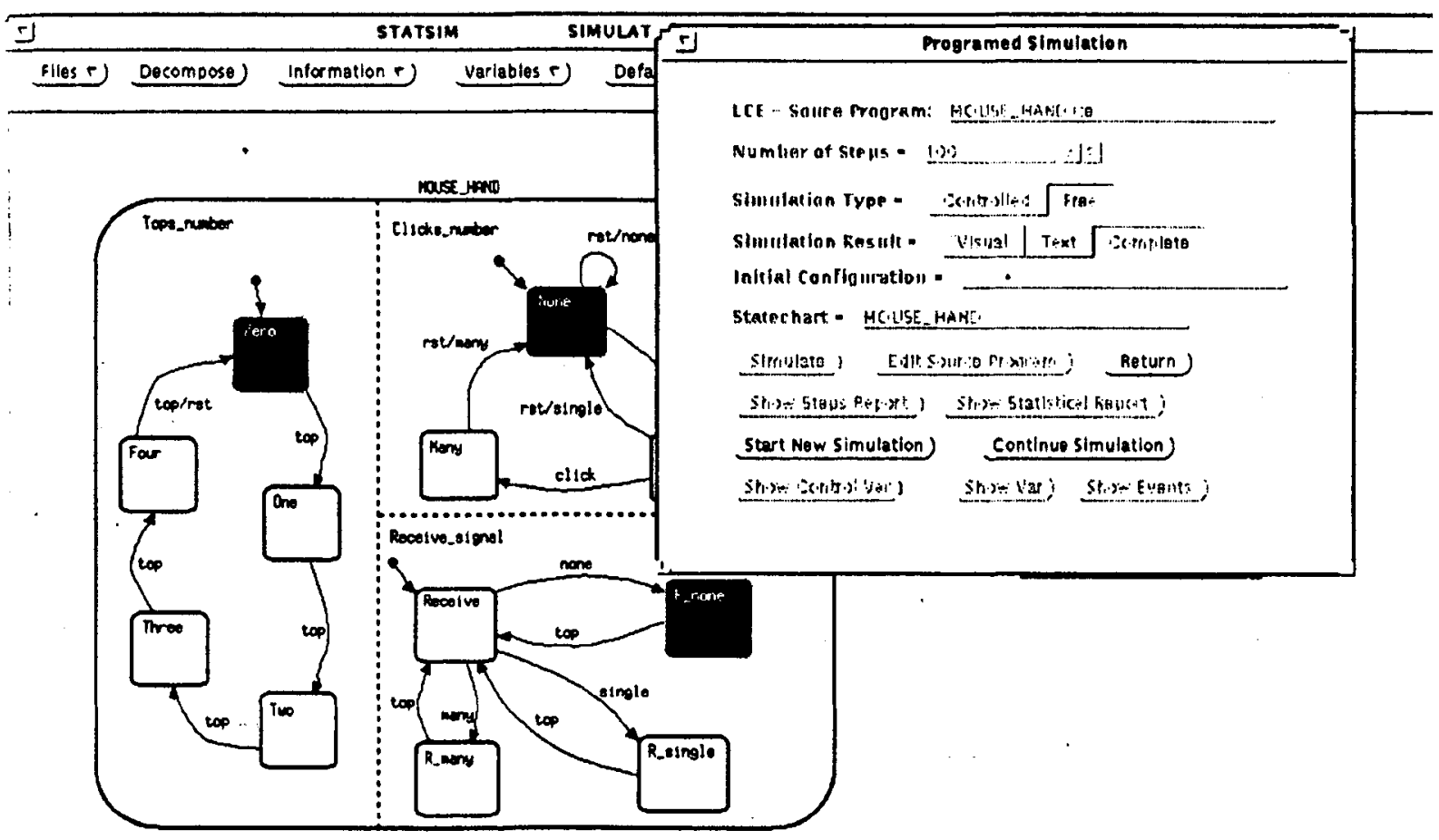

Figura 4.8 - Tela de Retorno à Simulação Interativa 


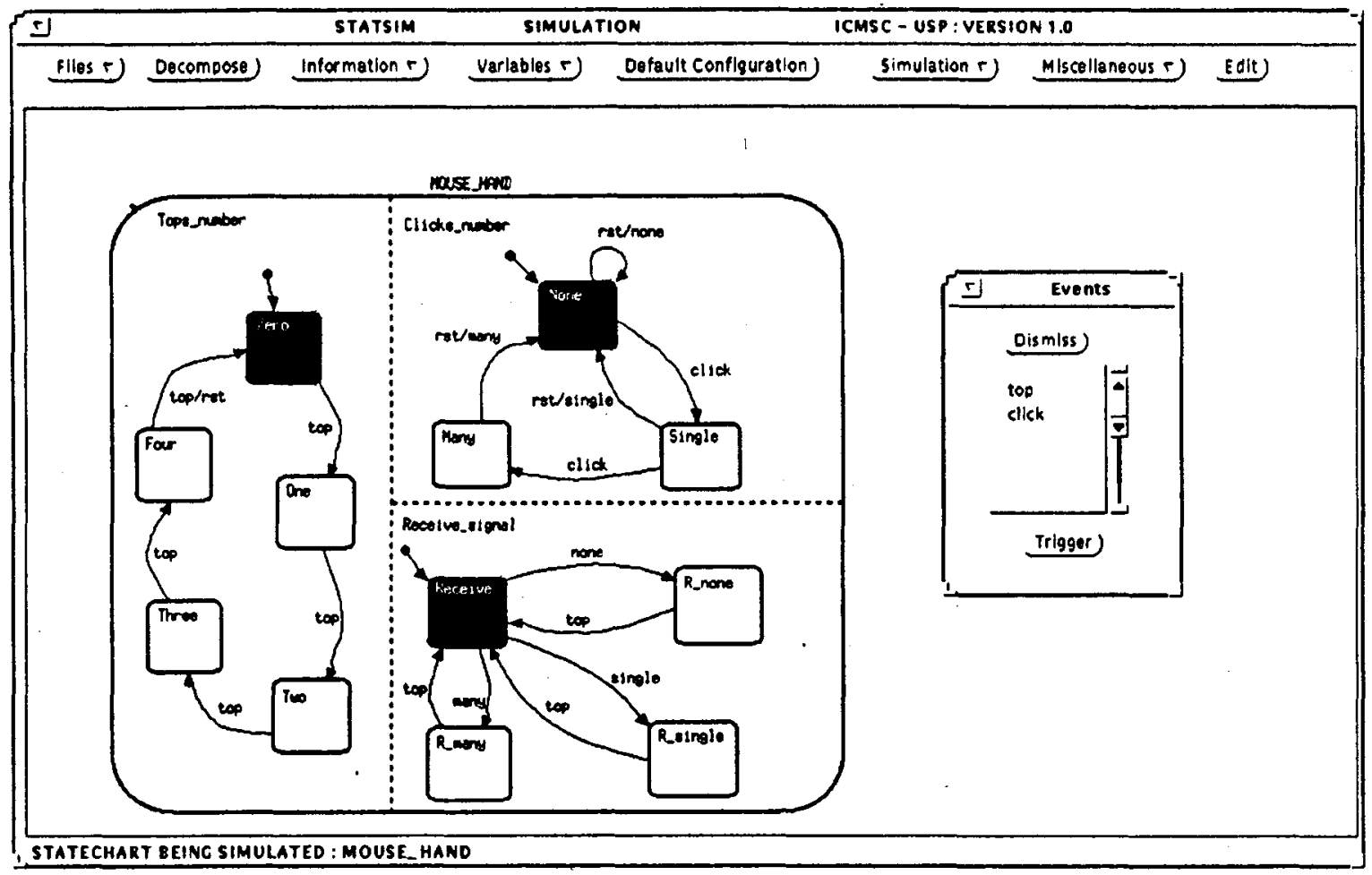

Figura 4.9 (a) - Primeiro Passo da Simulação do Manipulador de Mouse 


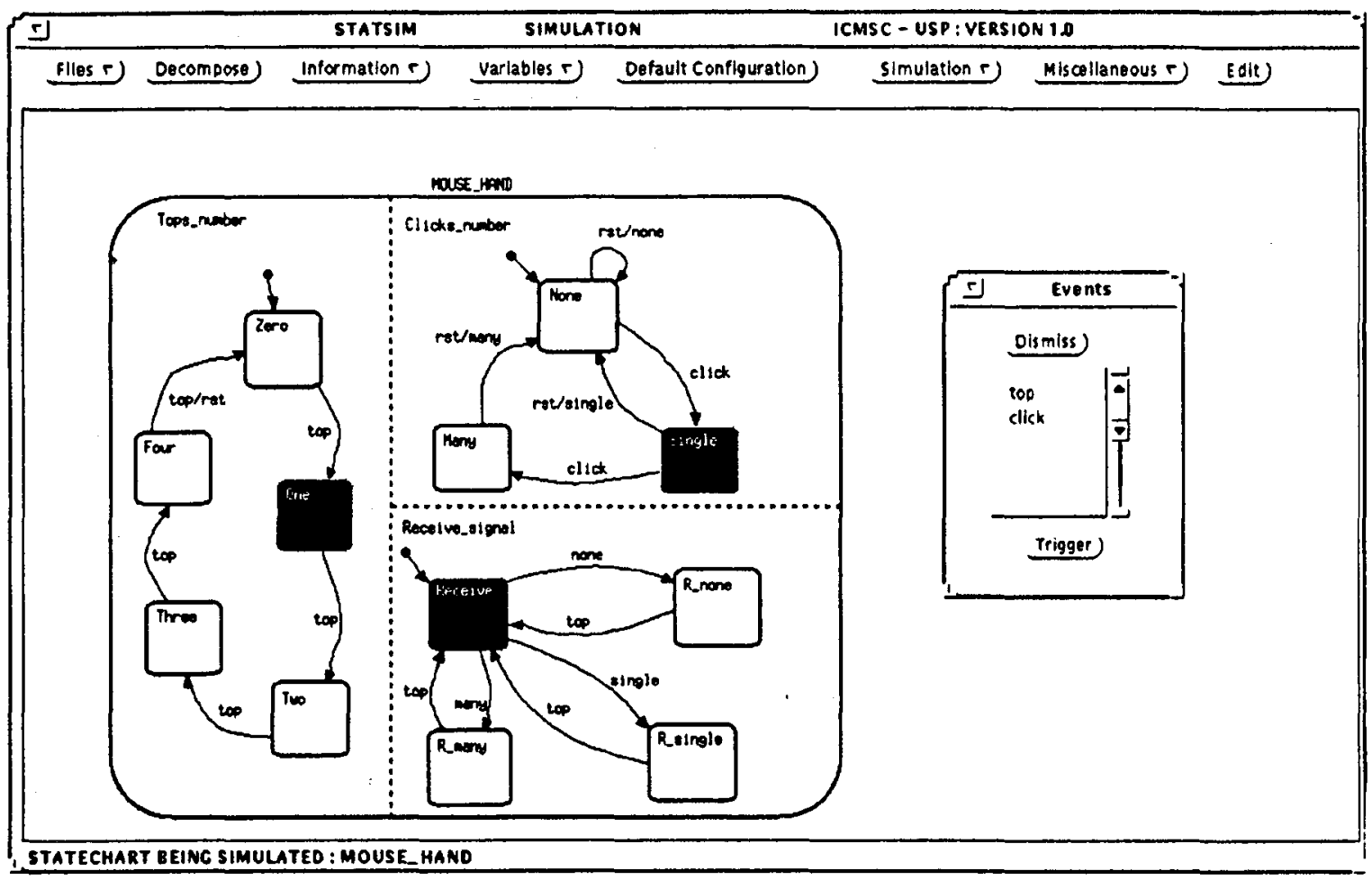

Figura 4.9 (b) - Segundo Passo da Simulação do Manipulador de Mouse

\section{5 - Estudo de Caso}

Será visto agora um modelo de um sistema de fila única com dois servidores. Este modelo foi escolhido pois exemplifica de forma bastante clara as características estatísticas da LCE e pode ser explorado de várias formas por programas escritos em LCE. Porém outros modelos podem ser encontrados nos Apêndices B e C deste trabalho, os quais possuem o objetivo de ilustrar outras características da LCE. 


\subsection{1 - O Modelo Especificado em Statecharts}

O sistema de fila única com dois servidores, o qual é exibido na Figura 4.10, é composto de três componentes paralelos. O primeiro componente ("Controle_Fila") executa o gerenciamento da chegada de clientes na fila de espera. A ocorrência do evento "g" corresponde à chegada de um cliente no sistema e a variável "x" controla o número de clientes que estão na fila. $O$ segundo componente descreve o primeiro servidor, possuindo dois estados: "Inativo1" que indica que o servidor nāo está trabalhando e "Ativo1" que indica que o servidor está disponível para atender aos clientes. O estado "Ativo1" possui dois subestados: "livre1" e "ocupado1", que indicam, respectivamente, que o servidor está desocupado e pode atender aos clientes que chegarem e que o servidor está ocupado atendendo um cliente. $O$ terceiro componente é praticamente idêntico ao segundo, diferindo somente pelo estado default, que no "Servidor1" é "Ativo1" e no "Servidor2" é "Inativo2".

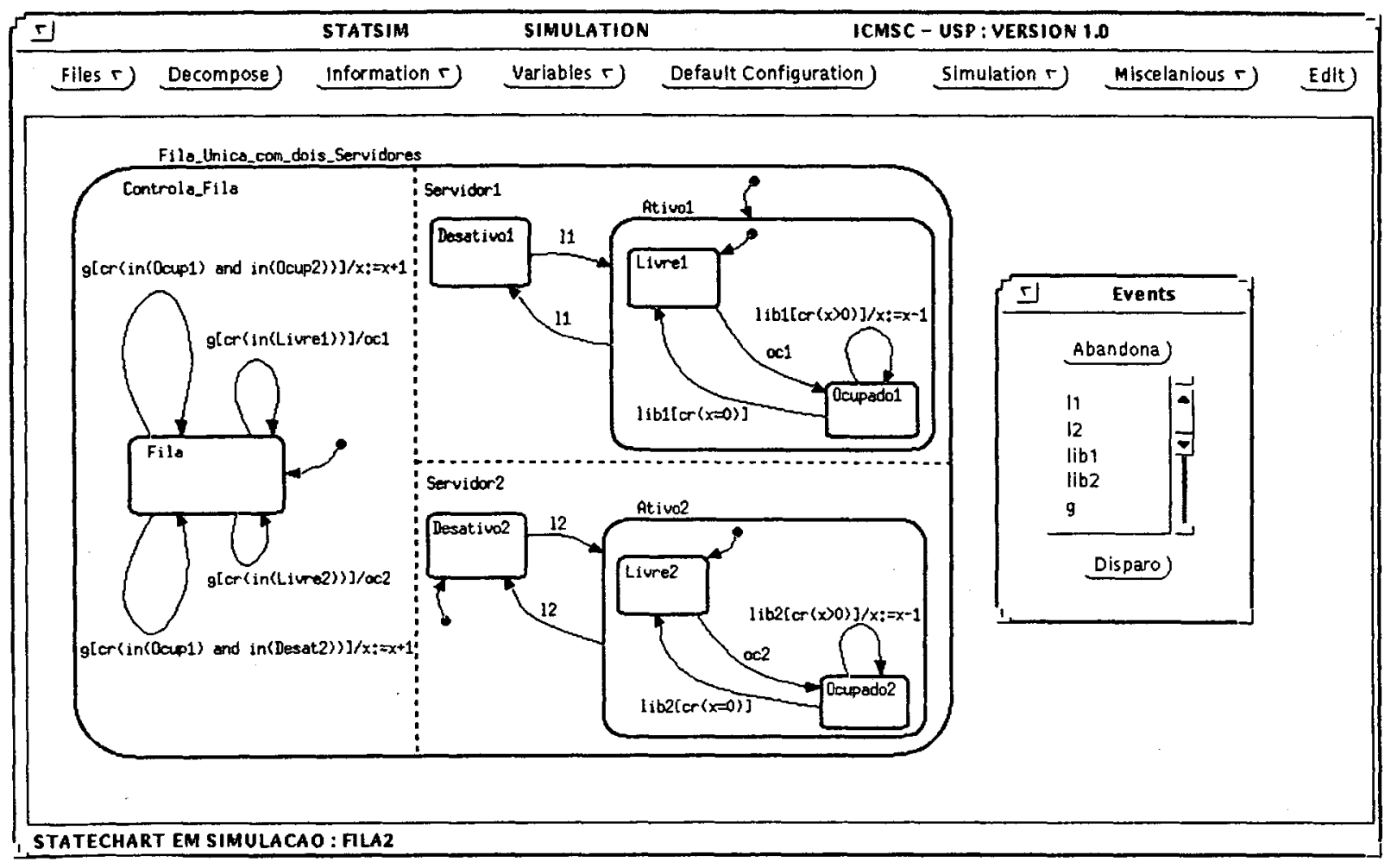

Figura 4.10 - Sistema de Fila Única com Dois Servidores 
Será analisado agora o comportamento do modelo. Partindo da situação inicial em que os estados "Fila", "livre1" e "Inativo2" estão ativos e que a variável "x" possui o valor 0 (zero). Suponha que ocorreu a chegada de um cliente no sistema, ou seja, o evento "g" foi acionado, então no componente "Controla_Fila" a única transição que pode ser disparada é "g[cr(in(livre1))]/oc1", que fará com que o evento "oc1" seja sentido no componente "Servidor1" que transicionará de "livre1" para "ocupado1". Se outro cliente chegar no sistema enquanto o servidor estiver ocupado, então a única transição possível no componente "Controla_Fila" é "g[cr(in(ocupado1) and in(Inativo2)) $] / x:=x+1$ ", ou seja, se o cliente chega e o servidor está ocupado, este deve aguardar na fila de espera, o que corresponde ao fato da variável " $x$ " ser incrementada.

O comportamento de saída de clientes é igual nos dois servidores, desde que ambos estejam ativos, dessa forma só será exemplificada a saída de clientes no primeiro servidor. Se o servidor está atendendo um cliente, ou seja, o estado "ocupado1" está ativo e ocorre o evento "lib1", que indica que o cliente já foi atendido e está abandonando o servidor, então se a fila estiver vazia $(x=0)$, o servidor irá transicionar para o estado "livre1", senão a transição "lib1[cr( $x>0)] / x:=x-1$ " será executada, a qual indica que o cliente que estava ocupando o servidor saiu e que um novo cliente, que estava aguardando na fila de espera, passou a ocupar o servidor.

Suponha agora que a situação inicial do sistema seja "Fila", "livre1" e "livre2" ativos e que a fila de espera esteja vazia $(x=0)$. Se ocorre a chegada de um cliente no sistema, então em "Controla_Fila" tem-se duas opções: ou dispara-se a transição "g[cr(in(livre1))]/oc1" ou a transição "g[cr(in(livre2))]/oc2". As duas transições possíveis, apesar de terem suas condições satisfeitas, não podem ser disparadas simultaneamente, devido à semântica. Dessa forma a transição que for avaliada primeiro será disparada e gerará o evento "oc1" ou o evento "oc2", que fará com que um dos dois servidores passe para o estado ocupado. Deve-se notar que a escolha de qual transição avaliar primeiro é aleatória. As transiçōes "g[cr(in(ocupado1) and in(Inativo2))]/x:=x+1" e "g[cr(in(ocupado1) and in(ocupado2)) $] / x:=x+1 "$ não foram disparadas devido ao fato de suas condiçōes não serem verdadeiras.

Suponha que na situação anterior a transição disparada foi "g[cr(in(livre2))]/oc2". Portanto, no componente "Servidor2" o evento "oc2" fez com que a transição de "livre2" para "ocupado2" fosse disparada. Obteve-se então a configuração \{Fila,livre1,ocupado2\} e a variável " $x$ " continuou com o valor 0(zero). Se ocorrer novamente o evento "g", a única transição que pode ser disparada em "Controla_Fila" é "g[cr(in(livre1))]/oc1", a qual gera 
o evento "oc1" que faz com que o componente "Servidor1" transicione de "livre1" para "ocupado1", isto corresponde ao fato de que se um cliente chega no sistema e encontra um dos servidores vazios, este vai diretamente para o servidor, sem esperar na fila. A configuração é agora \{Fila,ocupado1,ocupado2\} e a fila continua vazia $(x=0)$, portanto os dois servidores estão ocupados. Se ocorrer a chegada de um novo cliente (evento "g"), então este terá de esperar na fila, ou seja, no componente "Controla_Fila" a única transiçāo possível é "g[cr(in(ocupado1) and in(ocupado2))]/x: =x+1", logo a fila (variável "x") será incrementada de um cliente, isto ocorrerá toda vez que os dois servidores estiverem ocupados e um novo cliente chegar no sistema.

Nem todos os possíveis estados e valores de variáveis e condiçōes foram exemplificadas na descrição do comportamento do modelo de fila dado acima, pois isso prolongaria em muito sua descrição, porém o comportamento do sistema em outras situações pode ser facilmente deduzido, baseando-se na semântica de Statecharts.

\subsection{2 - O Programa escrito na LCE}

O programa em LCE descrito a seguir se refere ao modelo de fila única com dois servidores especificado em statechart na seção anterior. A descrição do programa será feita em três fases: primeiro serão especificados os parâmetros globais da LCE; depois serão especificados os eventos e variáveis de controle; e por último serão descritos os comandos de controle da execução propriamente dita. A última fase será subdividida de acordo com os comandos de controle de passos da simulação encontrados no programa.

A primeira parte do programa "Fila.lce" trata da especificação dos parâmetros globais da LCE, lembrando-se que se os mesmos tivessem sido omitidos os valores assumidos seriam os valores defaults. Os parâmetros especificados no programa indicam que o modelo será simulado por $100(\mathrm{cem})$ passos (NUMBER_OF_STEPS $=100$ ), a configuração inicial do modelo será a default (INITIAL_CONFIGURATION = DEFAULT) e que o modelo a ser simulado será o statechart de nome "FILA2" (STATECHART $=$ FILA2).

A parte de declarações especifica que o evento "g" será gerado nos 100 passos da simulação obedecendo a uma distribuição probabilística uniforme entre os valores $3 \pm 1.5$. As variáveis de controle declaradas são: 
- \%i - usada no controle da ativação do servidor 2;

- \%j - contador do número de vezes que o servidor 2 foi ativado;

- \%k - contador do número de vezes que o servidor 2 foi desativado; e

- \%libera - usada para controle de qual evento gerar: "lib1" ou "lib2".

A terceira parte do programa cuida realmente dos passos da simulação. $\mathrm{O}$ primeiro comando (ALL STEPS) é executado em todos os passos da simulação e interno a este o comando "IF ( $\mathrm{y}=1)$ THEN" é usado para detectar se algum cliente entrou na fila de espera do sistema. Se isso ocorreu, então de acordo com a configuração do statechart, ou o evento "lib1" ou o evento "lib2" será gerado para determinar em que passo este cliente irá abandonar o sistema. Deve-se notar que a variável "y" pertence à especificação do statechart, e apesar de não aparecer no rótulo das transiçōes de "Controla_Fila", sempre que uma dessas transiçōes for disparada a variável "y" receberá o valor 1(um). No final do comando "IF ( $y=1)$ THEN" a variável "y" retorna ao valor 0(zero). A variável "\%libera" controla qual servidor será liberado, ou seja, se "\%libera" possuir o valor 0(zero), então o servidor 1 será liberado, senão será liberado o servidor 2, logicamente a liberação de um ou outro servidor também depende da configuração do statechart. Outro ponto a ser notado é que os eventos "lib1" e "lib2" determinam o número de passos que o cliente irá ocupar o servidor, sendo que estes são gerados de acordo com uma distribuição uniforme entre os valores $5 \pm 1.5$.

O comando "IF ( $(x>4)$ AND ACTIVE(Inativo2) ) THEN" é executado determinando que, se existem mais de 4(quatro) clientes na fila de espera e o servidor 2 está desativado, então o mesmo deve passar para o estado "Ativo2", através da geração do evento "12".

O comando "IF ( (\%i $=0)$ AND $((x<3)$ AND ACTIVE(Ativo2) $))$ ) THEN" indica que se a fila possuir menos do que três clientes esperando e o servidor 2 está trabalhando, este deve parar de trabalhar assim que acabar de atender ao cliente; este atendimento é controlado pela variável "\%i".

O comando "IF ( (\%i =1) AND ACTIVE(Livre2) ) THEN" indica que se o servidor 2 já acabou de atender ao cliente, este irá para o estado "Inativo2", através da geração do evento "12".

O comando de controle de passos "AT STEP 45, 95 " indica que nos passos especificados, os eventos gerados no passo e os valores médio e instantâneo das variáveis do statechart poderão ser observados pelo usuário. 
O comando "FOR STEP 30 EACH 30 STEPS DO" fará com que a partir do passo 30 , a cada 30 passos da simulação, mensagens com o número de vezes que o servidor 2 foi ativado e desativado sejam impressas no relatório de passos da simulação e que os valores médio e instantâneo das variáveis de controle possam ser observados pelo usuário.

O comando "AT STEP 40" especifica que se no passo 40 da simulação, o servidor 2 ainda não estiver trabalhando, este será ativado independente do número de clientes na fila de espera.

Um ponto que deve ser considerado na análise do programa "Fila.lce" é que as distribuiçōes especificadas para os eventos "g", "lib1" e "lib2" não foram extraídas de dados estatísticos reais, mas sim especificadas com o intuito de ilustrar a utilização de uma das distribuições probabilísticas existentes na LCE.

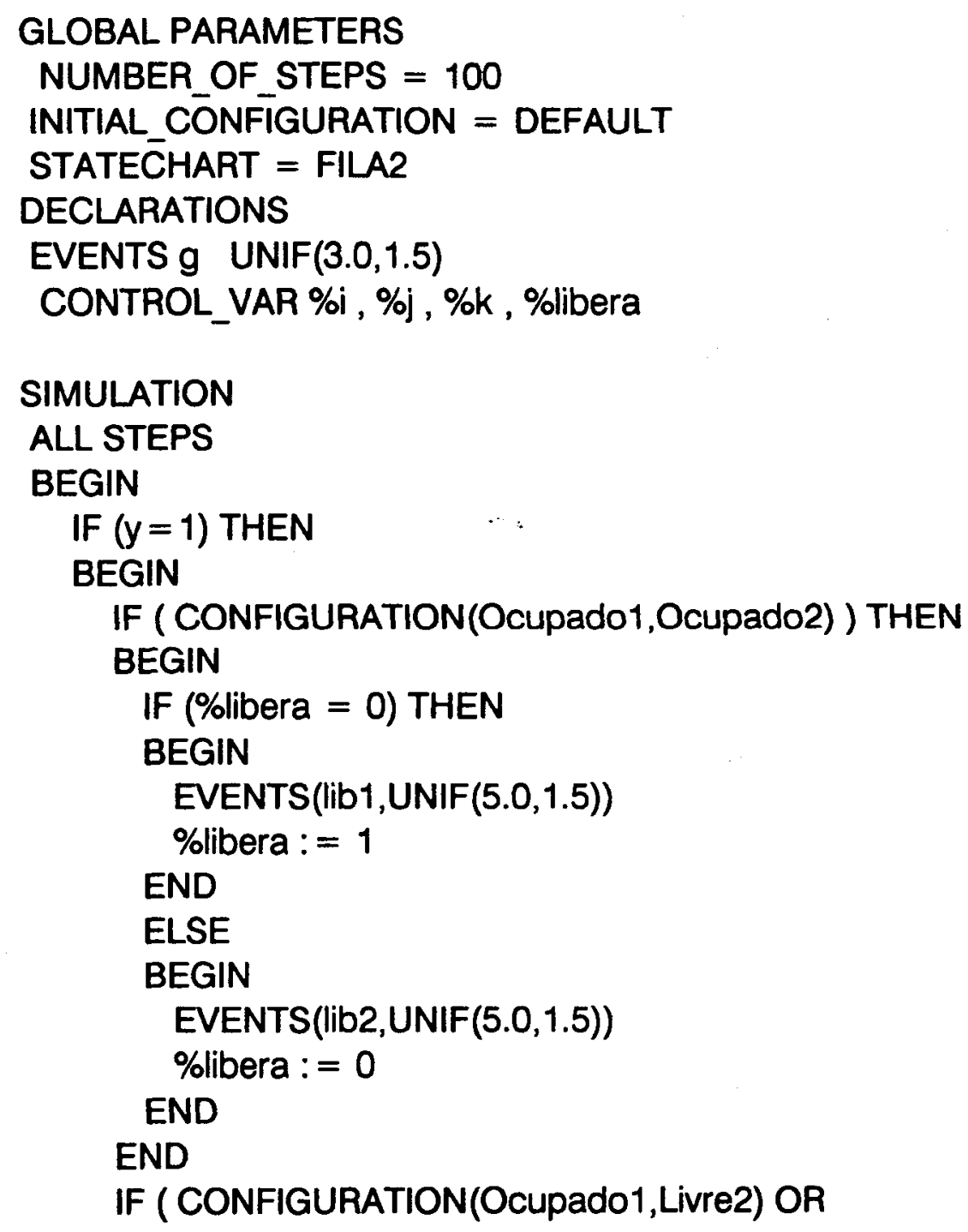




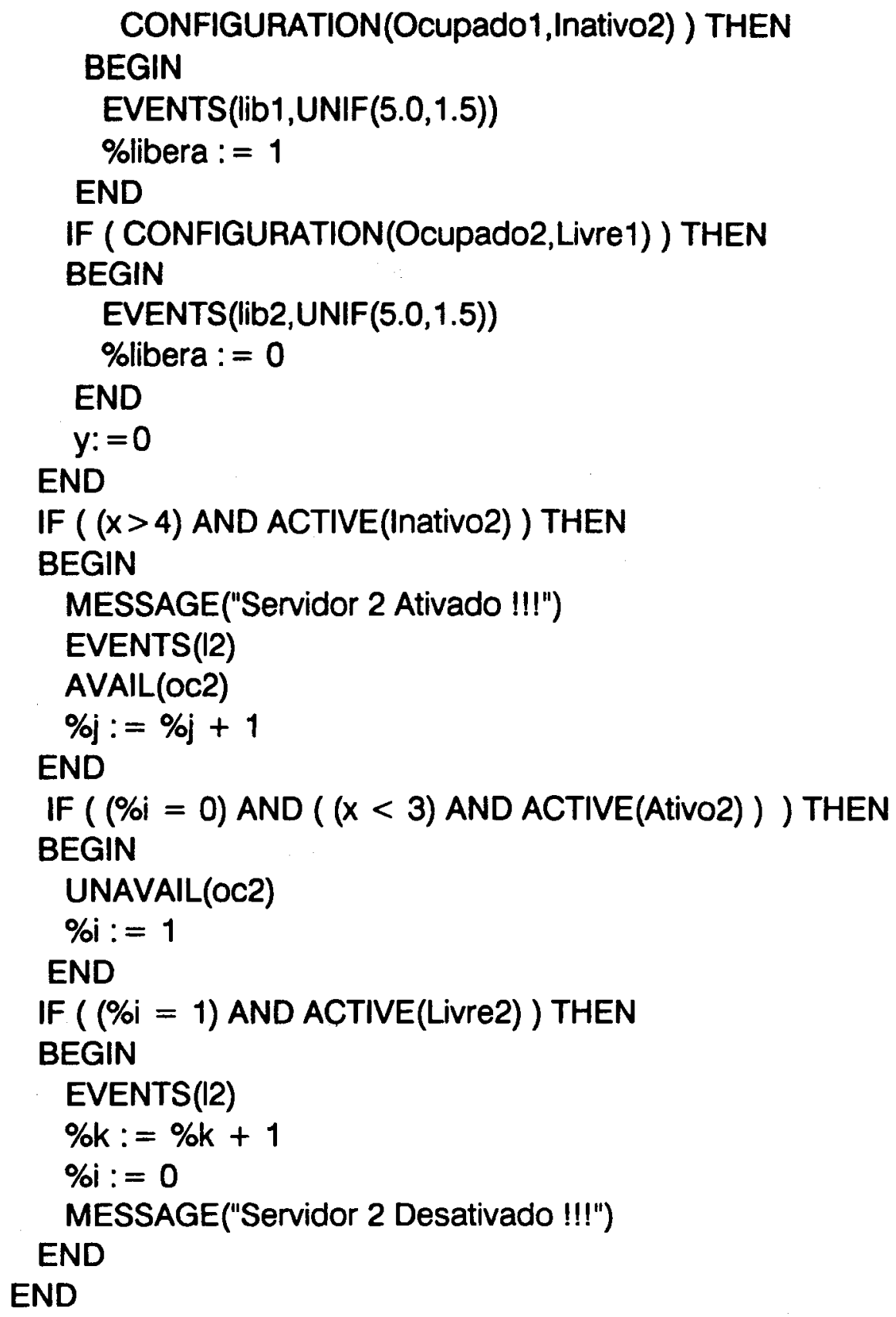




\begin{tabular}{|c|c|c|}
\hline Passo/Eventos & Passo/Eventos & Passo/Eventos \\
\hline 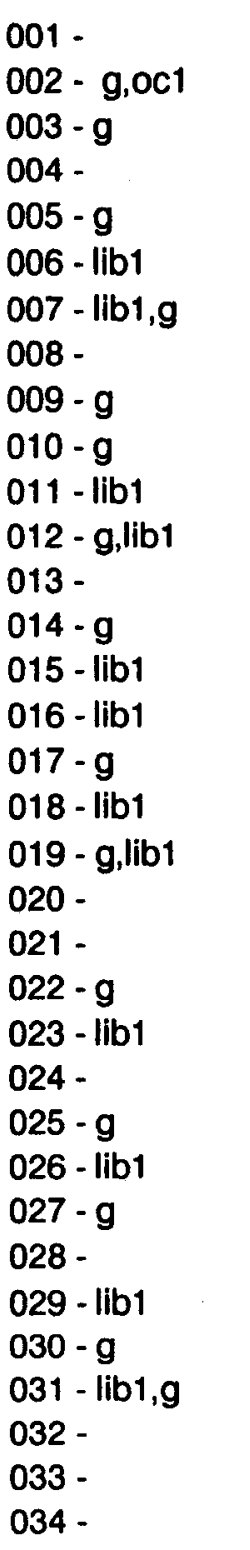 & 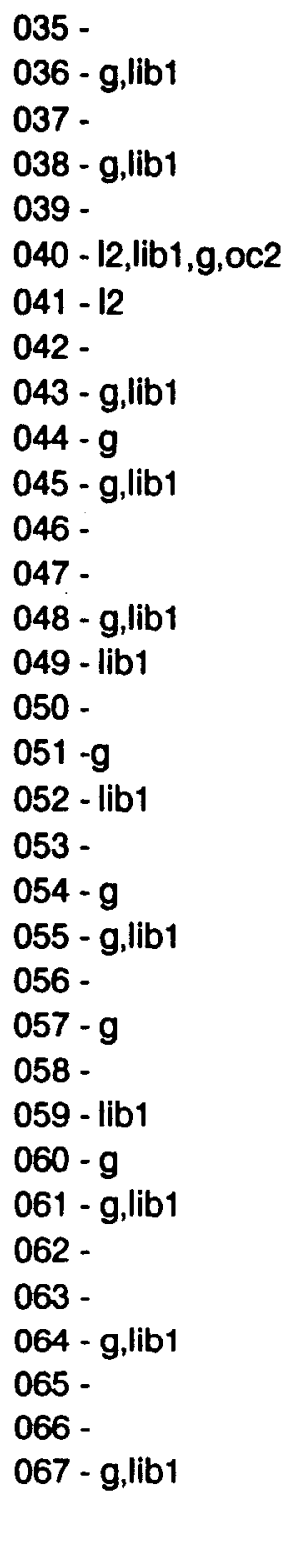 & $\begin{array}{l}068 \text { - lib1 } \\
069 \text { - } \\
070 \text { - g } \\
071 \text { - lib1 } \\
072 \text { - g } \\
073 \text { - } \\
074 \text { - lib1 } \\
075 \text { - g } \\
076 \text { - } \\
077 \text { - lib1 } \\
078 \text { - g } \\
079 \text { - g,lib1 } \\
080 \text { - } \\
081 \text { - } \\
082 \text { - g } \\
083 \text { - g } \\
084 \text { - lib1,12 } \\
085 \text { - } \\
086 \text { - g,0c2 } \\
087 \text { - } \\
088 \text { - g,lib1 } \\
089 \text { - } \\
090 \text { g,lib2 } \\
091 \text { - } \\
092 \text { - } \\
093 \text { - g,lib1 } \\
094 \text { - } \\
095 \text { - lib2 } \\
096 \text { - g } \\
097 \text { - lib1 } \\
098 \text { - } \\
099 \text { - g } \\
100 \text { - lib2 }\end{array}$ \\
\hline
\end{tabular}

Tabela 4.1 - Eventos gerados pela LCE 


\subsection{3 - O Relatório Estatístico}

O relatório de saída estatístico da "Execução Programada" exibido a seguir foi gerado pela execução do programa fonte "Fila.lce", o qual controla a execução do statechart que modela a fila de atendimento descrita na Seção 4.5.1 deste trabalho.

Os primeiros resultados a serem exibidos no relatório, depois do nome do statechart e do número total de passos, são os resultados referentes aos estados. Para cada estado tem-se: o percentual de passos em que o estado esteve ativo; a situação final do estado (ligado ou desligado); e o número médio de passos consecutivos no estado (que indica, por exemplo, o número médio de passos que cada cliente utilizou o servidor, ou o número médio de passos em que não houve a chegada de um cliente).

Os eventos são analisados através do número de vezes que foram gerados e do número de passos em que estiveram disponíveis. Pois como foi visto, é possível que um evento se torne indisponível através do comando "UNAVAIL(eventos)" da LCE.

A análise das transições é feita pela exibição do número de vezes que a transição foi disparada e do número de vezes que foi avaliada. A comparação destes números dá o percentual de disparo por avaliação da transição.

Os últimos resultados a serem apresentados no relatório estatístico são os valores médio e final das variáveis. $O$ valor médio da variável " $x$ " no modelo de fila corresponde ao número médio de clientes na fila de espera.

O exemplo do relatório estatístico do modelo de fila é apresentado a seguir. 
STATECHART: FILA2

NUMBER OF STEPS: 100

$\begin{array}{llll}\text { STATE } & \text { PERCENTAGE OF STEPS IN } & \text { FINAL } & \text { AVERAGE NUMBER OF } \\ & \text { WHICH WAS ACTIVE } & \text { SITUATION } & \begin{array}{l}\text { CONSECUTIVE STEPS IN } \\ \text { THIS STATE }\end{array}\end{array}$

$\begin{array}{llll}\text { Fila } & 100.00 & \text { on } & 2.2791 \\ \text { Inatlvo1 } & 0.00 & \text { off } & 0.0000 \\ \text { Inativo2 } & 83.00 & \text { off } & 40.5000 \\ \text { Livre1 } & 2.00 & \text { off } & 1.0000 \\ \text { Livre2 } & 3.00 & \text { off } & 0.5000 \\ \text { Ocupado1 } & 98.00 & \text { on } & 2.7647 \\ \text { Ocupado2 } & 14.00 & \text { on } & 4.3333\end{array}$

$\begin{array}{ll}\text { EVENT S } & \text { NUMBER OF STEPS IN WHICH } \\ & \text { THIS EVENT HAPPENED }\end{array}$

PERCENTAGE OF STEPS IN WHICH THIS EVENT WAS AVAILABLE

\begin{tabular}{lc} 
I1 & 0 \\
12 & 3 \\
lib1 & 39 \\
oc1 & 1 \\
lib2 & 3 \\
oc2 & 2 \\
g & 43 \\
\hdashline TRANSITIONS & NUMBER OF STEPS IN \\
& WHICH THIS TRANSITION \\
& WAS FIRED
\end{tabular}

g[cr(in(Livre2))]/oc2

g[cr(in(Ocup1) and in... 2

g[cr(in(Livre1))]/oc1

35

$\mathrm{g}[\mathrm{cr}$ (in(Ocup1) and in...

lib2 $[\operatorname{cr}(x=0)]$

oc2

$\operatorname{lib} 2[\operatorname{cr}(x 0)] / x:=x-1$

lib1 $[\operatorname{cr}(x=0)]$

oc1

lib1 $[\mathrm{cr}(\mathrm{x} 0)] / \mathrm{x}:=\mathrm{x}-1$

12

12

11

11

\begin{tabular}{lc}
\hline VARIABLE & AVERAGE VALUE \\
$x$ & 2.3000 \\
$y$ & 0.4300
\end{tabular}
100.00
100.00
100.00
100.00
100.00
57.00
100.00

NUMBER OF STEPS IN

WHICH THIS TRANSITION

RATE OF

FIRING

WAS EVALUATED

SUCESS

4.65

81.40

2.33

11.63

0.00

100.00

100.00

0.00

100.00

87.18

100.00

100.00

0.00

0.00
FINAL VALUE

3

0 
O Relatório Estatístico, como visto acima, é utilizado para dar uma visão geral de certas estatísticas do sistema modelado. Mesmo quando o sistema não necessita de uma análise estatística, o relatório se constitui em um resumo da simulação, ou seja, nele pode-se ver se um evento foi gerado um número correto de vezes, se uma transição em que a condição sempre deveria ser verdadeira foi disparada $100 \%$ das vezes que foi avaliada, etc. Estes números podem ajudar a detectar certos erros na especificação do statechart. Um exemplo de erro encontrado com a utilização da LCE é o statechart do manipulador de mouse (Apêndice B), o qual possui o erro descrito a seguir.

Suponha que o statechart em questão possua a configuração \{Four,None,Receive\} e que os eventos "top" e "click" tenham sido gerados. Então no componente "Tops_number" a transição de rótulo "top/rst" será disparada. No componente "Clicks_number" duas transições serão possíveis: "rst/none" e "click". Como as duas transiçōes são inconsistentes entre si, somente uma poderá ser disparada (a escolha é aleatória). Se a transição de rótulo "click" for disparada, então terão ocorridos cinco tops e nenhum dos sinais "none", "single" ou "many" terá sido emitido, o que se constitui em um erro na especificação. Este erro foi encontrado analisando-se o relatório estatístico gerado pela LCE, onde se percebe que a transição de rótulo "rst/none" foi avaliada 4(quatro) vezes e só foi disparada 3(três) vezes. Uma descrição do exemplo do manipulador de mouse pode ser encontrada em [CANG92c].

\subsection{4 - O Relatório de Passos da Simulação}

Assim como foi feito com o relatório de saída estatístico da "Execuçāo Programada", o relatório de passos da simulação exibido a seguir foi gerado pela execução do programa fonte "Fila.lce".

A cada passo da execução são observados os seguintes aspectos:

- configuração dos estados ativos;

- estados ligados no passo corrente;

- estados desligados no passo corrente;

- eventos externos gerados no passo corrente;

- eventos internos gerados no passo corrente;

- valores médio e instantâneo das variáveis até o passo corrente; e 
- mensagens especificadas pelo usuário ou pelo interpretador.

O relatório de passos da simulação do modelo de fila única com dois servidores é apresentado abaixo. Deve-se notar que pelo fato do relatório ser muito extenso, somente os passos iniciais e os passos finais da simulação são apresentados.

Statechart in Simulation: FILA2

Number of Steps Simulated: 100

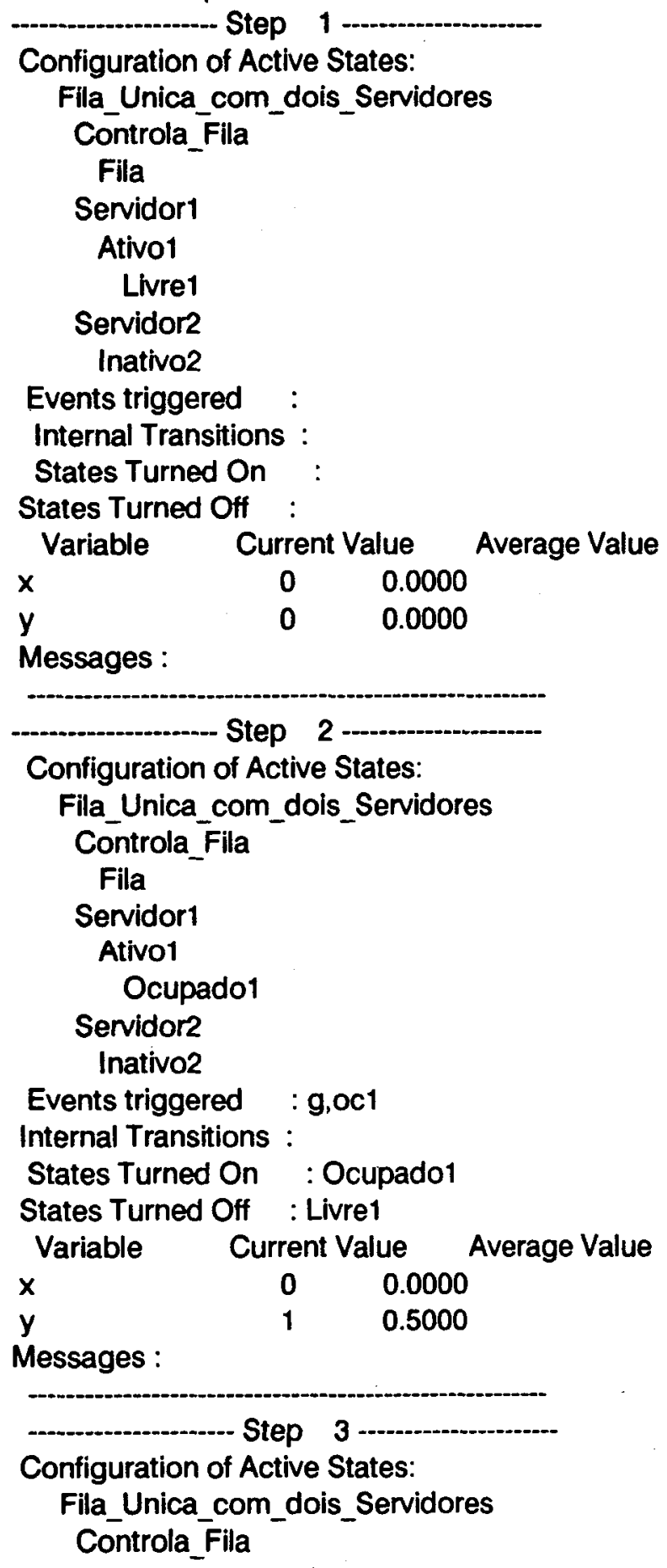


Fila

Senvidor1

Atlvo1

Ocupado1

Servidor2

Inativo2

Events triggered : $\mathrm{g}$

Internal Transitions :

States Turned On :

States Turned Off :

Variable Current Value Average Value

$\begin{array}{lll}x & 1 & 0.3333\end{array}$

$\begin{array}{lll}y & 1 & 0.6667\end{array}$

Messages:

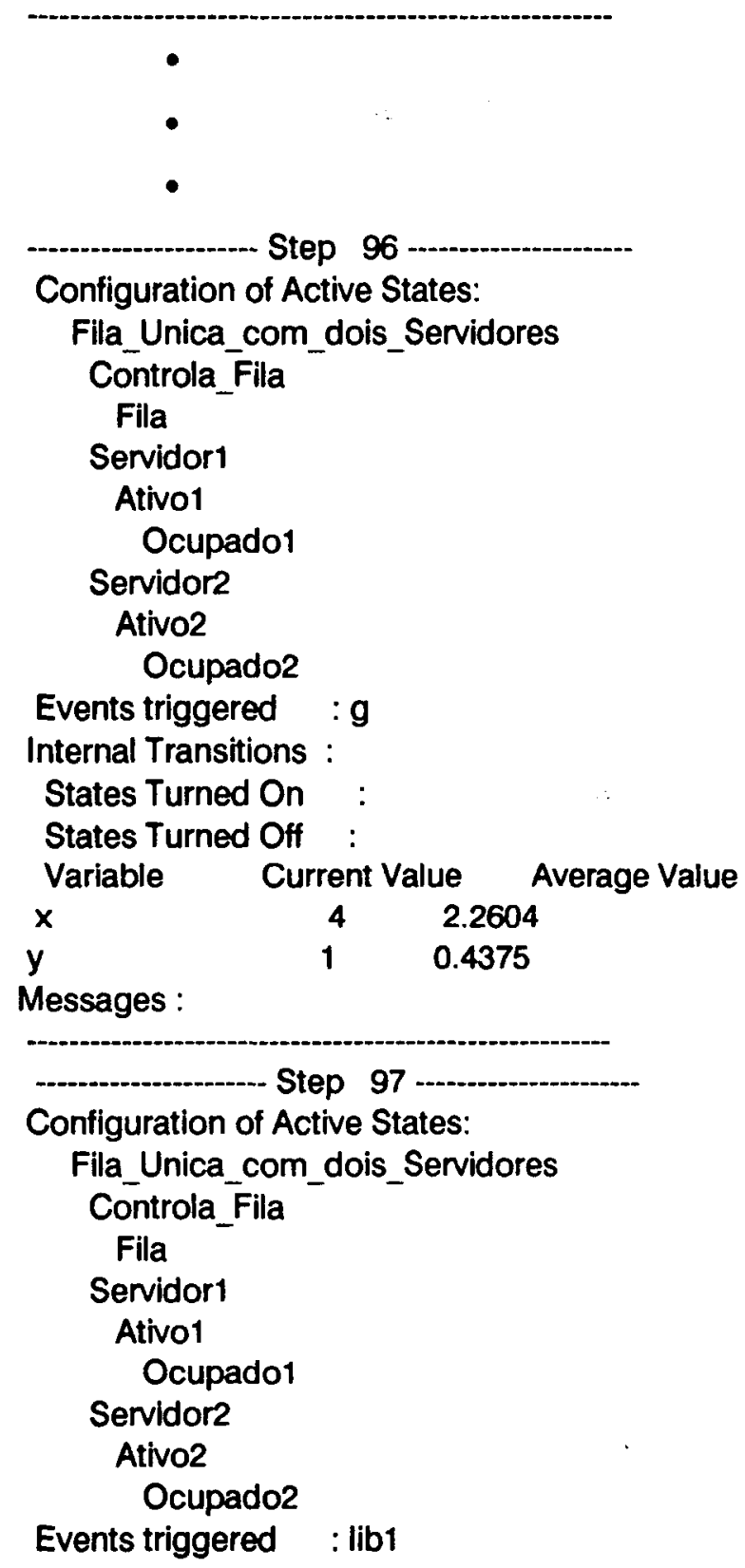

Configuration of Active States:

Fila_Unica_com_dois_Servidores

Controla Fila

Fila

Servidor1

Ativo1

Ocupado1

Servidor2

Ativo2

Ocupado2

Events triggered : $\mathbf{g}$

Internal Transitions :

States Turned On :

States Turned Off :

Variable Current Value Average Value

\begin{tabular}{ccc}
$x$ & 4 & 2.2604 \\
\hline & 1 & 0.4375
\end{tabular}

$\begin{array}{lll}x & 1 & 0.4375\end{array}$

Messages :

Step 97

Configuration of Active States:

Fila_Unica_com_dois_Servidores

Controla_Fila

Fila

Servidor1

Ativo1

Ocupado1

Servidor2

Ativo2

Ocupado2

Events triggered : lib1 


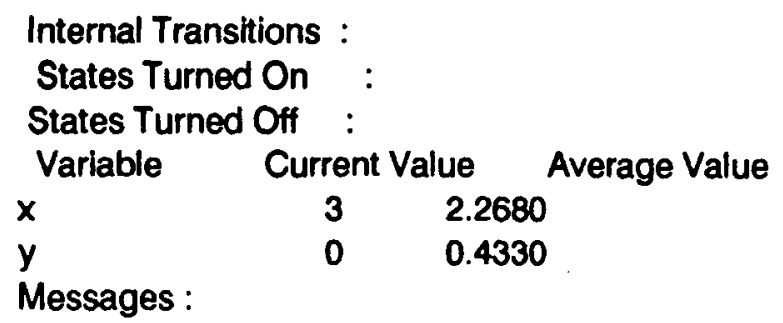

Configuration of Active States:

Fila_Unica_com_dois_Servidores

Controla_Fila

Fila

Servidor1

Ativo1

Ocupado1

Senvidor2

Ativo2

Ocupado2

Events triggered : $\mathrm{g}$

Internal Transitions :

States Turned On

States Turned Off

Variable Current Value Average Value

$\begin{array}{lll}X & 4 & 2.2929\end{array}$

$\begin{array}{lll}\mathrm{y} & 1 & 0.4343\end{array}$

Messages :

Configuration of Active States:

Fila_Unica_com_dois_Servidores 


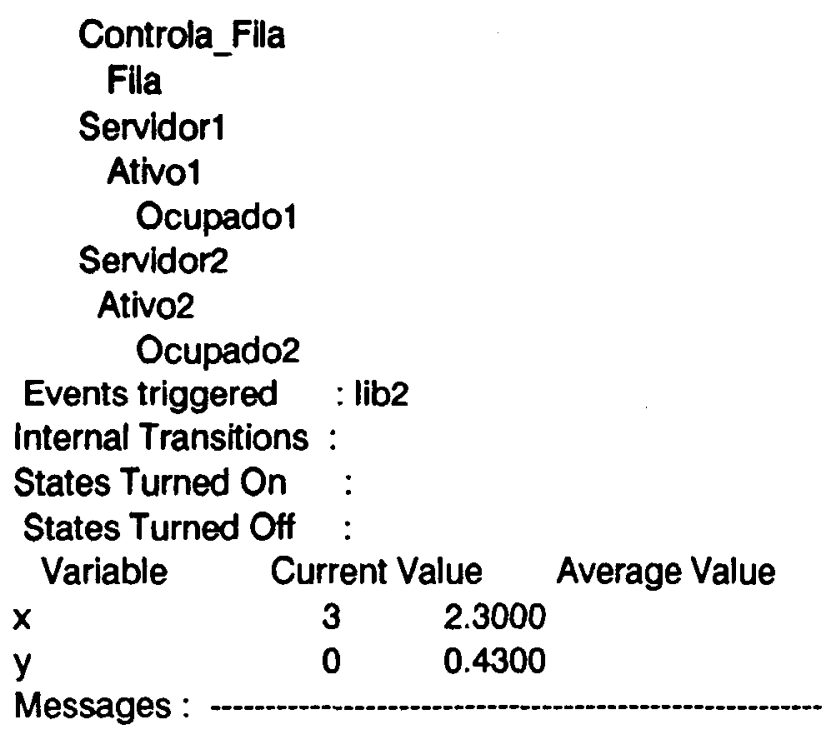

As informações contidas no relatório de passos da simulação fornecem uma visão detalhada de todos os passos de execução do statechart. Essa visão detalhada é de grande importância para análise dos modelos, pois alguns statecharts são muito grandes e complexos para serem analisados durante a simulação animada. Outro fato importante é que, em alguns casos, nem todos os estados de um statechart podem ser vistos na tela, ou seja, se um estado é decomposto em subestados em um nível abaixo na especificação, ou se analisa o nível superior, ou o nível inferior, pois o último se sobrepõe ao primeiro na maioria das vezes. No relatório de passos, o problema de visualização dos níveis não existe, pois a forma textual apresenta todos os níveis hierárquicos do sistema, sem restrições do número de níveis. Assim conclui-se que o relatório de passos pode ser utilizado para uma depuração minuciosa do statechart especificado.

\section{6 - Considerações Finais}

Neste capítulo foram apresentados os detalhes de implementação do MEP (Módulo de Execução Programada). A descrição tanto da arquitetura quanto da interface e dos detalhes de implementação do MEP foram feitas com o objetivo de posicionar o Módulo de Execução Programada (MEP) no contexto do ambiente StatSim. Primeiro no nível estrutural, pela arquitetura apresentada, segundo no nível de implementação e terceiro no nível de execução, pela descrição da interface. 
A implementação do MEP foi baseada na arquitetura que havia sido proposta para o mesmo, e na especificação da sintaxe e da semântica da LCE feitas no capítulo anterior. A arquitetura permitiu uma visualização de como o MEP deveria ser integrado ao ambiente StatSim, o que facilitou bastante essa tarefa. A definição formal da sintaxe e da semântica da LCE foram de grande importância para a fase de implementação, pois o fato da especificação estar completa e sem ambigüidades diminuiu bastante o tempo gasto na implementação e foram poucos os erros encontrados na fase de implementação.

O protótipo apresentado neste capítulo teve o objetivo de mostrar a aplicabilidade do que foi proposto no Capítulo 3 deste trabalho, ou seja, mostrar que a técnica de "Execução Programada" pode ser implementada e que pode ser utilizada para a validação e verificação de modelos, como no caso do sistema de fila única (Figura 4.10) apresentado. 


\section{Capítulo 5 Conclusão}

\section{1 - Considerações Iniciais}

Segundo Harel, ferramentas de desenvolvimento de software que não possuam capacidade de execução de modelos e de geração de código deverão desaparecer [HARE92]. Seguindo essa filosofia, neste trabalho, uma Linguagem de Controle de Execução (LCE) foi desenvolvida, baseada em técnicas e conceitos de linguagens como GPSS/H e Esterel. A Linguagem de Controle de Execução controla modelos especificados através de statecharts dentro do ambiente StatSim. Neste trabalho, também foram apresentadas e discutidas a sintaxe e a semântica da LCE, bem como sua integração ao ambiente StatSim, complementando as técnicas de execução interativa, não interativa e exaustiva. $O$ fato da $L C E$ complementar a execução interativa e não interativa pode ser facilmente deduzido analisando-se as características da LCE. Quanto ao fato da LCE complementar a execução exaustiva, isto se deve ao fato de que em muitos casos ela não pode ser aplicada, devido a restrições de tempo e de memória, podendo-se então executar o modelo através de um programa escrito em LCE e analisar os resul tados obtidos. Deve-se considerar que a "Execuçāo Programada" possui características que não são encontradas nas outras técnicas de execução de modelos, como por exemplo: a aleatoriedade com que os eventos podem ser gerados faz com que o modelo fique sujeito a situaçōes que seriam difíceis de serem previstas, o que auxilia a verificação e validação do modelo.

A LCE foi inspirada em uma linguagem encontrada no ambiente Statemate, denominada SCL (Simulation Control Language). Tal linguagem é citada em [HARE88b], 
sem se entrar em detalhes, entretanto, das suas características. Apenas sua funçāo, a de controlar a simulação de um statechart, e poucos aspectos da linguagem são descritos.

Com base na sintaxe e na semântica formalmente definidas, um interpretador para a Linguagem de Controle de Execução (LCE) foi implementado, estando inserido no MEP (Módulo de Execução Programada). O MEP foi baseado em uma arquitetura, na qual, além do interpretador da LCE, encontram-se um editor de textos para os programas fonte escritos em LCE, e geradores do relatório de passos e estatístico da simulação. Na interface do MEP, os parâmetros globais da LCE podem ser diretamente especificados.

Depois de definida a LCE e implementado um interpretador para a mesma, foram especificados alguns modelos em statecharts, e desenvolvidos programas em LCE que demostraram sua utilidade, tanto em relação à análise do sistema especificado, quanto em relação ao descobrimento de erros na especificação.

\section{2 - Contribuições do Trabalho}

O desenvolvimento da LCE teve como principal objetivo complementar as técnicas de execução de modelos existentes no ambiente StatSim, contribuindo dessa forma para ampliar o poder de validação e verificação de modelos já disponível no ambiente StatSim. Assim, a menos da geração de código, o ambiente StatSim consiste em uma ferramenta com muitos recursos para a especificação e análise do aspecto comportamental de sistemas reativos especificados através de statecharts.

Além da característica principal de controlar a execução de um modelo, a LCE possui outro aspecto importante, que são as características estatísticas da linguagem. Desta forma, a geração de eventos pode ser feita através de distribuições probabilísticas gerando-se, no final, o relatório estatístico.

Apesar de existirem linguagens similares à LCE, tal como a SCL, estas foram desenvolvidas por organizaçōes ou empresas internacionais (a SCL, por exemplo, foi desenvolvida pela i-Logix Inc.), as quais não tornam públicas as técnicas utilizadas no desenvolvimento. 


\section{3 - Sugestóes de Futuros Trabalhos}

Um dos primeiros trabalhos que pode ser realizado como extensão do projeto da LCE, é acrescentar outras características à LCE, ou seja, pode-se acrescentar mais distribuições probabilísticas para a geração de eventos; pode-se inserir a declaração e manipulação de variáveis de controle dos tipos cadeia de caracteres e ponto flutuante, além de outros comandos que são encontrados em várias linguagens de programação e de simulação. Somente com o uso da "Execução Programada" e a sua aplicação em modelos de casos reais mais diversificados, é que a necessidade de acrescentar mais comandos à LCE será realmente sentida.

A arquitetura de um sistema reativo foi apresentada na Figura 3.1. Naquela arquitetura viu-se que a LCE simula os eventos que seriam gerados pelas atividades e que o número de passos que um estado permanece ativo corresponde ao tempo que uma atividade demora para ser executada. Se um gerador de código estiver disponível, então a LCE poderá continuar a controlar a simulação, porém os eventos serão realmente gerados pelas atividades, as quais serão executadas de acordo com o código. $\mathrm{O}$ código gerado, entretanto, não representará o sistema final, mas provavelmente, estará bem mais próximo deste do que apenas a execução animada dos statecharts.

Outro ponto que pode ser explorado é o uso de linguagens similares à LCE para executar modelos em outras técnicas de especificação de sistemas reativos, ou seja, pode-se usar a LCE para controlar a execução de Máquinas de Estados Finitos e Redes de Petri,por exemplo. Porém, deve-se levar em consideração que um simulador para essas técnicas deve estar disponível para que a linguagem possa ser usada, e que, talvez, alterações na LCE deverão ser feitas para adaptá-la à semântica das Redes de Petri, das Máquinas de Estados Finitos, ou de outras técnicas. 


\section{Referências Bibliográficas}

[BANK84] BANKS, J. ; CARSON, J. S. Discrete Event System Simulation. New Jersey, Prentice-Hall, 1984.

[BANK89] BANKS, J. ; CARSON, J. S. ; SY, J. N. Getting Started with GPSS/H. Annandale, Wolverine Software Corporation, 1989.

[BATI91] BATISTA , J. E. S. Um Editor Gráfico para Statecharts. São Carlos, ICMSC-USP, 1991. (Dissertação de Mestrado)

[BERR88] BERRY, G. ; GANTHIER, G. The Esterel Synchronous Programming Language: Design, Semantics, Implementation. França, INRIA, 1988. (Rapports Techniques, 842)

[BOAV92] BOAVENTURA, I. A. G. Propriedades Dinâmicas de Statecharts. São Carlos, ICMSC-USP, 1992. (Dissertação de Mestrado)

[BOUS91] BOUSSINOT, F. ; SIMONE, R. D. The Esterel Language. Proceedings of the IEEE, v. 79, n. 9, p.1293-303, 1991.

[BUDK87] BUDKOWSKI, S. ; DEMBINSKI, P. An Introduction to Estelle: A Specification Language for Distributed Systems. Computer Networks and ISDN Systems, v. 14, p.3-23, 1987.

[BURN91] BURNS, A. Scheduling Hard Real Time System: a review. Software Engineering Journal, v. 14, n. 3, p. 116-28, 1991. 
[CANG92a] CANGUSSU, J. W. L.; MASIERO, P., C. Uma Linguagem para Execução Programada de Statecharts. In: Seminário Integrado de Software e Hardware, 19, Rio de Janeiro, 1992. Anais. Rio de Janeiro, SBC, p. 229-42, 1992.

[CANG92b] CANGUSSU, J. W. L. ; MASIERO, P. C. Sintaxe e Semântica da Linguagem de Controle de Execução. São Carlos, ICMSC-USP, 1992. (Relatório Técnico)

[CANG92c] CANGUSSU, J. W. L. Execução Programada de Statecharts. São Carlos, ICMSC-USP, 1992. (Exame de Qualificação)

[COUT91] COUTINHO, J. A.; et al. Uma Especificação e Simulação de FMS Através de Statecharts. Documento Pessoal, 1992.

[EliA92] ELIAS, V. G. S. ; LIESENBERG, H. Debugging Aids for Statecharts-Based Systems. Campinas, UNICAMP-DCC, 1992. (Relatório Técnico)

[FISC88] FISCHER, C. N.; LEBLANC, R. J. Crafting A Compiler. California, The Benjamin/Cummings Publishing Company, 1988.

[FORT91] FORTES, R. P. M. Uma Ferramenta de Apoio à Utilização de Statecharts para Especificação do Comportamento de Sistemas de Tempo Real Complexos. São Carlos, ICMSC-USP, 1991. (Dissertação de Mestrado)

[FORT91a] FORTES, R. P. M.; MASIERO, P. C. Uma Linguagem para Especificação de Statecharts e seu Analisador. São Carlos, ICMSC-USP, 1991. (Documento de Trabalho). 
[FURU92a] FURUUTI, R.; MASIERO, P., C. Extensões ao Ambiente StatSim para permitir a Simulação de Micro-Passos. São Carlos, ICMSC-USP, Março 1992. (Relatório CNPq)

[FURU92b] FURUUTI, R.; MASIERO, P., C. Extensões ao Ambiente StatSim para permitir a Simulação de Micro-Passos. São Carlos, ICMSC-USP, Setembro 1992. (Relatório CNPq)

[HARE87] HAREL, D. Statecharts: On the Formal Semantics of Statecharts. In: Proceedings of the 2nd IEEE Symposium on Logic in Computer Science, Ithaca, N. Y., p.54-64, 1987.

[HARE88a] HAREL, D. On Visual Formalism. Communications of the ACM, v.31 n. 5, p. 514-30, 1988.

[HARE88b] HAREL, D.; et al. STATEMATE: A Working Environment for the Development of Complex Reactive Systems. In: Proceedings of the Tenth International Conference on Software Engineering, Singapore, 1988, Washington, IEEE, 1988.

[HARE92] HAREL, D. Biting the Silver Bullet - Toward a Brighter Future for System Development. IEEE Computer, v. 25, n. 1, p. 8-20, 1992.

[HOOM91] HOOMAN, J. J. M.; RAMESH, S. ; ROEVER, W. P. A Compositional Axiomatization of Statecharts. (To appear in Theoretical Computer Science)

[HUIZ91] HUIZING, C.; ROEVER, W., C. Introduction design choices in the semantics of Statecharts. Information Processing Letters, v. 37, p.205-13, 1991. 
[JENS87] JENSEN, K. Computer Tools for Construction, Modification, and Analisys of Petri Nets. In: Hannef, B. Advances in Petri Nets, Il. New York, Springer, p. 4-19, 1987. (Lecture Notes in Computer Science, 255)

[LAW82] LAW, A. ; KELTON, W. D. Simulation Modeling and Analysis. USA, McGraw-Hill, 1982.

[MARA89] MARANINCHI, F. Argonaute: Graphical Description, Semantics and Verification of Reactive Systems by Using a Process Algebra. In: SIFAKIS, J. Automatic Verification Methods for Finite State Systems. Berlin, Springer, p. 38-53, 1989. (Lectures Notes in Computer Science, 407)

[MASI91] MASIERO,P. C.; FORTES, R. P. M. ; BATISTA, J. E. S. Edição e Simulação do Aspecto Comportamental de Sistemas de Tempo Real. In: Seminário Integrado de Software e Hardware, 18, Santos 1991. Anais. Santos, SBC, p.45-61, 1991.

[MILN80] MILNER, R. A calculus of communicating systems. LNCS 92, Springer-Verlag, 1980.

[SCHR91] SCHRIBER, T. J. An Introduction to Simulation Using GPSS/H. USA, John Wiley, 1991.

[SWAI91] SWAIN, J. Simulation Software Survey. OR/MS Today, v. 18, n. 5, p. 81-102, 1991.

[TUTU91] TUTUMI, R.; MASIERO, P. C. Simulação Visual de Statecharts. In: X Congresso de Iniciação Científica e Tecnológica em Engenharia, São Carlos 1991. Anais. São Carlos, CICTE, p.669, 1991. 
[TUTU92] TUTUMI, R.; ISHIY, S. Y. Implementação de um Editor Gráfico para Diagramas de Atividades. São Carlos, ICMSC-USP, 1992. (Relatório CNPq)

[WANG88] WANG, Y. A Distributed Specification Model and its Prototyping. IEEE Trans. Software Engineering, v. 14, n. 8, p.1090-7, 1987

[WING90] WING, J. M. A Specifier's Introduction to Formal Methods. IEEE Computer, p. 8-22, September 1990.

[ZAVE86] ZAVE,P. ; SCHELL, W. Salients Features of an Executable Specification Language an Its Environment. IEEE Trans. Software Engineering, v. 12, n. 2, p.312-25, 1986. 


\section{Apêndice A}

\section{BNF da Linguagem de Controle de}

\section{Execução (LCE)}

LCE $::=[<$ aspectos gerais $>][<$ declaracoes $>]<$ controle_simulacao $>$

$<$ aspectos gerais $>::=$ GLOBAL PARAMETERS $[<$ passos $>$ ] [<modo $>$ ] $[<$ tipo $>][<$ config_inicial $>][<$ modelo $>]$

$<$ passos $>::=$ NUMBER_OF_STEPS $=<$ natural $>$

$<$ modo $>::=$ SIMULATION_RESULT = VISUAL $\mid$ TEXT $\mid$ COMPLETE

$<$ tipo $>::=$ SIMULATION_TYPE $=$ CONTROLLED $\mid$ FREE

$<$ config_inicial $>]::=$ INITIAL_CONFIGURATION $=$

( DEFAULT | < configuracao >)

$<$ modelo $>::=$ STATECHART $=<$ arquivo $>$

$<$ declaracoes $>::=$ DECLARATIONS < declara eventos $>$

[ $<$ dec_var_controle $>$ ]

$<$ dec_var_controle $>::=$ CONTROL_VAR $<$ lista_var_controle $>$

$\{$ CONTROL_VAR $<$ lista_var_controle $>$ \} 


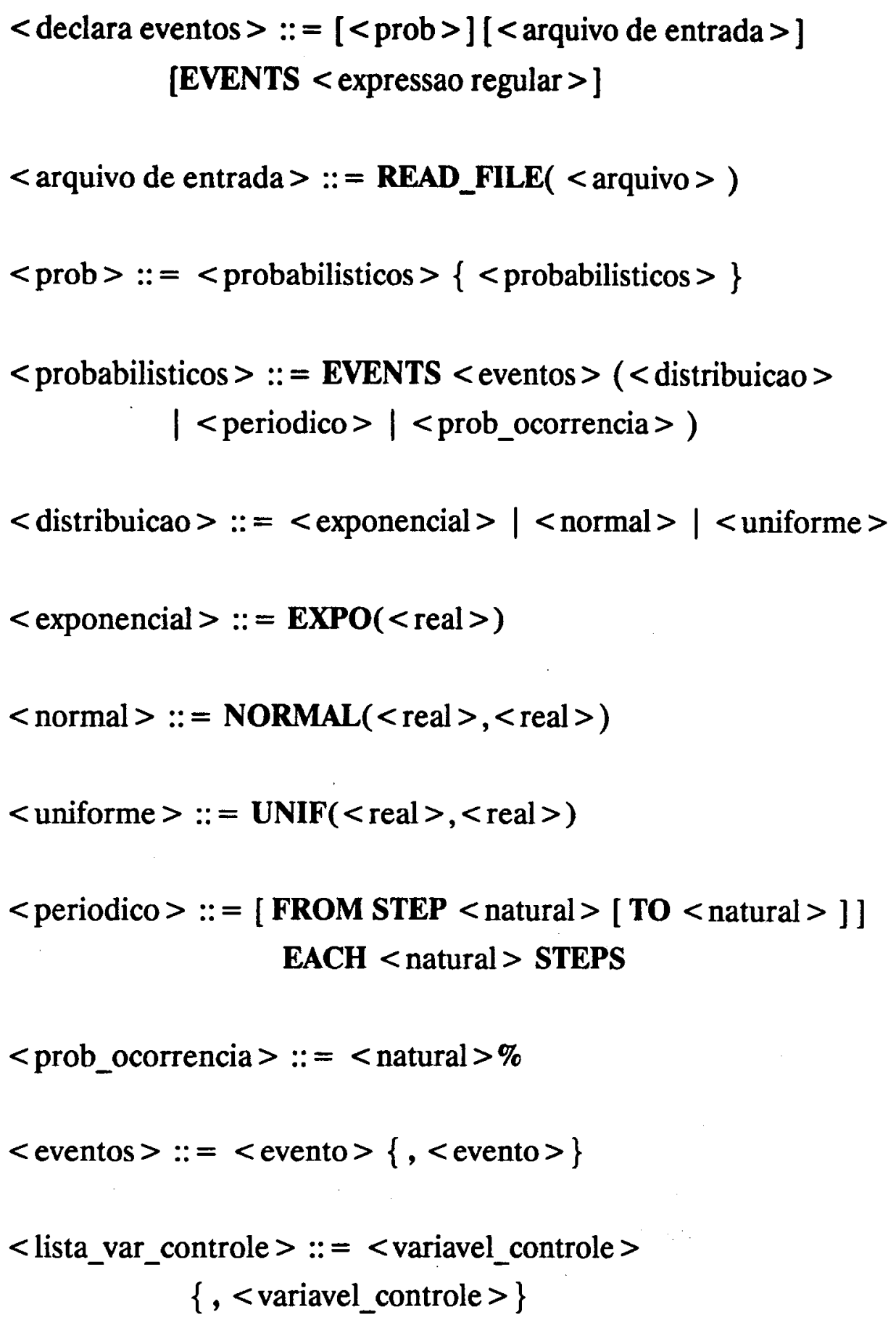




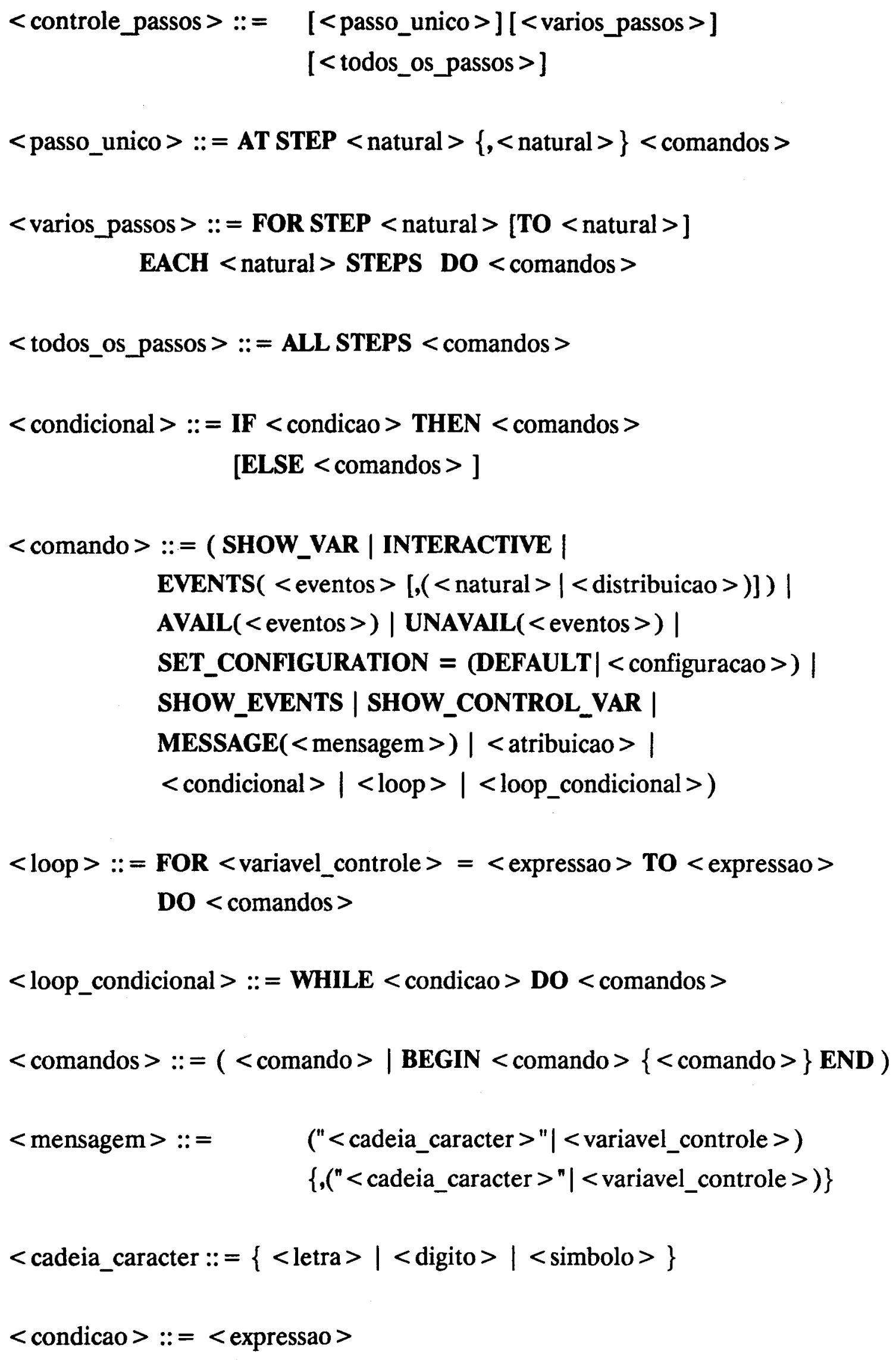




$$
\begin{aligned}
& <\operatorname{expressao}>::=<\operatorname{expS}>[(=|>|<|<=|>=\mid<>)<\operatorname{expS}>] \\
& <\operatorname{expS}>::=<\text { termo }>\{(+|-| \text { or })<\text { termo }>\} \\
& <\text { termo }>::=<\text { fator }>\{(*|/| \text { and })<\text { fator }>\} \\
& <\text { fator }>::=\text { ACTIVE }(<\text { estado }>) \text { | CONFIGURATION }<\text { configuracao }>\text { | } \\
& <\text { variavel }>\text { | < variavel_controle }>\text { | <inteiro > } 1 \\
& \text { NOT }<\text { fator }>\mid(<\text { expressao }>) \\
& <\text { atribuicao }>::=(<\text { variavel }>\mid<\text { variavel_controle }>) \\
& :=<\text { expressao }> \\
& <\text { configuracao }>::=\text { (<estado_or }>1<\text { estado_and }>1 \\
& <\text { estados_atomicos }>)\{,<\text { configuracao }>\} \\
& \text { <estado_and }>::=[(<\text { estado_or }>\mid<\text { etados_atomicos }>) \\
& \{,(<\text { estado_or }>\mid<\text { estados_atomicos }>)] \\
& <\text { estado_or }>::=(<\text { configuracao }>) \\
& <\text { estados_atomicos }>::=<\text { estado }>\{,<\text { estado }>\} \\
& <\text { identificador }>::=<\text { letra }>\left\{<\text { digito }>\mid<\text { letra }>\left.\right|_{-}\right\} \\
& <\text {natural }>::=<\text { digito }>\{<\text { digito }>\} \\
& <\text { arquivo }>::=<\text { letra }>\left\{<\text { digito }>\mid<\text { letra }>|\cdot|_{-}\right\} \\
& <\text {variavel_controle }>::=\%<\text { identificador }> \\
& <\text { real }>::=[+\mid-]<\text { natural }>[.<\text { natural }>] \\
& <\text { inteiro }>::=[+\mid-]<\text { natural }>
\end{aligned}
$$




$$
\begin{aligned}
& <\text { evento }>::=<\text { identificador }> \\
& <\text { estado }>::=<\text { identificador }> \\
& <\text { variavel }>::=<\text { identificador }> \\
& <\text { digito }>::=(0|1| 2|3| 4|5| 6|7| 8 \mid 9) \\
& <\text { simbolo }>::=\quad,|\cdot| ;|,|[\mid]|<|>|?| /|:| n \mid\{\mid \\
& \}|\backslash|||=|+| \cdot I_{-}|(\mid)| *|\&| \wedge|\%| \\
& \$ 1 \# 1 @ 1 \text { ! } \\
& <\text { letra }>::=<\text { maiuscula }>\mid<\text { minuscula }> \\
& <\text { maiuscula }>::=\text { A }|\mathbf{B}| \mathbf{C}|\mathbf{D}| \mathbf{E}|\mathbf{F}| \mathbf{G}|\mathbf{H}| \mathbf{I}|\mathbf{J}| \mathbf{K} \mid \mathbf{L} \text { | } \\
& M|N| O|P| Q|R| S|T| U|V| W|X| \\
& \mathbf{Y} \mid \mathbf{Z} \\
& <\text { minuscula }>::=\mathbf{a}|\mathbf{b}| \mathbf{c}|\mathbf{d}| \mathbf{e}|\mathbf{f}| \mathbf{g}|\mathbf{h}| \mathbf{i}|\mathbf{j}| \mathbf{k}|\mathbf{l}| \\
& m|n| o|p| q|r| s|t| u|v| w|x| \\
& \mathbf{y} \mid \mathbf{z}
\end{aligned}
$$




\section{Apêndice B}

\section{Exemplo 1: Manipulador de Mouse}

Este apêndice apresenta um exemplo da utilização da LCE. O statechart executado é "MOUSE_HAND", que representa um manipulador de mouse simplificado. A descrição do manipulador pode ser vista em [CANG92c].

O Apêndice B está organizado da seguinte forma: primeiro apresenta-se o statechart do manipulador de mouse e em seguida um programa escrito em LCE para controle da execução do statechart; depois são apresentados os relatórios gerados pela execução do programa, ou seja, são apresentados o relatório estatístico e os passos iniciais e finais do relatório de passos da simulação. 


\section{Especificação em Statecharts}

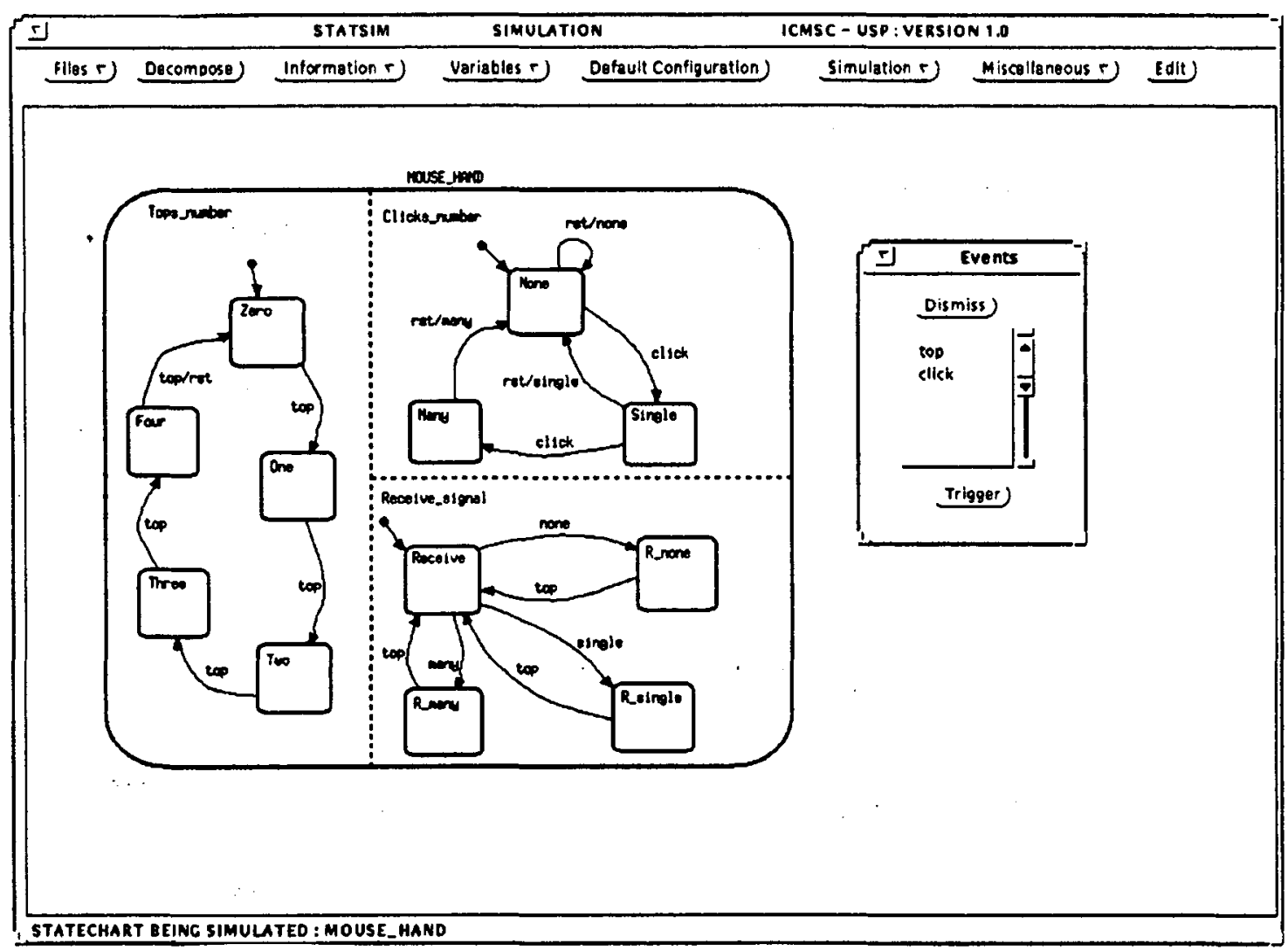




\section{Programa Fonte em LCE}

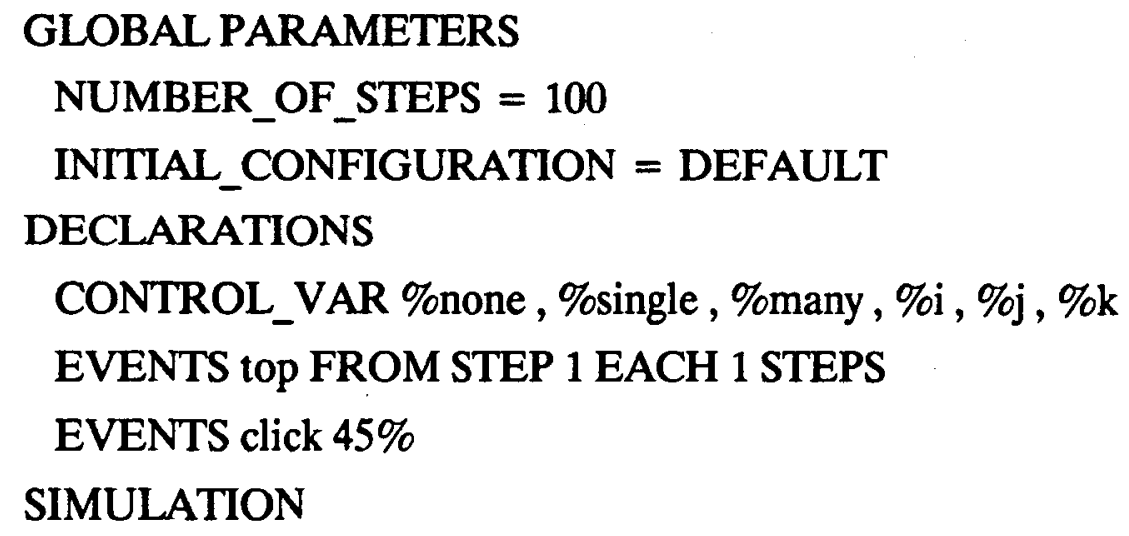

END_SIMULATION 


\section{Relatório Estatístico}

STATECHART: MOUSE_HAND

NUMBER OF STEPS: 100

\begin{tabular}{|c|c|}
\hline STATE & $\begin{array}{l}\text { PERCENTAGE OF STEPS IN } \\
\text { WHICH WAS ACTIVE }\end{array}$ \\
\hline Zero & 20.00 \\
\hline One & 20.00 \\
\hline Two & 20.00 \\
\hline Three & 20.00 \\
\hline Four & 20.00 \\
\hline None & 30.00 \\
\hline Single & 35.00 \\
\hline Many & 35.00 \\
\hline Receive & 83.00 \\
\hline R_none & 1.00 \\
\hline $\mathbf{R}_{-}^{-}$single & 2.00 \\
\hline$R_{\text {Imany }}$ & 14.00 \\
\hline
\end{tabular}

FINAL AVERAGE NUMBER OF

SITUATION CONSECUTIVE STEPS IN

THIS STATE

on $\quad 0.0000$

off $\quad 0.0000$

off $\quad 0.0000$

off $\quad 0.0000$

off $\quad 0.0000$

on $\quad 0.7222$

off $\quad 1.0588$

off $\quad 1.3333$

off $\quad 3.6111$

off $\quad 0.0000$

off $\quad 0.0000$

on $\quad 0.0000$

EVENT S NUMBER OF STEPS IN WHICH THIS EVENT HAPPENED

\begin{tabular}{ll} 
none & 1 \\
top & 100 \\
single & 2 \\
many & 15 \\
click & 48 \\
rst & 20 \\
\hline
\end{tabular}

TRANSITIONS

NUMBER OF STEPS IN WHICH THIS TRANSITION WAS FIRED

top/rst

top

top

top

top

rst/none

rst/many

rst/single

click

click

top

many

top

20
20
20
20
20
1
15
2
15
17
14
15
2

PERECENTAGE OF STEPS IN WHICH THIS EVENT WAS AVAILABLE
100.00
100.00
100.00
100.00
100.00
100.00

\section{NUMBER OF STEPS IN \\ WHICH THIS TRANSITION \\ WAS EVALUATED \\ RATE OF \\ FIRING \\ SUCESS}

100.00

100.00

100.00

100.00

100.00

100.00

100.00

50.00

100.00

94.44

100.00

100.00

100.00 
single

top

none

2

1

1

100.00

100.00

100.00

\section{VARIABLE AVERAGE VALUE FINAL VALUE




\title{
Relatório de Passos da Simulação
}

\author{
Statechart in Simulation: MOUSE_HAND \\ Number of Simulated Steps: 100 \\ Step 1 \\ Configuration of Active States:

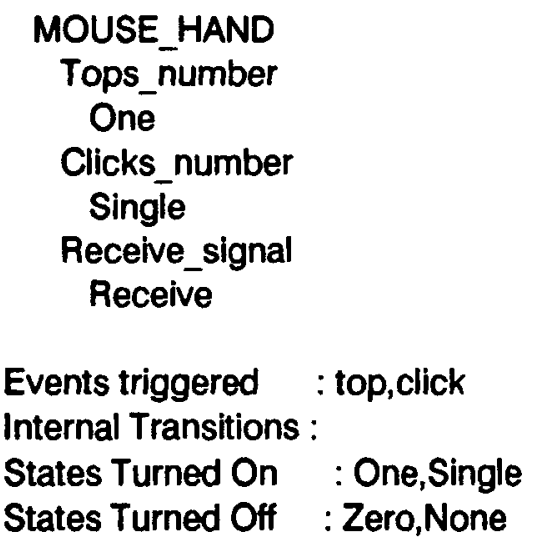 \\ Variable Current Value Average Value \\ Messages : \\ Step
}

Configuration of Active States:

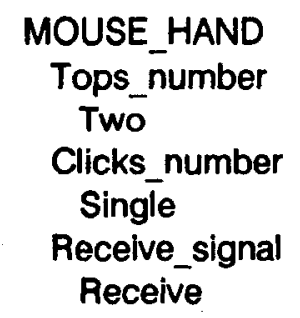

Events triggered : top

Internal Transitions :

States Turned On : Two

States Turned Off : One

Variable Current Value Average Value

Messages :

Step 3 
Configuration of Active States:

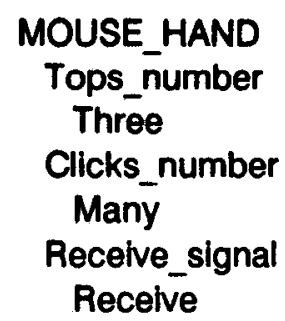

Events triggered : click,top

Internal Transitions :

States Turned On : Many,Three

States Turned Off : Single,Two

Variable Current Value Average Value

Messages :

Step 97

Configuration of Active States:

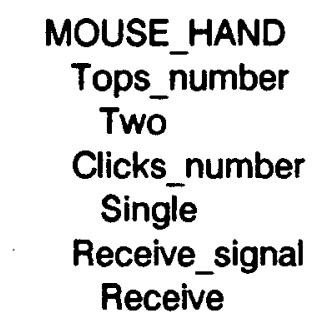

Events triggered : top,click

Internal Transitions :

States Turned On : Two,Single

States Turned Off : One,None

Variable Current Value Average Value

Messages :

Step 98

Configuration of Active States:

MOUSE HAND

Tops_number

Three 
Clicks_number

Single

Recelve_signal

Recelve

Events triggered : top

Internal Transitions :

States Turned On : Three

States Turned Off : Two

Variable Current Value Average Value

Messages :

Step 99

Configuration of Active States:

MOUSE_HAND

Tops_number

Four

Clicks_number

Many

Receive_signal

Receive

Events triggered : top,click

Internal Transitions :

States Turned On : Four,Many

States Turned Off : Three,Single

Variable Current Value Average Value

Messages :

Step 100

Configuration of Active States:

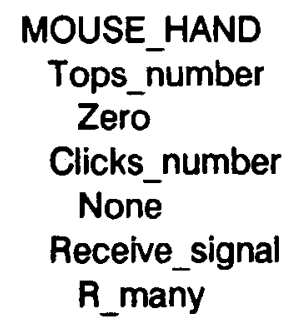

Events triggered : top,rst, many

Internal Transitions :

States Turned On : Zero,None,R_many 
States Turned Off : Four,Many,Recelve

Variable Current Value Average Value

Messages:

Numero de sinais none emitidos $=1$

Numero de sinais single emitidos $=2$

Numero de sinals many emitidos $=14$ 


\section{Apêndice C}

\section{Exemplo 2: Jantar dos Filósofos}

O exemplo de utilização da LCE apresentado neste apêndice controla a execução de um statechart, o "DINING_PHILOSOPHERS", que corresponde ao problema do jantar dos filósofos. O statechart apresentado possui o seguinte comportamento: se um dos filósofos está pensando (estados "P1",...,"P5"), por exemplo o filósofo1, e resolve comer (estados "C1",..."C5"), entāo os dois filósofos adjacentes a este, ou seja, os filósofos 5 e 2, devem estar pensando para que o filósofo1 possa comer. Se um filósofo está comendo, ele não depende dos outros filósofos para voltar a pensar.

O Apêndice C está organizado da mesma forma que o Apêndice $B$, apresentando a especificação em statechart, seguida de um programa em LCE e do relatório estatístico e relatório de passos da simulação 


\section{Especificação em Statecharts}

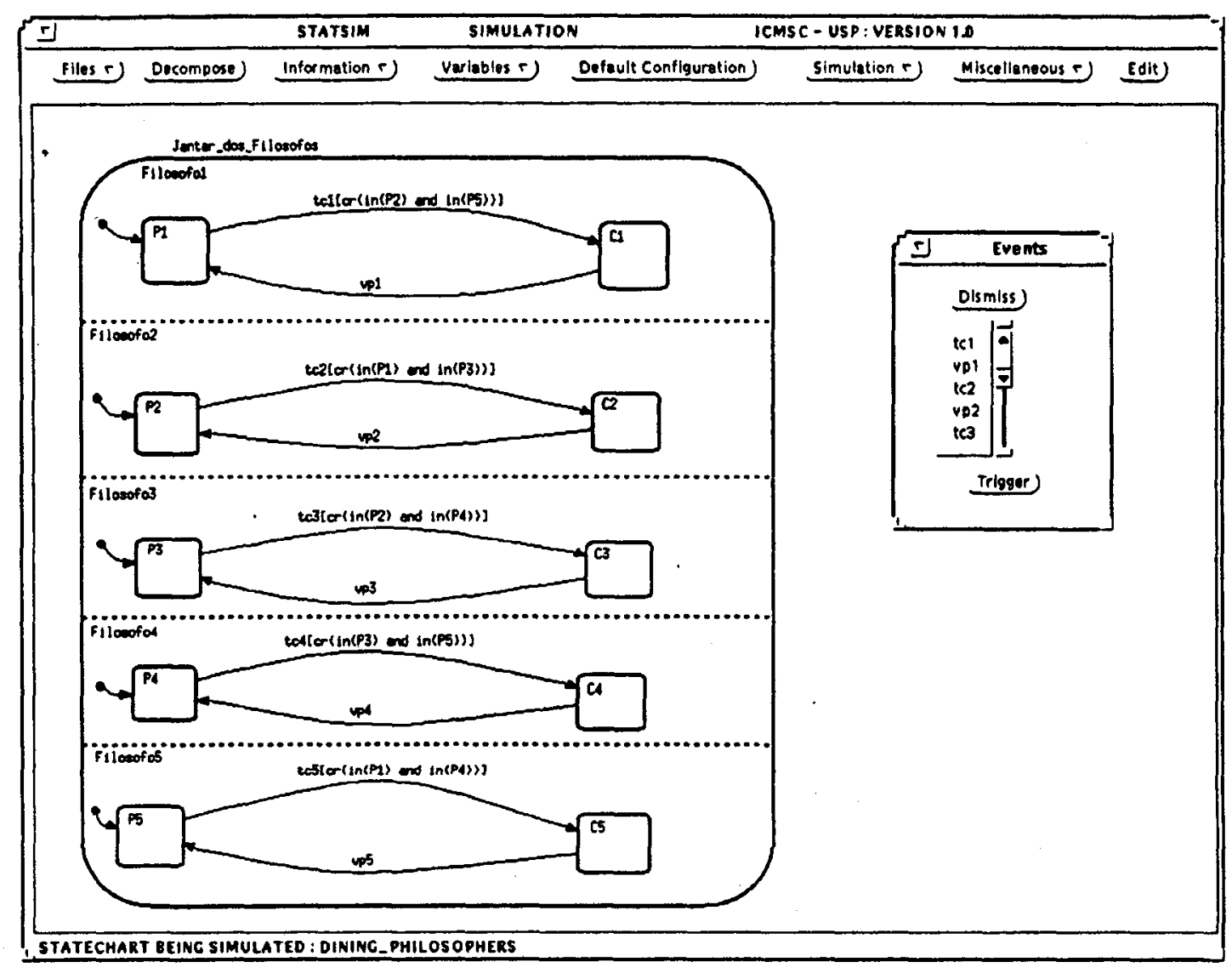




\section{Programa Fonte em LCE}

GLOBAL PARAMETERS

NUMBER_OF_STEPS $=300$

INITIAL_CONFIGURATION $=$ DEFAULT

DECLARATIONS

CONTROL_VAR \%f1, \%f2, \%f3, \%f4,\%f5

EVENTS tc1, tc3 EXPO(2.5)

EVENTS tc2, tc5 NORMAL $(4.2,0.5)$

EVENTS tc4 UNIF(4.0,1.2)

SIMULATION

ALL STEPS

BEGIN

$$
\begin{aligned}
& \text { IF }(\mathrm{fd} 1=1) \text { THEN } \\
& \text { BEGIN } \\
& \mathrm{fd} 1:=0 \\
& \% \mathrm{f} 1:=\% \mathrm{f} 1+1
\end{aligned}
$$$$
\text { EVENTS(vp1,UNIF(5.0,1.5)) }
$$

END

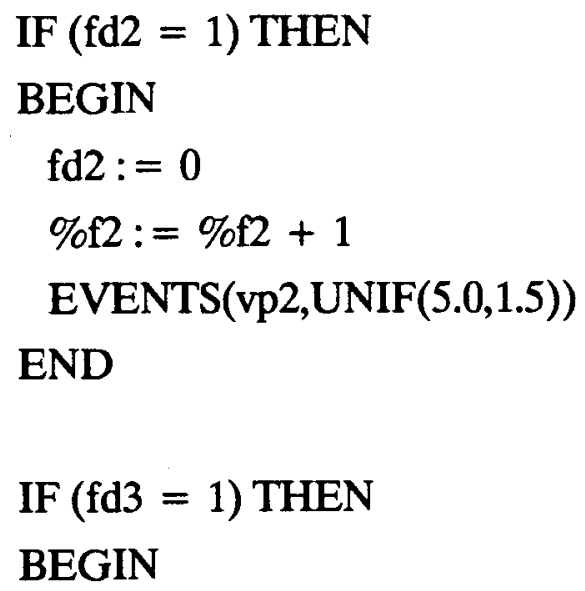




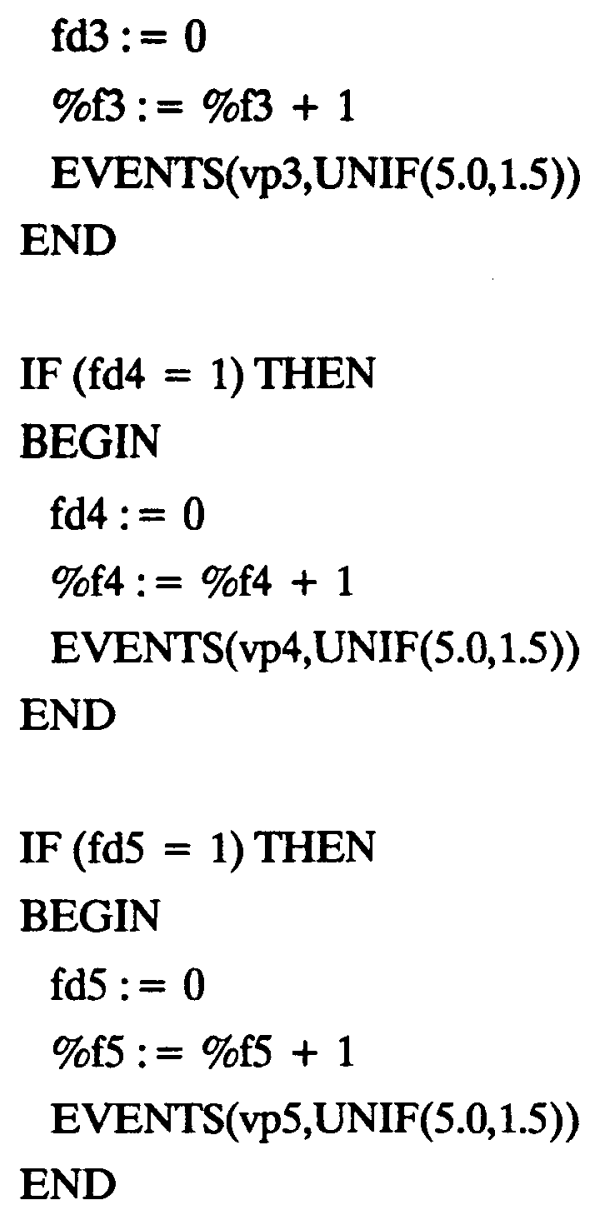

END

FOR STEP 50 EACH 50 STEPS DO SHOW_CONTROL_VAR

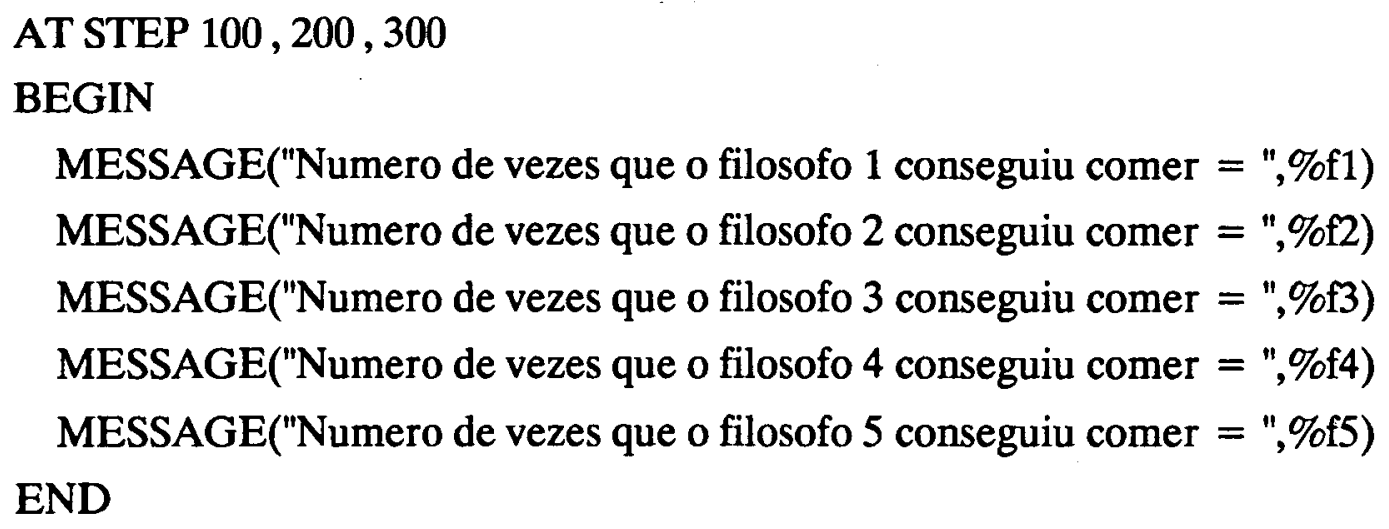

END_SIMULATION 


\section{Relatório Estatístico}

STATECHART: PHILOSOFY_DINNER NUMBER OF STEPS: 300

$\begin{array}{llll}\text { STATE } & \begin{array}{l}\text { PERCENTAGE OF STEPS IN } \\ \text { WHICH WAS ACTIVE }\end{array} & \begin{array}{l}\text { FINAL } \\ \text { SITUATION }\end{array} & \begin{array}{l}\text { AVERAGE NUMBER OF } \\ \text { CONSECUTIVE STEPS IN } \\ \text { THIS STATE }\end{array} \\ \text { P1 } & & & \\ \text { C1 } & 41.33 & \text { on } & 0.9714 \\ \text { P2 } & 58.67 & \text { off } & 4.0286 \\ \text { P5 } & 86.00 & \text { off } & 27.6667 \\ \text { P3 } & 89.33 & \text { on } & 36.5714 \\ \text { C2 } & 61.00 & \text { on } & 3.0870 \\ \text { P4 } & 14.00 & \text { on } & 4.1250 \\ \text { C3 } & 60.33 & \text { off } & 6.5417 \\ \text { C4 } & 39.00 & \text { off } & 4.0870 \\ \text { C5 } & 39.67 & \text { on } & 4.0000 \\ & 10.67 & \text { off } & 3.5714\end{array}$

EVENT S NUMBER OF STEPS IN WHICH THIS EVENT HAPPENED

$\begin{array}{ll}\text { tc1 } & 226 \\ \text { vp1 } & 35 \\ \text { tc2 } & 68 \\ \text { vp2 } & 8 \\ \text { tc3 } & 187 \\ \text { vp3 } & 23 \\ \text { tc4 } & 119 \\ \text { vp4 } & 23 \\ \text { tc5 } & 70 \\ \text { vp5 } & 7\end{array}$

TRANSITIONS

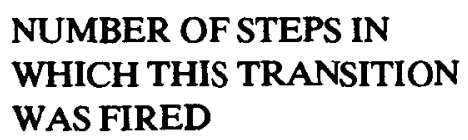

NUMBER OF STEPS IN WHICH THIS TRANSITION

WAS EVALUATED
100.00
100.00
100.00
100.00
100.00
100.00
100.00
100.00
100.00

100.00

\section{PERECENTAGE OF STEPS IN WHICH THIS EVENT WAS AVAILABLE}

RATE OF
FIRING
SUCESS
100.00
11.11
100.00
29.63
100.00
28.05
100.00
15.00
100.00
52.24

$\begin{array}{llll}\text { vp5 } & 7 & 7 & 100.00 \\ \text { tc5[cr(in(P1) and in(... } & 7 & 63 & 11.11 \\ \text { vp4 } & 23 & 23 & 100.00 \\ \text { tc4[cr(in(P3) and in(... } & 24 & 81 & 29.63 \\ \text { vp3 } & 23 & 23 & 100.00 \\ \text { tc3[cr(in(P2) and in(... } & 23 & 82 & 28.05 \\ \text { vp2 } & 8 & 8 & 100.00 \\ \text { tc2[cr(in(P1) and in(... } & 9 & 60 & 15.00 \\ \text { vp1 } & 35 & 35 & 100.00 \\ \text { tc1[cr(in(P2) and in(... } & 35 & 67 & 52.24\end{array}$




\section{VARIABLE AVERAGE VALUE FINAL VALUE}

$\begin{array}{lll}\text { fd1 } & 0.1167 & 0 \\ \text { fd2 } & 0.0300 & 0 \\ \text { fd3 } & 0.0767 & 0 \\ \text { fd4 } & 0.0800 & 0 \\ \text { fd5 } & 0.0233 & 0\end{array}$




\section{Relatório de Passos da Simulação}

Statechart in Simulation: PHILOSOFY_DINNER

Number of Simulated Steps: 300

Step 1

Configuration of Active States:

Jantar_dos_Filosofos

Filosofo1

P1

Filosofo2

P2

Filosofo3

P3

Filosofo4

P4

Filosofo5

P5

Events triggered :

Internal Transitions :

States Turned On :

States Turned Off :

Variable Current Value Average Value

$\begin{array}{lll}\text { fd1 } & 0 & 0.0000\end{array}$

$\begin{array}{lll}\mathrm{fd} 2 & 0 & 0.0000\end{array}$

$\begin{array}{lll}\mathrm{fd} 3 & 0 & 0.0000\end{array}$

$\begin{array}{lll}\text { fd } 4 & 0 & 0.0000\end{array}$

$\begin{array}{lll}\text { fd5 } & 0 & 0.0000\end{array}$

Messages :

Step 2

Configuration of Active States:

Jantar_dos_Filosofos

Filosofo1

$\mathrm{C} 1$

Filosofo2

P2

Filosofo3

C3

Filosofo4

P4

Filosofo5

P5 
Events triggered : tc1,tc3

Internal Transitions :

States Turned On : C1,C3

States Turned Off $\quad: \mathbf{P 1}, \mathbf{P 3}$

$\begin{array}{lcc}\text { Variable } & \text { Current Value } & \text { Average Value } \\ \text { fd1 } & 1 & 0.5000 \\ \text { fd2 } & 0 & 0.0000 \\ \text { fd3 } & 1 & 0.5000 \\ \text { fd4 } & 0 & 0.0000 \\ \text { fd5 } & 0 & 0.0000\end{array}$

Messages :

Step 3

Configuration of Active States:

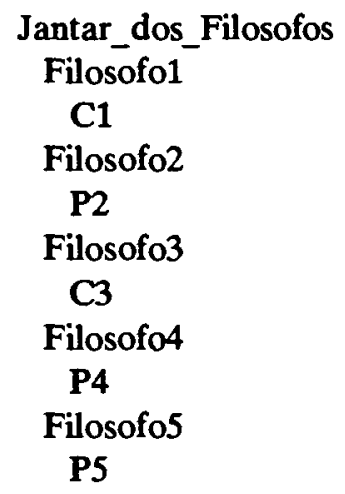

Events triggered : tc4,tc1

Internal Transitions :

States Turned On :

States Turned Off :

$\begin{array}{lcc}\text { Variable } & \text { Current Value Average Value } \\ \text { fd1 } & 0 & 0.3333 \\ \text { fd2 } & 0 & 0.0000 \\ \text { fd3 } & 0 & 0.3333 \\ \text { fd4 } & 0 & 0.0000 \\ \text { fd5 } & 0 & 0.0000\end{array}$

Messages : 
Configuration of Active States:

Jantar_dos_Filosofos

Filosofo1

P1

Filosofo2

P2

Filosofo3

P3

Filosofo4

C4

Filosofo5

P5

Events triggered :

Internal Transitions :

States Turned On :

States Turned Off :

Variable Current Value Average Value

$\begin{array}{lll}\text { fd1 } & 0 & 0.1178\end{array}$

$\begin{array}{lll}\text { fd2 } & 0 & 0.0269\end{array}$

$\begin{array}{lll}\mathrm{fd} 3 & 0 & \mathbf{0 . 0 7 7 4}\end{array}$

$\begin{array}{lll}\text { fd4 } & 0 & 0.0808\end{array}$

$\begin{array}{lll}\text { fd5 } & 0 & 0.0236\end{array}$

Messages :

Step 298

Configuration of Active States:

Jantar_dos_Filosofos

Filosofo1

P1

Filosofo2

P2

Filosofo3

P3

Filosofo4

C4

Filosofo5

P5

Events triggered : tc4

Internal Transitions :

States Turned On :

States Turned Off : 


\begin{tabular}{|c|c|c|}
\hline Variable & Curren & lue \\
\hline fd1 & 0 & 0.1174 \\
\hline $\mathrm{fd} 2$ & 0 & 0.0268 \\
\hline $\mathrm{fd} 3$ & 0 & 0.0772 \\
\hline fd 4 & 0 & 0.0805 \\
\hline fd 5 & 0 & 0.0235 \\
\hline
\end{tabular}

Messages :

Step 299

Configuration of Active States:

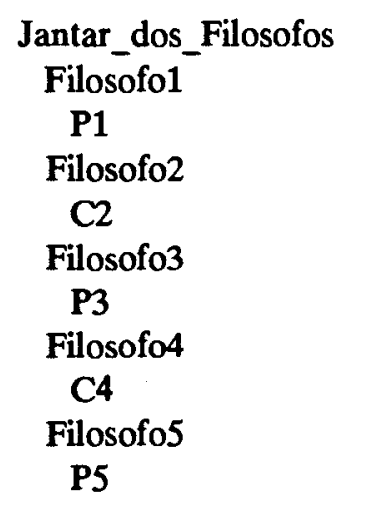

Events triggered $:$ tc2

Internal Transitions :

States Turned On : C2

States Turned Off : P2

Variable Current Value Average Value

$\begin{array}{lll}\text { fd1 } & 0 & 0.1171\end{array}$

$\begin{array}{lll}\mathrm{fd} 2 & 1 & 0.0301\end{array}$

$\begin{array}{lll}\mathrm{fd} 3 & 0 & 0.0769\end{array}$

$\begin{array}{lll}\mathrm{fd} 4 & 0 & 0.0803\end{array}$

$\begin{array}{lll}\mathrm{fd} 5 & 0 & \mathbf{0 . 0 2 3 4}\end{array}$

Messages :

Step 300

Configuration of Active States:

Jantar_dos_Filosofos

Filosofo1

P1

Filosofo2

C2

Filosofo3

P3

Filosofo4 
C4

Filosofo5

P5

Events triggered : tc5

Internal Transitions :

States Turned On :

States Turned Off :

Variable Current Value Average Value

$\begin{array}{lll}\text { fd1 } & 0 & 0.1167\end{array}$

$\begin{array}{lll}\mathrm{fd} 2 & 0 & 0.0300\end{array}$

$\begin{array}{lll}\mathrm{fd} 3 & 0 & 0.0767\end{array}$

$\begin{array}{lll}\text { fd4 } & 0 & 0.0800\end{array}$

$\begin{array}{lll}\text { fd5 } & 0 & 0.0233\end{array}$

Messages :

Numero de vezes que o filosofo 1 conseguiu comer $=35$

Numero de vezes que o filosofo 2 conseguiu comer $=9$

Numero de vezes que o filosofo 3 conseguiu comer $=23$

Numero de vezes que o filosofo 4 conseguiu comer $=24$

Numero de vezes que o filosofo 5 conseguiu comer $=7$ 